NBER WORKING PAPER SERIES

\title{
MONETARY POLICY COMMUNICATIONS AND THEIR EFFECTS ON HOUSEHOLD INFLATION EXPECTATIONS
}

\author{
Olivier Coibion \\ Yuriy Gorodnichenko \\ Michael Weber \\ Working Paper 25482 \\ http://www.nber.org/papers/w25482 \\ NATIONAL BUREAU OF ECONOMIC RESEARCH \\ 1050 Massachusetts Avenue \\ Cambridge, MA 02138 \\ January 2019, Revised November 2021
}

We thank the Fama-Miller Center and the Initiative on Global Markets, both at the University of Chicago Booth School of Business for financial support for conducting the surveys. Coibion and Gorodnichenko also thank the NSF for financial support. We are grateful to seminar and conference participants at many institutions. We thank Jonas Dalmazzo, Mathieu Pedemonte and especially Vitaliia Yaremko for excellent research assistance. We also thank Shannon Hazlett and Victoria Stevens at Nielsen for their assistance with the collection of the PanelViews Survey. Results in this article are calculated based on data from The Nielsen Company (US), LLC and marketing databases provided by the Kilts Center for Marketing Data Center at The University of Chicago Booth School of Business. Information on availability and access to the data is available at http://research.chicagobooth.edu/nielsen. The randomized control trial is registered at the AER RCT Registry (\#AEARCTR-0003649). The views expressed herein are those of the authors and do not necessarily reflect the views of the National Bureau of Economic Research.

NBER working papers are circulated for discussion and comment purposes. They have not been peer-reviewed or been subject to the review by the NBER Board of Directors that accompanies official NBER publications.

(C) 2019 by Olivier Coibion, Yuriy Gorodnichenko, and Michael Weber. All rights reserved. Short sections of text, not to exceed two paragraphs, may be quoted without explicit permission provided that full credit, including $(\odot)$ notice, is given to the source. 
Monetary Policy Communications and their Effects on Household Inflation Expectations

Olivier Coibion, Yuriy Gorodnichenko, and Michael Weber

NBER Working Paper No. 25482

January 2019, Revised November 2021

JEL No. C83,D84,E31

\section{ABSTRACT}

We study how different forms of communication influence inflation expectations in a randomized controlled trial using nearly 20,000 U.S. individuals. We elicit individuals' inflation expectations in the Nielsen Homescan panel and then provide eight different forms of information regarding inflation. Reading the actual Federal Open Market Committee (FOMC) statement has about the same average effect on expectations as simply being told about the Federal Reserve's inflation target. Reading news articles about the most recent FOMC meetings results in a forecast revision which is smaller by half. This exogenous variation in inflation expectations has subsequent effects on household spending. Our results have implications for how central banks should communicate to the broader public.

Olivier Coibion

Department of Economics

University of Texas at Austin

2225 Speedway

Austin, TX 78712

and NBER

ocoibion@gmail.com

Yuriy Gorodnichenko

Department of Economics

530 Evans Hall \#3880

University of California, Berkeley

Berkeley, CA 94720-3880

and IZA

and also NBER

ygorodni@econ.berkeley.edu
Michael Weber

Booth School of Business

University of Chicago

5807 South Woodlawn Avenue

Chicago, IL 60637

and NBER

michael.weber@chicagobooth.edu

A randomized controlled trials registry entry is available at

https://www.socialscienceregistry.org/trials/3649 
"Since I've become a central banker, I've learned to mumble with great incoherence. If I seem unduly clear to you, you must have misunderstood what I said."

Alan Greenspan, September 22, 1987

"[B]ecause monetary policy affects everyone, I want to start with a plain-English summary of how the economy is doing, what my colleagues and I at the Federal Reserve are trying to do, and why."

Jerome Powell, June 13, 2018.

\section{Introduction}

Central bank communications have changed a lot in the last thirty years, as illustrated by the statements above from different chairmen of the Federal Reserve. Central bankers now announce their policy decisions, explain their reasoning and describe their plans for the future. These new communications strategies have been targeted primarily at financial markets, both to minimize financial volatility as well as to shape longer-term interest rates to better achieve central banks' objectives. In this respect, they seem to have been successful, as illustrated e.g. by the effects of forward-guidance announcements on long-term interest rates (Swanson 2018).

In terms of influencing the expectations of households or firms, central banks have had the much more targeted goal of "anchoring" their inflation expectations. ${ }^{2}$ Yet despite this modest objective, central banks appear to have systematically failed in achieving it across most advanced economies. Firms and households in low-inflation countries report beliefs about inflation that are far from anchored, seem unaware of even dramatic monetary policy announcements, and more generally display almost no knowledge of what central banks do (see e.g. Bachmann et al. 2015, Coibion et al. 2020, D’Acunto et al. 2018a, and Binder 2017). This ignorance may be a sign of central banks' success (since firms and households have little incentive to worry about inflation or monetary policy in a stable low-inflation environment), but it is unlikely to be innocuous: some of the non-traditional policies at the zero lower bound (ZLB) are thought to operate primarily through the inflation expectations of households and firms. If their expectations are unresponsive to central bank announcements and communications, as they seem to be (Coibion et al. 2020, D'Acunto et al. 2018b), then this class of policies cannot be effective. The fact that pre-treatment inflation expectations are dispersed and substantially differ from the Fed's inflation target of $2 \%$ also implies that the current focus of central bank communication on

\footnotetext{
${ }^{1}$ The Greenspan quote is from Geraats (2007) who cites the Wall Street Journal. The Powell quote is from the press conference that day, transcripts of which are available here: https://www.federalreserve.gov/mediacenter/files/FOMCpresconf20180613.pdf

${ }^{2}$ Janet Yellen stated the communications objective as "Put differently, the purpose of providing greater clarity about the FOMC's longer-run inflation goal is to anchor inflation expectations more firmly. These more firmly anchored expectations in turn free the Committee's hand to more actively and effectively stabilize short-run fluctuations in economic activity.”
} 
financial market participants and professional forecasters limits its power to affect the real decisions of households and firms, and ultimately the overall economy. Hence, understanding how central banks can communicate their policies to shape the expectations and decisions of households is especially important right now, when actual inflation is low and nominal interest rates are stuck at zero. Several central banks have realized the limited power of conventional communication tools and have already started to explore more unconventional channels such as music videos on inflation targeting by the Central Bank of Jamaica or the extensive use of Twitter to discuss and explain monetary policy decisions as exemplified by Olli Rehn, the Governor of the Bank of Finland. Understanding how central banks can better communicate with the general public to shape their expectations is therefore of firstorder importance for the implementation of policies at the ZLB. ${ }^{3}$

We combine a new large-scale survey of households with a range of randomized information treatments to study how different types of communications affect the inflation expectations of consumers and ultimately their spending decisions. While randomized control trials (RCTs) have recently begun to be applied in macroeconomics (e.g., Armona, Fuster and Zafar 2018, Coibion, Gorodnichenko and Kumar 2018, Binder and Rodrigue 2018, D’Acunto et al. 2020), our approach is unique in the magnitude of the survey. Approximately 20,000 consumers responded to our survey, more than ten times the size of the New York Federal Reserve of Bank's Survey of Consumer Expectations or the size of other household surveys used for RCTs. This unprecedented scale allows us to consider simultaneously a wide range of different information treatments (eight different treatments and a control group) as well as to explore how different characteristics of respondents might affect their response to the treatment, both immediately as well as in subsequent months in which we deploy follow-up surveys. The scale of our analysis is crucial to study targeted communications since the size of conventional surveys does not yield enough statistical power to detect potentially differentiated responses for various population groups or treatments. In addition, we implement follow-up surveys three and six months later, through which we can also measure the persistence of the information effect much more systematically than previous work relying on rapid follow-ups. Finally, through a combination of survey questions and spending data from Nielsen, we are able to evaluate how exogenous changes in inflation expectations affect the spending decisions of households.

\footnotetext{
${ }^{3}$ Improved central bank communication with the public could potentially also enhance the credibility of those institutions. Since households and firms in low-inflation countries are largely unaware of the central bank's policy objectives or of recent inflation rates, informing them of both could improve the credibility of these institutions in the eyes of the public (see D’Acunto, Fuster, and Weber, 2021).
} 
We aim to inform academic research and policymakers on how to better communicate with ordinary people using actual information releases. While we do not control the macroeconomic environment or all elements of communication (the identity of the sender, the content and complexity of the provided information, the means of communication, etc.) as one could do in a lab setting, our approach tests and provides implementable recommendations to real-world policymakers. This yields a novel set of facts about which types of information are most effective at influencing the beliefs of households, both immediately as well as over longer periods. We find that providing households with simple statistics about inflation, such as the most recent rate of inflation, the Fed's inflation target or the FOMC's inflation forecast has statistically and economically significant effects on inflation expectations: this type of information reduces households' average forecast of inflation by 1.0-1.2 percentage points. The effect on households' inflation expectations from these simple pieces of information is also mildly persistent: in follow-up interviews three months after the information treatment, the inflation expectations of treated households had converged more than half-way to the expectations of households in the control group but fully converged within six months. These results suggest central banks cannot rely on one-off messages but have to develop a repeated communication strategy to the extent that central banks intend to manage consumer expectations through communication.

While these information treatments seem to have large effects on expectations, we find that not all information is processed in the same way. For example, a random subset of households was instead provided with the entire post-meeting statement of the Federal Open Market Committee (FOMC). Despite its length and detail, the effect of this treatment was no larger than simply providing households with the FOMC inflation forecast, reducing the average inflation expectation by about 1.2 percentage points. Another subset of households was given a news article from the USA Today covering the same FOMC meeting. Strikingly, this short and easy-to-read summary of the Fed's decision and motivation had a much smaller effect on inflation expectations: about half of the other treatments. Despite being written explicitly for the general public, this media transmission of the FOMC's decision and motivation seems to have either dissipated the message or, more likely given that the article is much clearer than the FOMC statement, been discounted by households because of its origin. ${ }^{4}$ This suggests one reason why monetary policymakers have had so little success in

\footnotetext{
${ }^{4}$ One important caveat is the fact that besides the medium of transmission (newspaper versus official release), the content of the pieces of information also varies. While it is conceivable that individuals do not discount the source of information but rather the specific content in the USA Today article, we show that this interpretation is unlikely for several reasons. First, we have two different newspaper articles as treatments in the first wave of the survey and households react similarly to both treatments. Second, we find individuals with lower education and lower income systematically discount the information in the newspaper article more than other survey participants but they do not differ in their reaction to the FOMC statement. Third
} 
affecting the inflation expectations of households: relying on the conventional media to diffuse their message to the public can be ineffective because many households no longer read newspapers and even if they do, individuals discount reports from the news media. We provide direct survey evidence that households consider traditional news media as less credible compared to social media or information from family and friends. Moreover, survey respondents view the USA Today as being more credible than the New York Times or Wall Street Journal.

We also study other practical elements of central bank communication. Specifically, although central banks have recently been emphasizing forward guidance and anchored inflation expectations, it is not clear whether informing the broader population about the prevailing inflation rate, the forecast of the inflation rate, or the inflation rate that the central bank aims to achieve over longer periods of time is most effective in shaping and moving individuals' expectations. ${ }^{5}$ Strikingly, we find that all three options (past, forecasted, or targeted inflation rate) affect households' expectations in a quantitatively similar way on impact but the forward-looking information, that is, the inflation forecast and the inflation target, appear to result in slightly more persistent forecast revisions. Thus, a key contribution of our paper is that we jointly study how different forms of communication (forward- vs backward-looking, official government releases vs. news media) affect the forecast revision in a broad cross-section of a representative population.

Exploiting the micro-level heterogeneity underlying these results sheds additional insight on the potential of targeted communication. First, there is in general little variation in terms of how different types of consumers respond to most signals: conditional on their initial beliefs (which do differ across groups), the way they respond to a common signal is broadly similar. This pattern in updating yields declines in disagreement across agents after each treatment. Consistent with this homogeneity in how people respond to a common signal, we find that the average responses of beliefs to each treatment are not driven by large changes in the beliefs of a subgroup within the treatment. The one exception to these otherwise fairly systematic responses to information treatments lies in the USA Today treatment: we find that low-income and low-education individuals disproportionately downweigh the article from this

and most directly, we show survey respondents view newspapers as generally less credible than friends and co-workers, direct communication from the government, or even social media.

${ }^{5}$ Relatedly, most central banks currently only communicate directly with financial markets. They hold press conferences after policy decisions and have Q\&As to affect financial markets' and experts' expectations. Furthermore, communication with ordinary people is typically left to the news media under the assumption that individuals adjust their consumption and savings in response to changes in financial market interest rates and adjust expectations after reading the newspaper. One important shortcoming of this idealized world is that many people do not actively adjust the savings and consumption decisions to movements in financial markets (D’Acunto et al, 2018a) but also do not follow news reports. 
news source, although all groups tend to discount the news report from USA Today. One explanation might have to do with political perspective, but the USA Today is a non-partisan newspaper. Our results call for more research toward understanding how consumers interpret news from the media, such as whether all newspapers would be treated alike (e.g., Wall Street Journal vs. USA Today vs. New York Times), the role that the media plays in communicating news about the economy and policy to households, and which individuals acquire news via traditional media outlets. In addition, more research is needed to understand which medium is most effective for policy communication and whether the sender of the message affects the response of the broader population.

Finally, because communication matters for economic outcomes only to the extent that the information ultimately affects decision-making, we assess whether changes in inflation expectations stemming from the exogenously provided information treatments alter household spending decisions. We do so by using households' scanned purchases tracked by Nielsen as well as through follow-up surveys in which households report the amount of spending they have done across a wide range of goods and services. Higher inflation expectations arising from information treatments lead to a rise in the monthly spending of households over the next six months, consistent with an intertemporal substitution motive, whether spending is measured using self-reported survey data or the scanner data collected by Nielsen. This effect is strongest for those who earn more income and are more educated. However, we also find that when individuals raise their inflation expectations, they tend to reduce their purchases of larger durable goods such as cars, houses, and other big-ticket items over the next six months. In short, despite pervasive inattention on the part of U.S. households to inflation and monetary policy, households' inflation expectations still play a statistically and economically significant role in their spending and saving decisions.

This paper builds on a growing literature focusing on how economic agents form their expectations and process information (see Coibion, Gorodnichenko and Kamdar 2018 for a survey and Bordalo et al. 2020 for a recent example). It is most closely related to recent work using randomized information treatments to characterize how agents learn and respond to new information. Randomized information treatments applied to firms in New Zealand, for example, suggest that managers' expectations respond strongly to information about recent inflation or the inflation target (Coibion, Gorodnichenko and Kumar 2018) as well as to the higher-order beliefs of other managers (Coibion et al. 2021). Coibion, Gorodnichenko and Ropele (2020) document similarly large responses of firm expectations in Italy to information about recent inflation or the inflation target, as do Humziker et al. (2018) for firms in Switzerland. Additional results have also been documented for households. In related work, Haldane and 
McMahon (2018) use randomized treatments to explore how/whether changing the presentation of the Bank of England's statements alters the public's understanding of their message. D’Acunto et al. (2020) find that households react more strongly to communication about policy targets rather than about instrument communication, especially the least sophisticated consumers. Finally, Binder and Rodrigue (2018) document that households revise their long-run inflation forecasts when presented with information about recent inflation or the central bank's inflation target. The two closest papers are Armantier et al. (2016), who provide information about past food inflation and inflation forecasts of professional forecasters to a subset of individuals in a controlled survey experiment to study individuals’ forecast revision, and Cavallo et al. (2017), who provide a random subset of the population information about past inflation to study the formation of inflation expectations.

Relative to this prior work, we make a number of contributions. First, the scale of our randomized information treatment is simply unprecedented relative to this literature, which among other things allows for much more precise identification of estimated effects. Second, we are able to consider a much wider range of information treatments simultaneously than in prior work, including not just the provision of simple facts about inflation but also more original treatments like the FOMC statement or a newspaper description of FOMC decisions. This is important because ex ante it is unclear whether households' inflation expectations react more to information about past inflation, inflation forecasts, or detailed discussions about the state of the economy. Third, we have a more systematic follow-up of individuals than in prior work on household expectations that allows us to rule out experimenter demand effects. Fourth, we provide a placebo treatment to disentangle genuine learning from anchoring affects and spurious learning. Fifth, our larger cross-section allows us to examine micro-heterogeneity in expectations and updating in exceptional detail. Finally, we can assess the extent to which changes in inflation expectations affect actual household spending decisions. These features of our survey (placebo treatment, jointly studying many treatments, the systematic follow-ups, the measures of spending, and the large cross section) allow us to make important contributions to the literature and inform policy making which in times of low interest rates and inflated central bank balance sheets heavily relies on communication as a policy tool (Coibion et al. 2020).

Our work also speaks to a broader literature on central bank communication. While much of this work focuses on financial markets, as does central bank communication (see e.g. Blinder et al. 2008), there has been growing concern about the ability of central banks to communicate with the broader public. Blinder (2009), for example, was an early voice advocating for more focus on communicating with an audience beyond experts and financial markets. Recent work has documented the shortcomings of current 
communications strategies. Carvalho and Nechio (2014) find that few households in the U.S. form macroeconomic expectations that are consistent with how the Federal Reserve makes policy, a finding largely confirmed in Drager et al. (2016). Binder (2017) shows that most households do not know the names or objectives of U.S. monetary policymakers. Not only do we provide more (and larger-scale) evidence on U.S. households' lack of knowledge about monetary policy, we also document a novel possible source for this: a dismissal of news reports about monetary policy.

Finally, this paper is closely related to a growing body of work that provides causal evidence on how expectations translate into economic decisions. For example, Roth and Wohlfart (2018) consider how households' consumption plans respond to professionals' opinions about the likelihood of a recession, Armona et al. (2018) assess how households respond to news about housing prices, and Fuster, Kaplan, and Zafar (2019) study the spending response to unanticipated spending shocks in a survey. Coibion, Gorodnichenko and Kumar (2018) and Coibion, Gorodnichenko and Ropele (2020) provide causal evidence that changes in inflation expectations of firms affect their investment and employment decisions. On the household side, there is an extensive literature looking at the association between inflation expectations and either their spending or their perception of whether now is a good or bad time to purchase durable goods (e.g., Bachmann, Berg and Sims 2012, D’Acunto, Hoang and Weber 2016, Drager and Nghiem 2020, Burke and Ozdagli 2015, Crump et al. 2015). We differ from these papers in the larger cross-section of our sample, the fact that we have both self-reported and scanner measures of spending, and an RCT approach to identifying the causal effect of inflation expectations on spending decisions. With respect to the latter, the closest paper to ours is Coibion, Georgarakos, Gorodnichenko and van Rooij (2019), who also use an RCT to study how the inflation expectations of households in the Netherlands affect their spending decisions. Compared to the latter, this paper has a much larger cross-section of households (ten times larger), a longer time horizon over which spending is measured (six months versus three months), a larger set of information treatments (seven versus two) that provide much stronger identifying variation in inflation expectations (Fstatistics are approximately ten times larger), and spending data that is measured not just using selfreported survey data but also through high-frequency scanner-collected data compiled by Nielsen.

\section{Data and Survey Design}

This section describes the survey design we use to elicit inflation expectations, the various treatments, and provides descriptive statistics of individual inflation expectations. We first detail the Nielsen Homescan panel on which we run the survey and then provide more information on the structure of the survey. 


\subsection{Nielsen Panel}

In June, September, and December of 2018, we fielded three waves of the Chicago Booth Expectations and Communications Survey inviting participation by all household members in the Kilts-Nielsen Consumer Panel (KNCP). The KNCP represents a panel of approximately 80,000 households that report to AC Nielsen (i) their static demographic characteristics, such as household size, income, ZIP code of residence, and marital status, and (ii) the dynamic characteristics of their purchases, that is, which products they purchase, at which outlets, and at which prices. We use the scanned purchase data in Section 5 to study how exogenous variation in inflation expectations moves individuals' spending choices. Panelists update their demographic information at an annual frequency to reflect changes in household composition or marital status.

Nielsen attempts to balance the panel on nine dimensions: household size, income, age of household head, education of female household head, education of male household head, presence of children, race/ethnicity, and occupation of the household head. Panelists are recruited online, but the panel is balanced using Nielsen's traditional mailing methodology. Nielsen checks the sample characteristics on a weekly basis and performs adjustments when necessary.

Nielsen provides households with various incentives to guarantee the accuracy and completeness of the information households report. They organize monthly prize drawings, provide points for each instance of data submission, and engage in ongoing communication with households. Panelists can use points to purchase gifts from a Nielsen-specific award catalog. Nielsen structures the incentives to not bias the shopping behavior of their panelists. The KNCP has a retention rate of more than $80 \%$ at the annual frequency. Nielsen validates the reported consumer spending with the scanner data of retailers on a quarterly frequency to ensure high data quality. The KNCP filters households that do not report a minimum amount of spending over the previous 12 months.

\subsection{Chicago Booth Expectations and Communication Survey}

Nielsen runs surveys on a monthly frequency on a subset of panelists in the KNCP, the online panel, but also offers customized solutions for longer surveys. Retailers and fast-moving consumer-goods producers purchase this information and other services from Nielsen for product design and targetgroup marketing. At no point of the survey did Nielsen tell their panelists that the survey they fielded was part of academic research which minimizes the concerns of survey demand effects.

In spring 2018, we designed a customized survey consisting of 37 questions in total in cooperation with Nielsen, the Chicago Booth Expectations and Communication Survey. The survey also 
contains eight different information treatments as well as one control group. To reduce the burden of participating in the survey, some questions were asked only of a subset of respondents. We report the full survey of the first wave in the online appendix. Our survey design builds on the Michigan Survey of Consumers, the New York Fed Survey of Consumer Expectations, the Panel on Household Finances at the Deutsche Bundesbank as well as D’Acunto et al. (2020).

Nielsen fielded the first wave of the survey in May-June of 2018. The survey sample was 83,061 households. 24,510 individuals responded for a response rate of $26.50 \%$ and an average response time of 15 minutes. The response rate compares favorably to the average response rates of surveys on Qualtrics that estimates a response rate between 5\% to 10\%. The second and third waves were shorter, consisting mostly of follow-up questions, with median response times of about 10 minutes and 32,658 unique respondents for the second wave and 13 minutes and 29,348 unique respondents for the third wave. Nielsen provides weights to ensure representativeness of the households participating in the survey.

The initial wave of the survey covers a wide range of questions. First, respondents are presented with a series of questions about their demographic characteristics, which are more detailed relative to the basic demographic information the KNCP provides. We collect information on employment status, current occupation, financial constraints, savings and portfolio choice, gas prices and expectations, recent spending behavior in various categories including expenses that are not covered in the KNCP, and we identify the primary shopper of the household among all the responding members. Participants are then asked a sequence of questions about their perceptions and expectations of inflation. We follow the design in the recent New York Fed Survey of Consumer Expectations (SCE) and ask specifically about inflation, because asking about prices might induce individuals to think about specific items whose prices they recall rather than about overall inflation (see Crump et al. (2015) for a recent paper using the SCE data). We first ask individuals about their perception of past inflation, that is, inflation over the previous 12 months. We then ask them about their expectations for 12-month-ahead inflation. We elicit a full probability distribution of expectations by asking participants to assign probabilities to different possible levels of the inflation rate. We then construct the mean and standard deviation of these expectations by using the midpoints of each bin and fixed values for the bins on each end. ${ }^{6}$ In addition, we also ask about the perception of the current unemployment rate and the expected unemployment rate in twelve months. We

\footnotetext{
${ }^{6}$ Specifically, we use values of $-14 \%$ and $14 \%$ when respondents assign weights to bins for "Less than $-12 \%$ " and "More than 12\%" respectively. We show in Appendix Table 14 that our baseline results are insensitive to using medians of these distributions or means of generalized beta distributions applied to the bins as in the SCE.
} 
do not ask about longer-run inflation expectations due to space constraints and the fact that other work has found a strong correlation between short-run and long-run inflation expectations (Kumar et al. 2015).

Subsequent waves largely follow the same structure but in a much shorter form. Demographic characteristics are assumed to be time invariant. Hence, the follow-up surveys are primarily used to measure individuals' perceptions and expectations of inflation over time, as well as the evolution of their spending.

\subsection{Treatments}

After respondents answered the initial set of questions in the first wave, they were assigned to one of nine groups: a control group and eight treatment groups. We designed the treatments to disentangle the effects of different possible types of monetary policy communication, especially ones that provide some simple statistics that might help individuals update their inflation expectations. In addition, we also provided a placebo treatment to differentiate true learning from spurious learning possibly due to anchoring effects. Each group consists of $1 / 9^{\text {th }}$ of the total sample that received the survey and the treatments are randomly assigned. Appendix Table 6 confirms that the different treatment groups are comparable along all major observable characteristics.

Specifically, the treatments are (i) the actual CPI inflation rate over the last twelve month (2.3\%); (ii) the inflation target of the Federal Reserve of 2\% per year; (iii) the FOMC forecast for inflation in 2018 of 1.9\% (we informed participants that the FOMC is responsible for setting short term interest rates); (iv) the most recent FOMC statement; (v) the coverage of the most recent FOMC decision in USA Today. We were also interested to see whether participants might have a Philips curve in mind and provided the most recent unemployment numbers as treatment (vi). D’Acunto et al. (2020) document that individuals extrapolate from salient price changes to overall inflation and, hence, we informed one of the treatment groups that the national average gas price inflation over the previous three months was $6.4 \%$ (vii). As placebo treatment, we provided the actual fact that the U.S. population grew by $2 \%$ over the last three years (viii). As required by professional standards, treatments provide only factually correct information. We report the treatments as part of the overall survey in the Online Appendix. Ex-ante it is not clear whether individuals might react more to information about current inflation, the inflation target, or inflation forecasts. Some households might extrapolate from current inflation to future inflation and providing them with accurate information about current inflation might be most effective in shaping expectations. Other individuals instead might have fully forward-looking expectations and providing these households with information on the forecasts of professionals or the official inflation target might 
be more relevant for shaping expectations. Finally, some individuals might form expectations about inflation jointly with expectations about other economic variables such as the unemployment rate and providing these households information about these variables could result in the largest revision in inflation expectations (Andre et al. 2019). The presence of different information treatments for households allows us to speak to the fact that different central banks follow different communication strategies to the extent they have any systematic communication with the general public at all.

Treatments to survey participants must be truthful, e.g. we cannot implement a treatment in which we provide the FOMC statement but claim it is actually from a newspaper. Hence, there is a limit in our ability to assess why different treatments might have different effects on expectations since we cannot always vary one characteristic of the treatment at a time. However, the large range of treatments still provides significant guidance on which forms of communication affect household expectations.

Following each treatment (as well as for the control group), respondents were again asked about their inflation forecasts and perceptions, but this time in the form of a point estimate to avoid them having to answer the exact same question twice. This allows us to measure the instantaneous revision in expectations (if any) after the information treatments compared to the control group. The treatments were only applied in the first wave of the survey. In subsequent waves, respondents were again asked for their inflation expectations and perceptions, but questionnaires were identical across all respondents in the two follow-up waves. The first follow-up was after three months and the second after six months.

\subsection{Preliminary Facts and External Validity}

We present in Table 1 average 12-month ahead inflation expectations and perceptions of all individuals in the survey prior to any information treatment being applied, as well as these same facts along a number of observable characteristics of the individuals. The average inflation expectation across all households is $2.5 \%$ with a standard deviation of $2.6 \%$. Here and in what follows we use a Huber estimator to compute moments and estimate regression coefficients. This approach allows us to remove outliers and influential observations automatically and have estimates that are robust to extreme observations in the data (as a result, the sample size for reported estimates is reduced). ${ }^{7}$ For comparison, the average 12-month ahead inflation expectation in the Michigan Survey of Consumers in May 2018 was 3.3\% (with a standard deviation of 2.9\%) while the median expectation of 12-month ahead inflation in the New York Fed's Survey of Consumer Expectations was 3.0\%. Hence, our results are broadly in

\footnotetext{
${ }^{7}$ Descriptive statistics for unfiltered data are reported in Appendix Table 4. We apply sampling weights everywhere.
} 
line with other surveys of households taking place at the same time, both in terms of the first and second moments of the inflation expectation distribution.

We find that the perceived inflation rate of households in our sample was $2.5 \%$, at a time when the annual CPI inflation rate was 2.3\% (May 2018). While the average perceived inflation was therefore quite close to the actual inflation rate, there is a profound level of disagreement across households about recent inflation: the cross-sectional standard deviation of perceived inflation was $2.7 \%$, about the same amount of disagreement as for inflation forecasts. This points toward significant levels of inattention on the part of many individuals toward aggregate inflation. As documented in Jonung (1981) for Swedish households, there is a high correlation between households’ perceptions of recent inflation and their expectations of future inflation at 0.79. D’Acunto et al. (2020) document in a preceding survey of U.S. households that individuals' perceptions of recent inflation are disproportionately shaped by the recent price movements of goods they purchase frequently. The associated inattention to recent aggregate inflation suggests that information treatments focusing on actual values of recent inflation might lead to significant revisions in households’ expectations of future inflation.

The inattention of households extends beyond inflation to monetary policy more generally. For example, respondents were also asked what inflation rate the Federal Reserve was trying to achieve in the long-run. The results of this question are displayed in Figure 1. Less than twenty percent of respondents correctly answered 2\%. Barely 50\% answered a number ranging from 0\% to 5\%. Strikingly, almost forty percent answered that the Federal Reserve was targeting an inflation rate of $10 \%$ or more, which suggests a pervasive lack of knowledge on the part of households about the objectives of the Federal Reserve. The lack of mass for answers between $6 \%$ and $9 \%$ can be attributed to the large degree of rounding to multiples of 5 among households (D’Acunto et al. 2018a). This is consistent with previous evidence on the limited knowledge of households and firms about monetary policy in low-inflation environments (Binder 2017, Kumar et al. 2015, Cavallo et al. 2017).

Other features of the survey are also consistent with previously documented evidence. For example, we find that men have lower and less dispersed inflation expectations than women on average (as in Bryan and Venkatu 2001 and D’Acunto et al. 2019), higher-income households also have lower and less dispersed inflation expectations (as in Binder 2015) as do households with higher stocks of savings and higher savings rates, where the latter is consistent with D’Acunto et al. (2020). Taken together, these results suggest that our survey replicates the main cross-sectional stylized facts of households' inflation expectations and therefore supports the validity of our survey as a measure of individuals’ beliefs about inflation. 
In this section, we present and discuss how different treatments affect the inflation expectations of individuals.

\subsection{Average Effects on Beliefs}

To characterize how information treatments affect expectations, we first regress, for each treatment group combined with the control group, the change in the inflation expectations of agents from before to after the information treatment on a dummy variable for their treatment group (equal to zero if in the control group and one otherwise), that is,

$$
E_{i}^{\text {post }} \pi-E_{i}^{\text {pre }} \pi=a+b \times \text { Treatment }_{i}+\boldsymbol{\beta} \boldsymbol{X}_{i}+\text { error }_{i},
$$

where $E_{i}^{\text {post }} \pi$ is the posterior forecast of individual $i, E_{i}^{\text {pre }} \pi$ is their prior average belief, Treatment $_{i}$ is the dummy variable, and $\boldsymbol{X}_{i}$ is a vector of individual-specific controls. These include a quadratic polynomial in the respondent's age and a rich set of dummy variables for a respondent's gender, employment status, household income, household size, race, census region, spectra life style, and spectra behavior stage. ${ }^{8}$ For the posterior forecasts of individuals, we use the forecast provided immediately after the treatment as well as the forecasts provided three and six months later in followup waves. In Table 2, we report estimated values of $b$ for each treatment group with and without these individual controls. ${ }^{9}$ Note that $b$ identifies the average change in expectations of agents in the treatment group relative to the average change in the control group. Including the control group is important because inflation expectations before and after the treatment are measured using questions with different wording, so the control group serves to capture any effect driven by wording. Because initial beliefs about inflation are biased upwards prior to the treatment, this baseline specification focusing on the average revision provides a simple benchmark for assessing the power of each treatment on expectations. We also study convergence in beliefs below. In each regression, we use sampling weights in the regressions and use Huber regressions to control for outliers and influential observations. ${ }^{10}$

\footnotetext{
${ }^{8}$ The last two variables are constructed by Nielsen to classify households into several types. Spectra life style has the following categories: Cosmopolitan Centers; Affluent Suburban Spreads; Comfortable Country; Struggling Urban Cores; Modest Working Towns; Plain Rural Living. Spectra behavior stage includes the following categories: Start Up Families; Small Scale Families; Younger Bustling Families; Older Bustling Families; Young Transitionals; Independent Singles; Senior Singles; Established Couples; Empty Nest Couples; Senior Couples.

${ }^{9}$ We find little evidence of nonlinear effects depending on the prior beliefs of respondents for respondents expecting nonnegative inflation (see Appendix Figure 1).

${ }^{10}$ Appendix Tables 7-9 present equivalent results with alternative methods of dealing with outliers as well as using the raw data.
} 
Consider first the placebo treatment. In this case, individuals were told that the population growth of the U.S. was $2 \%$ over the last three years, a statement of little relevance to inflation but which included the number $2 \%$. This placebo helps identify the potential importance and size of anchoring effects. We find very mild evidence for contemporaneous anchoring effects: the average respondent in this group reduces their inflation forecast by $0.2-0.3 \%$, or less than one-tenth of the cross-sectional standard deviation of inflation expectations. These small anchoring effects have completely dissipated by the first follow-up, and the inflation expectations of individuals in this group are no different from those in the control group three and six months after the treatment.

We now turn to the direct treatments about inflation applied to three of the groups. One group was told the most recent 12-month CPI inflation rate (2.3\%), one group was told that the Federal Reserve targets an inflation rate of $2 \%$, and the third group was told that the FOMC was forecasting an inflation rate of $1.9 \%$ over the next twelve months. The effects across these three groups are very similar. On impact, all three reduce the average inflation forecast by $1.0-1.1 \%$ relative to the control group. Hence, these very simple information treatments have large effects on the beliefs of individuals. These effects are also mildly persistent. Three months later, the average expectations of these treated individuals are still lower than those of the control group, with the effect having dissipated by about 75\%. Six months later, the effects of the treatments have fully dissipated. ${ }^{11}$ This persistence of information treatments is consistent with those observed in previous work (Coibion et al. 2021, Coibion, Gorodnichenko and Kumar 2018, Coibion, Gorodnichenko and Ropele 2020, and Cavallo et al. 2017) and is not driven by a changing composition across waves: we find nearly identical results when we restrict our attention to individuals that participate in all waves (Appendix Table 5). ${ }^{12}$ Furthermore, these results indicate that all three treatments seem to convey broadly similar information to respondents, in that they adjust their beliefs in a comparable manner despite the treatments being conceptually distinct. ${ }^{13}$ One important difference between the treatments is the fact that telling individuals the current rate of inflation has fully dissipated after three months, whereas the forwardlooking treatments are mildly persistent, possibly because some households perceive them as more relevant for inflation expectations in three months.

\footnotetext{
${ }^{11}$ The effect of being treated with the recent inflation rate is positive after six months, whereas we cannot reject the null of zero effect for all other treatments. We conjecture that this positive effect is a statistical aberration, given little reason exists why the treatment effect should become positive over time and no such effect exists for any other treatment group. ${ }^{12}$ We also find no evidence of differential attrition rates across information treatments.

${ }^{13}$ One difference across treatments is the specific inflation rate included (e.g. CPI vs PCE). The similarities in results across treatments suggests that households do not make much of a distinction between these measures. When asking them for their inflation expectations, we do not specify a specific measure of inflation to forecast.
} 
The transitory nature of the effect of these treatments on inflation expectations reflects the fact that the treatment itself seems to have only transitory effects on underlying knowledge. For example, when some respondents were told about the Fed's inflation target in the first wave as their treatment, their recall of this information in subsequent waves was relatively low. We illustrate this by running the same regression as before but using changes in beliefs about the FOMC's target in the two follow-up waves as dependent variables:

$$
E_{i}^{\text {post }, 3 m} \text { FedTarget }-E_{i}^{\text {pre }} \text { FedTarget }=a+b * \text { Treatment }_{i}+\text { error }_{i} \text {. }
$$

The results are reported in Table 3. Within three months, being treated with the Fed's inflation target leads to modest revisions in beliefs about the target relative to priors before treatment. By six months, the effect of the treatment has dissipated and the recall of this information is close to zero. Similar results obtain for other treatments for which we measured the prior belief of respondents, which includes the contemporaneous rate of inflation and the contemporaneous rate of unemployment. Table 3 shows that respondents similarly seem to forget the provided information about each within three to six months. The very transitory nature of information treatments on inflation expectations therefore seems to reflect the fact that respondents are unable to remember the information for more than a few months. Therefore, policymakers that aim to influence inflation expectations of individuals might have to engage in a more persistent form of communication given that simple, one-off messages are not effective in moving expectations persistently. ${ }^{14}$

Going beyond these simple information treatments, the next treatment group was presented with the entire statement released by the Federal Reserve following FOMC meetings. ${ }^{15}$ Respondents in May 2018 received the FOMC statement from the March 21 2018 FOMC meeting whereas those who took the survey in June 2018 received the FOMC statement from the May $2^{\text {nd }} 2018$ FOMC meeting. Both statements describe recent developments in the economy similarly, including that inflation had approached 2\%, as well as the broader objectives of the Federal Reserve including its symmetric $2 \%$ objective for the inflation rate. We describe differences between the two in more detail in the next section. The statements, while not exceedingly long, are written in the dense language that is typical of central bank communications. On impact, reading the statement from the FOMC has approximately the same effect on inflation expectations as the previous three treatments, reducing the

\footnotetext{
${ }^{14}$ The mild persistence in the treatment effects after three and six months also alleviates concerns of experimenter demand effects. Moreover, de Quidt et al. (2018) show in settings similar to ours that these effects are plausibly small.

15 The FOMC statements are available in Appendix 1 as well as at this link: https://www.federalreserve.gov/monetarypolicy/fomccalendars.htm. They are discussed in more detail in section 3.2.
} 
average forecast by $1.2 \%$ relative to the control group. The effect of reading the FOMC statement dissipates a little more rapidly, however, having no discernible effect on expectations relative to the control group after three or six months.

Another treatment group was presented with a news article from the USA Today covering the same FOMC meeting as the statement provided to the previous treatment group. ${ }^{16}$ Those participating in May 2018 were given an article summarizing the March FOMC decision while those participating in June received an article summarizing the May FOMC decision. We describe differences between the two in more detail in section 3.2. Both articles, each published the day after FOMC meetings, are written in a much more accessible (and shorter) style than the FOMC statements but still transmit information about inflation and the central bank's objective. For example, the second sentence of the second article reads "The Fed held its key interest rate steady Wednesday but noted that inflation has climbed closer to its $2 \%$ goal, paving the way for another rate hike in June.” Participants who read the USA Today article reduced their inflation expectations by only $0.5 \%$ points relative to the control group, less than half the effect of any of the other inflation-related treatments. Despite the fact that the articles seemingly transmit the same information about the central bank's inflation objective as the FOMC statement or our information treatment on the central bank's target (as well as information about the most recent inflation rate), this information appears to be discounted by households. With approximately the same objective information content but only the source of the information varying, it seems that households view information coming from the news media as being less reliable, leading them to place less weight on it when they revise their views. ${ }^{17}$ However, its effect is relatively longerlived, in that three months after reading the article, the average effect on expectations remains half of its instantaneous effect, but it too dissipates fully within six months after the information treatment.

Of course, households can form and change their beliefs about inflation using many different types of information. To assess how other forms of information affect their views, we consider two other types of information treatments. The first tells individuals that national gasoline prices rose $11 \%$

16 The USA Today article from March 21, 2018 can be found in the appendix and at this link: https://www.usatoday.com/story/money/2018/03/21/fed-powell-hikes-interest-rates-consumer-loans/444986002/.

${ }^{17}$ We picked the USA Today as the article source to avoid the fact that other news sources like the New York Times or the Wall Street Journal are often perceived to have partisan leanings which might lead some to discount the quality of the information they provide. The USA Today, to the best of our knowledge, has no particular political association. Until 2016, the USA Today had never endorsed any presidential candidate. In the 2016 election, the Editorial Board declared that it considered Donald Trump unfit for the presidency but did not explicitly endorse Hillary Clinton (https://www.usatoday.com/story/opinion/2016/09/29/dont-vote-for-donald-trump-editorial-board-editorials-

debates/91295020/). The 2020 election was the first time that it officially endorsed a presidential candidate (Joe Biden). 
over the previous three months. ${ }^{18}$ As documented in Table 2, this information about salient prices leads to an immediate upward revision in households' inflation expectations of approximately 1.4$1.5 \%$ relative to the control group, even though the average household expenditure share of gasoline is only around 5\% (Binder 2018). This high sensitivity of individuals' inflation expectations to gasoline prices is consistent with the evidence provided in Coibion and Gorodnichenko (2015) and Binder (2018). However, this effect is relatively transitory. Within three months, individuals in this treatment group have slightly lower inflation expectations than the control group and the effect is again fully dissipated within six months. The extrapolation from salient prices like gas and groceries to overall inflation expectations poses a challenge to central banks because their conventional policy tools have little direct effect on these prices which is the reason why many central banks focus on measures of core inflation that exclude these price series (D’Acunto et al. 2020).

Second, we provide individuals with information about the most recent rate of unemployment. All respondents in the first wave were initially asked what they thought was the current unemployment rate in the U.S. Their average answer was $6.3 \%$ with a standard deviation of $3.9 \%$. Only 12 percent of respondents reported unemployment rates less than or equal to 3.9\%. Hence, when respondents in this group were told the actual value of the unemployment rate in the previous month of $3.9 \%,{ }^{19}$ they were almost always being told that the unemployment rate was significantly lower than what they believed. The result was an immediate downward revision in their inflation expectation, albeit a relatively small one, of $0.3 \%$. This is the opposite of what one would expect if households were perceiving this as a movement along a Phillips curve, in which case the reduction in unemployment would have been associated with higher inflation. Instead, they seem to hold a supply-side view of unemployment and inflation, associating higher levels of one with the other. Appendix Table 12 shows that average unemployment expectations moved in the same direction as average inflation expectations for each information treatment, consistent with such a supply-side view. This is the same pattern as that observed in Italian firms (Coibion, Gorodnichenko and Ropele, 2020) or previously in U.S. households (Kamdar 2018). Other evidence pointing to supply-side interpretations of inflation include Andre et al. (2019), Binder (2020a) and Binder (2020b). This information effect is still somewhat visible in inflation expectations after three months but is also fully dissipated within six months.

\footnotetext{
${ }^{18}$ Respondents participating in the May 2018 (June 2018) part of the survey were informed in this treatment that the actual price of gasoline increased by $6.4 \%$ (11\%). Consistent with this difference in the size of the treatment, we find that the average change in beliefs of households surveyed in June was approximately twice as large as for those surveyed in May conditional on being treated with the information about gasoline prices.

${ }^{19}$ Respondents participating in the May 2018 wave were told that unemployment rate was $4.1 \%$.
} 
Jointly, these results indicate that simple messages provided to households can have remarkably powerful, albeit transient, effects on their expectations. We find no evidence that the complicated and detailed information from FOMC statements have effects that are any more powerful than simply telling households what inflation has been or what inflation rate the central bank is targeting. This means communication strategies targeting households could potentially focus on presenting them with basic facts about inflation and monetary policy without resorting to "Fedspeak”. The major caveat is that relying on the media to transmit the central bank's message is unlikely to be very successful: not only do many households not follow news about monetary policy but even when exposed to news articles focusing explicitly on monetary policy decisions, these news articles seem to be heavily discounted by the public due to their source.

\subsection{Interpreting the USA Today Treatment Effects}

The most striking feature of Table 2 is probably the fact that the USA Today treatment has a much smaller effect than either simple messages about recent inflation, the Fed's inflation target, or the corresponding FOMC statement. To better understand this effect, we first exploit the fact that two different versions of both the FOMC and USA Today treatments were presented in May and June. The two FOMC statements are broadly similar, with the most noticeable difference being the language with respect to inflation. In May 2018, it read

“On a 12-month basis, both overall inflation and inflation for items other than food and energy have continued to run below 2 percent... Inflation on a 12-month basis is expected to move up in coming months and to stabilize around the Committee's 2 percent objective over the medium term.”

whereas the June 2018 version is

"On a 12-month basis, both overall inflation and inflation for items other than food or energy have moved close to 2 percent. Inflation on a 12-month basis is expected to run near the Committee's symmetric 2 percent objective.”

The latter makes clear that inflation was close to and expected to remain around 2 percent whereas the former points to recent inflation being lower but expected to rise to 2 percent.

To assess whether this difference in language about inflation matters, we consider whether the revision in beliefs of households differs depending on which of these two treatments they received. The results in Table 4 suggests that this language has little discernible effect: inflation expectations fell by $1.1 \%$ on average for those surveyed in May and 1.3\% on average for those in June. 
The language of the USA Today articles covering these FOMC decisions is also somewhat different given the changing inflation outlook. In the article provided to households surveyed in May, the FOMC decision is described as

"Citing a brighter economic outlook, the Federal Reserve raised its key short-term interest rate Wednesday but maintained its forecast for a total of three hikes this year amid still-modest inflation... [The federal funds rate] is still low by historical standards but it marks the central bank's fourth increase in the past 12 months and another vote of confidence in an economy that's picking up steam nearly nine years after the Great Recession ended. 'We're trying to take that middle ground' on rate hikes, boosting rates enough to head off an eventual spike in inflation without derailing the economic expansion, Fed chairman Jerome Powell said at a news conference.”

This article identifies that inflation is "modest" but emphasizes the upside potential to the economy and the possibility of an eventual spike in inflation raised by Chairman Powell. The June article, following the FOMC’s May $2^{\text {nd }}$ decision to hold rates steady, takes a somewhat more ominous note:

"Inflation is creeping higher, and that's making the Federal Reserve more confident about raising interest rates. The Fed held its key interest rate steady Wednesday but noted that inflation had climbed close to its $2 \%$ goal, paving the way for another rate hike in June... Fed policymakers have forecast two more rate increases this year, according to their median estimate, but faster inflation could trigger three additional moves.”

Like the corresponding FOMC statement, this article makes clear that recent inflation was close to $2 \%$ and that its rise justified an expected path of rising interest rates.

Table 4 then considers whether the two different USA Today articles had differential effects on inflation expectations. We find mild differences between the two: participants in the May sample revised their inflation expectations downward by $0.6-0.7 \%$ on average while those in the June sample revised their expectations by $0.3-0.4 \%$, about half. While the darker language about rising inflation in the June article therefore seems to have some effect on how individuals revise their beliefs, it remains the case that revisions due to the USA Today treatment are much smaller than corresponding ones from the FOMC treatments. ${ }^{20}$ We also want to note that the June article explicitly mentioned the $2 \%$ inflation target but resulted in a smaller downward revision compared to the May article that did not include a specific number. Given that the FOMC statements and USA Today articles broadly conveyed the same information and the USA Today article did so using less jargon, the stronger effect from FOMC statements suggests that respondents discounted some of the information in the newspaper article.

\footnotetext{
${ }^{20}$ The other treatments regarding recent inflation, the inflation target and the Fed's inflation forecast have similar effects in May and June waves.
} 
To investigate the source of this discounting, we asked questions to participants in subsequent (and unrelated) surveys of Nielsen households in June 2019. These individuals were asked to rate how credible they viewed different news outlets as sources of information about the economy on a scale of 1 (very credible) to 5 (not credible). Results from more than 28,000 respondents presented in Table 5 indicate that U.S. households on average view newspapers as somewhat less reliable than television, the government, and friends/coworkers as a source of news, with social media being reported as the most credible news source of them all. We find small differences in the relative credibility of various newspapers: the USA Today is perceived as more credible than the New York Times, Washington Post or Wall Street Journal, but less credible than the Chicago Tribune or the Los Angeles Times. ${ }^{21}$ Hence, the discounting of the USA Today by our survey respondents does not appear to reflect the fact that they view this particular newspaper as unreliable but rather a more widespread skepticism that traditional media such as newspapers and television serve as a reliable source of news.

There could be other explanations. For example, we cannot determine if households focus only on certain subsets of FOMC or newspaper articles (e.g., first paragraph, title, etc.), so we cannot assess whether there is specific language driving the difference across treatments. However, the fact that there is a large difference between the FOMC treatment and both newspaper articles tentatively suggests that it is the source rather than the content that drives the differential treatment effect. The evidence on the low credibility of traditional news media further supports this view. Another possibility is that "demand characteristics” in which respondents want to please the experimenter could lead to stronger effects for the FOMC than for news media treatments if respondents thought this was a “desired” outcome (Weber and Cook 1972). However, respondents were not aware of the existence of other treatments or the purpose of the information treatments. Furthermore, the fact that the relative effects on expectations are similar three months later is difficult to reconcile with demand effects. In short, we view differential credibility across treatments as the most plausible source of differential effects.

\subsection{Convergence in Beliefs}

While the results above describe the average change in beliefs after an information treatment, this does not fully characterize how these treatments affect beliefs. For example, if agents act like Bayesians, their beliefs after the information treatments should be a weighted average of their initial beliefs and the treatment. If their initial beliefs were symmetrically distributed around the signal, one could observe no

\footnotetext{
${ }^{21}$ However, respondents chose the "do not know" option for the Chicago Tribune and the Los Angeles Times much more frequently than for the other four newspapers. This may reflect a more regional nature of the Chicago Tribune and the Los Angeles Times.
} 
change in average belief after a treatment, even though all households actually changed their beliefs in the expected way. However, one would still expect to see a reduction in the cross-sectional post-treatment dispersion of beliefs, since everyone moved toward the signal.

To assess whether beliefs are converging after receiving common signals, we directly quantify the weight that agents assign to signals they receive versus the weight they assign to their priors beliefs. If they act as Bayesians, the weight they assign to the signal in updating their beliefs should be the Kalman gain, and this weight should be increasing in the perceived precision of the signal. The weight they assign to their prior belief should then be one minus the Kalman gain. We assess this framework by regressing individuals' posterior beliefs on their prior beliefs. We allow for both the intercept and the slope coefficient to vary across groups since different signals have different values and are likely to have different perceived precisions, leading to different gains associated with each. The regression is given by:

$$
E_{i}^{\text {post }} \pi=a+\sum_{j} b_{j} \times \text { Treat }_{i, j}+\sum_{j} \gamma_{j} \times \text { Treat }_{i, j} \times E_{i}^{\text {pre }} \pi+\psi \times E_{i}^{\text {pre }} \pi+\text { error }
$$

where $i$ denotes the individual respondent and $j$ denotes the different treatment groups while Treat $_{i, j}$ are indicator variables indicating which treatment was received by respondent $i$.

The results of these regressions, across different horizons, are presented in Table 6. When looking at the control group, one would expect an intercept of zero and a slope coefficient of one since these individuals are receiving no additional information. However, since posterior beliefs are measured using point forecasts while prior beliefs are measured using distributional questions, the associated measurement error naturally leads to a coefficient on priors of less than one, and these coefficients fall over time. This provides the benchmark relative to which we can measure the weight assigned to different signals.

Consider first the results when individuals are presented with the inflation forecast of the FOMC, a signal directly comparable to their own inflation forecast. The associated weight on their prior belief is only around 0.2 , meaning that they place a very high weight on this signal, i.e. it is perceived as being very informative. These results suggest that survey participants converge in their beliefs once presented with this common source of information. Given that average priors are significantly higher than this signal, this updating also accounts for the large average decline in expectations documented in Table 2 when the treatment is received. Very similar results obtain when households are presented with information about recent inflation, the Fed's inflation target, or the FOMC statement. Strikingly, the weight on the prior is significantly higher when presented with the USA Today article, consistent with households treating this as a less informative signal. Information about gasoline prices, unemployment and population growth also receive much less weight upon treatment, consistent with households either perceiving these as less informative about inflation or something that is already largely known to them. 
Jointly, these results confirm that consumers respond to signals about inflation in the expected way. They systematically place weight on informative signals, leading to convergence in their beliefs upon receiving common information. They also assign more weight to signals that are perceived as more informative. While previous evidence for households has also largely been consistent with Bayesian updating, we are the first, to the best of our knowledge, to find these results for such a large group of households as well as being able to compare across a wide range of signals.

\subsection{Heterogeneity}

Do information treatments affect everyone equally? D’Acunto et al. (2020) find large differences in how individuals adjust consumption plans to their inflation expectations by demographics. In this section, we investigate this question by considering whether the effects of information treatments on inflation forecasts differ along observable characteristics of respondents. Such heterogeneity can be useful for policy-makers if they aim to affect the actions of specific subsets of the population, for example those who have unusually high or low inflation expectations. We therefore regress respondents' revisions across treatment groups on a range of observable characteristics along which they differ including gender, income (by tercile), education, race, access to and amount of available credit, purchasing plans, wealth, savings behavior, and shopping behavior (e.g. if they are the main person in the household that does the shopping or frequency of purchasing gasoline). The full set of results are presented in Appendix Tables 1 and 2, and summary results for observable heterogeneity are in Table 7. In each case, we focus on the specification which includes individual-specific controls and uses the contemporaneous response of inflation forecasts as the dependent variable, but similar results obtain at longer horizons.

There is surprisingly little heterogeneity in how respondents change their beliefs in response to new information on average. For example, white and non-white individuals respond to information treatments similarly. So do young, middle-aged and senior respondents. There is little variation between those who are planning to purchase expensive durable goods (cars, house, or other big-ticket items) and those who are not. Nor do we find systematic differences in responses to information treatments based on shopping behavior. Political preferences have some effect, as Democrats seem to respond somewhat more to information about inflation than do Republicans or Independents. We also consider whether there are systematic differences in responses to information depending on whether respondents have ready access to credit, have any savings or wealth, and their savings rate: we again find little variation along these dimensions. Gender, however, does seem to matter. Women respond more strongly to every information treatment including the placebo treatment of population growth, with information about gasoline prices 
being the only exception. The differences across the two groups are large in economic terms: women's responses to information treatments are often twice as large as men's. This may reflect the fact that men report more confidence in their beliefs about inflation, which should result in less weight being placed on new information. Income also matters for how individuals respond to information. We find that those in the middle of the income distribution of respondents (income between $\$ 40,000$ and $\$ 100,000$ ) respond significantly more to information about recent inflation or unemployment, the Federal Reserve's inflation target, the FOMC's inflation forecast, FOMC statements, as well as news reports about the FOMC's decisions than either lower-income or higher-income respondents. Strikingly, lower-income individuals do not respond at all, on average, to the USA Today news report about the FOMC meeting even though they respond strongly to most other treatments. We find a similar result when we decompose households by education: those with no more than a high school degree do not respond at all to the USA Today news report treatment, even though they respond strongly to other information treatments.

Low-income and less-educated individuals are, on average, systematically less well-informed about inflation and monetary policy. For example, in our survey, both low-income and less-educated individuals have higher average beliefs about the Fed's inflation target. Hence, one might think that monetary policy-makers might be able to have the largest effects on the beliefs of these individuals by providing them with information about inflation and monetary policy. What our results indicate, however, is that these are also the individuals that are least likely to incorporate information about inflation from the news media. This implies that traditional communications strategies of central banks, which rely largely on the transmission of information via standard news outlets, are unlikely to be successful and raises the concern that purely relying on these transmission channels results in redistributive effects of monetary policy (see also Coibion et al. (2017) and D’Acunto et al. (2018b)).

\section{$4 \quad$ Discussion}

The narrative around inflation expectations that is commonly promoted by central bankers is that 1) inflation expectations are important for inflation dynamics, 2) they are anchored to the inflation target as a result of the credibility of the central bank, and 3) this anchoring is a source of economic stability. The first point was most clearly illustrated by Federal Reserve Chairman Jerome Powell when he said in Congressional testimony that inflation expectations were the most important driver of inflation. ${ }^{22}$ The second point was emphasized by the President of the San Francisco Federal Reserve, Mary Daly:

\footnotetext{
${ }^{22}$ See https://www.bloomberg.com/news/articles/2019-03-15/fed-puts-inflation-expectations-at-heart-of-major-policy-review.
} 
"Once inflation was under control, the Fed committed to keeping it that way. This commitment became a well-known and accepted position that people could depend on. And it ushered the conditions that dominate today -the era of well-anchored expectations...”

The third step in their argument is summarized by Mary Daly simply as "when the Fed is credible, it's easier for the economic system to absorb shocks..." while the mechanism underlying it is described in more detail by Chairman Powell in the following:

"Anchored [inflation] expectations give a central bank greater flexibility to stabilize both unemployment and inflation. When a central bank acts to stimulate the economy to bring down unemployment, inflation might push above the bank's inflation target. With expectations anchored, people expect the central bank to pursue policies that bring inflation back down, and longer-term inflation expectations do not rise. Thus, policy can be a bit more accommodative than if policymakers had to offset a rise in longer-term expectations. ... I am confident that the FOMC would resolutely "do whatever it takes" should inflation expectations drift materially up or down."

Our results, using one of the largest surveys of U.S. households' expectations ever conducted, contradict this comforting narrative along many dimensions. We find little evidence that people know and accept the Fed's commitment to a low inflation target. Many individual respondents are unwilling to even guess what the Fed's inflation target is, and of those that do few answer correctly. Households' average perceptions of recent inflation are quite different from actual inflation and their inflation forecasts bear little resemblance to those of the FOMC. When presented with the most basic facts about inflation or monetary policy, their views often change dramatically. The limited evidence on U.S. firms' inflation expectations closely resembles that of households and available evidence from other advanced economies yields similar messages for both households and firms (see Coibion et al. 2020 for a review). The notion that most U.S. citizens, those individuals signing the wage and rental agreements at the heart of the mechanism described by Chairman Powell, have well-anchored expectations therefore flies in the face of the available evidence.

We view this as having a number of potentially important implications that call both for future work as well as renewed consideration by policy-makers. First is the notion of the credibility of the Federal Reserve and comparable central banks. In an era where central banks in advanced economies are coming under intense criticism from politicians and populist movements, they should not assume that their credibility with the broader public will help protect their independence. While professional forecasters and some financial market participants may have embraced the Fed's inflation target, the broader public has not. The lack of public understanding of just how successful modern central banking has been in the last thirty years makes central banks an easy target for populist leaders. Communication 
campaigns that describe, in easy-to-understand messages, what inflation rate the central bank targets and how close to that target inflation has been on average could boost not only the average knowledge about inflation of the broader population but also, as a result, the credibility of central banks. Central banks, however, should not stop here but should also explain in detail the benefits of stable prices and the implications of changes in inflation expectations for economic choices. Many households in the US perceive persistent deflation as desirable and have little knowledge about basic economic concepts such as the consumer Euler equation (D’Acunto et al. 2018a).

A second implication of our results, and one that is more positive for central banks, is the scope for how potentially powerful communications policies toward the broader public could be. We find that simple information treatments that reach the public can easily move inflation expectations by over one hundred basis points. Relative to quantitative easing policies or forward guidance, this suggests that policy-makers may be able to change perceived real interest rates of households and firms in a quantitatively important way through new communications strategies, a feature that could be immensely useful at the zero bound on nominal interest rates (Candia, Coibion, and Gorodnichenko 2020 and D'Acunto et al. 2020 provide guidance on how this communication could be implemented). Doing so will require much more systematic evaluation of how different types of information affect the expectations of economic agents as well as formal models that characterize how these signals affect expectations and decisions as well as their general equilibrium implications. Intuitively, the decline in both the level and volatility of inflation since the early 1980s has lowered the benefit of being informed about inflation for households, leading to pervasive inattention on their part. ${ }^{23}$ To offset this force, policy-makers would need to reduce the price of collecting and processing this information for households, which would require simpler communication strategies that reach individuals in a more direct and systematic manner. Our simple messages about inflation resulted in an average revision in forecasts of more than $1 \%$. For comparison, the first quantitative-easing program (QE1) of the Federal Reserve Bank amounted to \$1.725 trillion and resulted in a reduction in interest rates of only 0.34 percentage points according to estimates in Bhattarai and Neely (2018). In terms of changing perceived real interest rates, communication policies therefore have the scope for providing an important additional tool to policymakers.

A third implication for central banks has to do with the policy framework to use: e.g. inflation targeting vs price-level targeting. The Federal Reserve system implemented a process of reviewing its

\footnotetext{
${ }^{23}$ This is consistent with the fact that households in higher and more volatile inflation environments are more informed about inflation and monetary policy than those living in low and stable inflation environments. It is also consistent with the evolution of inflation expectations over time in the U.S. as inflation went from high and volatile in the 1970s to low and stable in the 1980s. See Coibion et al. (2020).
} 
policy objectives and procedures which led it to adopt an average inflation target in lieu of its more traditional inflation targeting strategy. The rationale for doing so is that, when the economy is facing the zero bound on interest rates, an average inflation targeting regime entails that inflation must be higher than the target after the zero bound ends, as this will be necessary to make up for the low inflation that occurs during the zero bound period. The expectation of higher future inflation while at the zero bound is predicted to be stimulative in New Keynesian models since higher expected inflation implies lower perceived real interest rates and therefore higher demand on the part of households. Average inflation targeting can therefore help stabilize economic outcomes during zero bound episodes relative to inflation targeting regimes. However, these effects hinge on households' inflation expectations correctly incorporating the effects of the regime and the zero bound such that they anticipate higher inflation than the target after the zero bound period ends. The absence of knowledge of what the target rate even is (documented in Figure 1) as well as the striking disconnect between household inflation expectations and recent inflation documented in this paper suggests that such a mechanism is unlikely to be effective as long as U.S. households remain as uninformed about inflation and monetary policy as they have been.

Ultimately, the power of any communication strategy on the part of central banks hinges on how any resulting changes in economic expectations affect actual decision-making. If households’ spending or other decisions are unaffected by their inflation expectations, then how the central bank communicates with households becomes a moot point. While this would be strongly at odds with standard macroeconomic models, the fact that households in advanced economies with a history of low and stable inflation are so uninformed about inflation and monetary policy could potentially reflect a perception by households that information about inflation or monetary policy is largely irrelevant to their decisions. We therefore turn to whether changes in inflation expectations stemming from information treatments have any discernible effect on the spending decisions of households.

\section{$5 \quad$ Inflation Expectations and Spending Decisions}

Do the large changes in inflation expectations generated by some of the information treatments have any effect on household decisions? We investigate this question using two sources of data. First, our surveys include a question which asks respondents to report their monthly spending on a wide category of goods and services, including food, utilities, etc. This question was asked both in the initial wave as well as the two follow-up waves. It therefore allows us to track spending of households over this sixmonth period, both overall as well as for specific categories of goods and services. In addition, respondents were asked in the first wave whether they expected to buy a) a house, b) a car, or c) any 
large big-ticket items over the next six months and if so, to report how much they expected to spend on each of those planned purchases. In the two subsequent waves, respondents were asked if they had recently purchased any of these and, if so, how much they had spent. This self-reported spending data therefore allows us to track the monthly spending of households on both non-durable goods and services as well as any purchases of larger durable goods following our information treatments.

Because our survey is run on households participating in the Nielsen Homescan Panel, information on their spending is also available from Nielsen based on their scanned purchases. These purchases are tracked at a high frequency but cover a relatively narrow set of goods, focusing on food and other consumer products. While more limited in scope, these data are less subject to measurement error than self-reported spending data in surveys. Scanner data therefore provide a useful check on what households report to us. Panel A of Figure 2 plots a binscatter comparing reported spending on food for survey respondents in the first wave against spending on food for those same individuals as measured by Nielsen. ${ }^{24}$ We find a strong positive relationship between the measures. Panel B of Figure 2 plots kernel densities of spending for the two data sources. The distribution of survey spending measures is clearly more "lumpy," reflecting the fact that most survey respondents round their reported spending. It also displays a larger tail of higher monthly spending amounts, which could reflect some undercounting in Nielsen data if respondents fail to scan all of their purchases. Overall, we view these figures as indicating that self-reported measures of spending are overall quite consistent with outside measures of spending, which is comforting given that self-reported data is the only type of information available for some categories of spending.

We begin by characterizing how changes in inflation expectations are related to households' total monthly spending (excluding large durable goods) in the following months. This is done using the following regression, which follows Coibion et al. (2019):

$$
\log (\text { spend })_{i, t+h}=\beta E_{i}^{\text {post }} \pi+\gamma E_{i}^{\text {prior }} \pi+\kappa \log (\text { spend })_{i t}+\text { Controls }_{i t}+\text { error }_{i, t+h}
$$

Where $\log (\text { spend })_{i, t+h}$ is the $(\log )$ spending of household $i$ either $h=3$ or $h=6$ months after the treatment, $E_{i}^{\text {post }} \pi$ is the posterior inflation expectation of household $i$ after the treatment (if any), $E_{i}^{\text {prior }} \pi$ is the prior inflation expectation of household $i$ before the treatment, $\log (\text { spend })_{i t}$ is the (log) spending of household $i$ in the month prior to the initial survey wave. $E_{i}^{\text {post }} \pi$ is instrumented using equation (3) augmented with $\log (\text { spend })_{i t}$ and Controls $_{i t}$. In addition, we group treatments

\footnotetext{
${ }^{24}$ We apply some restrictions to Nielsen data. In particular, we drop individuals whose food spending in Nielsen is less than $\$ 20$ per week or missing for 8 or more weeks in a quarter.
} 
T2 (past inflation), T3 (inflation target), T7 (FOMC forecast) and T8 (FOMC statement) into a single treatment block in the first stage since these have such similar effects on expectations. We use Huber regression in the first stage, then apply a jackknife procedure to control for any remaining outliers in the second stage of the regression, as in Coibion et al. (2019). The coefficient $\beta$ provides a causal estimate of how changes in inflation expectations translate into subsequent spending decisions.

This approach has several advantages. First, it provides a simple and tractable framework for relating how ex-post spending decisions across horizons vary with changes in inflation expectations, after controlling for past spending, past expectations, and observable characteristics. Second, the instrumental-variables (IV) strategy helps address the possible endogeneity of inflation expectations. For example, households at time $t$ who expect to spend more in subsequent periods may expect others to spend more as well and therefore that prices will rise, leading them to have higher inflation expectations. By using the treatments as a source of exogenous variation in inflation expectations, our approach can resolve this type of endogeneity.

To be clear, this approach is not estimating an Euler equation, as done in e.g. Crump et al. (2015) that identifies the intertemporal elasticity of substitution. Instead, our approach yields a "total" estimate of how exogenous variation in inflation expectations ultimately affects spending. This effect can reflect the intertemporal substitution channel, as in the Euler equation, but a number of other channels as well. For example, a rise in inflation expectations may lead households to expect a reduction in their future real wage, which could lead to lower spending. They could also infer that perceived changes in inflation reflect a stronger or weaker economy, which can in turn affect their risk of job loss and therefore desired spending levels. Our estimating equation combines all of these channels into a single estimate.

We begin by presenting results for total self-reported monthly spending of households in Panel A of Table 8 both three months and six months after the initial treatment. The first thing to note is that the F-statistic for the first stage is quite high (around 50), indicating that our information treatments generate enough exogenous variation in inflation expectations for identification purposes. Second, the coefficient on posterior inflation expectations is significantly positive after three months but somewhat smaller and not significant after six months, indicating that higher inflation expectations are followed by at least a brief period of higher monthly spending on the part of households. The economic magnitude is non-trivial and implies that a 1 percentage point increase in inflation expectations leads to a rise in overall monthly spending of around 1.8 percent, although the confidence interval around this estimate is large. 
Panel B provides equivalent estimates of the response of total household spending using the Nielsen scanner data. The included categories are more limited and the measured spending is therefore just a subset of the total spending captured in Panel A. However, the sample size is significantly larger since we are unconstrained by respondents needing to participate in follow-up waves of the survey. Between the larger sample size and the reduced noise in spending data, the estimates are much more precise. Both three and six months after the initial wave, we find that households with inflation expectations higher by 1 percentage point have higher spending by 0.85-0.95 percent, which is close to the six-month estimate from the survey data. Hence, regardless of which spending measure we use, the results indicate that when households raise their inflation expectations, they subsequently increase their spending over at least several months.

Panels C-D provide results for food, a subset of household spending with consistent measurement across datasets, as illustrated in Figure 1. We again find qualitatively similar results using either the self-reported survey data (Panel C) or the Nielsen scanner data (Panel D) for spending on food. Once again, through a combination of larger sample size and less noisy spending data, the results using the scanner measure of food spending are much more precise than those using the survey data, but even the latter point toward a statistically significant increase in spending over the first three months, with the effect over six months being insignificantly different from zero.

We then turn to whether large durable goods purchases are affected by the information treatments. Consistent with the approach used for spending measures, we estimate the following regression:

$$
\begin{aligned}
\mathbf{1}(\text { Durable purchas })_{i, t+h} \times 100= & \beta E_{i}^{\text {post }} \pi+\gamma E_{i}^{\text {prior }} \pi+\psi \mathbf{1}(\text { PurchasePlan })_{i t}+ \\
& \text { Controls }_{i t}+\text { error }_{i, t+h}
\end{aligned}
$$

where $\mathbf{1}$ (Durable purchas $)_{i, t+h}$ is an indicator variable indicating whether household $i$ reported having purchased any large durable good (house, car, or other big-ticket item) either in the previous three months (for the first follow-up wave) or over the previous six months (for the second follow-up wave). We control for $\mathbf{1}($ PurchasePlan) $i t$, an indicator variable indicating whether the household reported in the initial survey wave that they planned to purchase any large durable good over the following six months. We use the same instrumenting strategy for inflation expectations. ${ }^{25}$

\footnotetext{
25 The survey also asked respondents to report their planned and actual spending on durable goods but many respondents chose to not report spending ("prefer not to answer", "uncertain or do not know"). As a result, the sample available for estimation of the intensive margin is much smaller. For this sample, we did not find statistically significant effects of inflation expectations on the intensive margin of spending on durable goods, which is consistent with Coibion et al. (2019).
} 
Results are reported in Panel E of Table 8. We find a strong negative relation between the instrumented posterior inflation expectations from the first survey wave and ex-post purchases of durables from the follow-up waves. These negative effects extend to the second follow-up wave. A one percentage point increase in inflation expectations reduces the probability of a household purchasing a large durable good by about 1.5 percentage points. Appendix Table 11 provides equivalent estimates for different types of durable goods: houses, cars, and other big-ticket items. We find negative effects of inflation expectations for both cars and other durable goods, but the number of observations for purchased houses is too small to provide reliable inference.

What underlies the differential response of monthly spending on non-durables and services versus the purchase of large durable goods? First, this is the same qualitative pattern as found in Coibion et al. (2019) for households in the Netherlands. However, due to weaker instruments and a much smaller cross-section, those estimates were very imprecise and more ambiguous in nature. Here, the pattern of increasing their spending on non-durable goods and services when households raise their inflation expectations, while simultaneously delaying or canceling their purchases of large durable goods, is much more clearly identified. Nonetheless, the consistency in results across settings strongly suggests that this pattern is not by chance but instead characterizes the "total" effects of higher inflation expectations on consumer spending patterns.

There are in principle several forces that can make consumption move in the manner documented here. The increase in spending on non-durables and services could be a natural consequence of prices being expected to rise more rapidly in the future and is precisely the effect predicted by the Euler equation. If this is the force behind the rise in non-durables and services, one would expect it to be strongest for more educated individuals, consistent with D’Acunto et al. (2018a) who show using Finnish data that low-IQ men are less able to follow the Euler equation than higher IQ men. We might also expect it to be stronger for those who are not financially constrained, since financial constraints can prevent the borrowing against future income needed to finance the higher spending today. In Table 9, we report estimates of the response of total spending as measured using Nielsen data to inflation expectations for different subgroups of the population. We focus on total spending in Nielsen since this measure has less noise than the self-reported data and provides significantly more precise estimates as we cut the data into subgroups of households. The point estimates are consistent with less educated and lower income individuals raising their monthly spending by less than more educated and higher income individuals when they have higher inflation expectations, consistent with an Euler equation, although the differences are not statistically 
significant. The point estimates suggest that the financially constrained respondents may not able to increase their spending as much as the financially unconstrained, although again the differences are not statistically significant. We view the results of the effect of inflation expectations on monthly spending as being broadly consistent with intertemporal substitution given these patterns but it must be emphasized that the noise in the data makes it difficult to have precise estimates as soon we try to restrict our attention to subsamples of the data.

The postponement or cancellation of large durable good purchases in response to higher inflation expectations, however, is a priori less consistent with the standard intertemporal substitution logic. One explanation could be that, when survey participants raise their inflation expectations, they put off large durable good purchases to finance the short-term increase in spending on non-durables. One would expect this effect to be stronger for those groups who change their non-durable purchases more and for the financially constrained. Table 9 provides mixed evidence for this possibility. On the one hand, both richer and more educated respondents who raise their non-durable spending more with higher inflation expectations are also more likely to postpone their purchases of large durable goods. On the other hand, we do not find a stronger effect on durable goods purchases for women than men even though women are more likely to increase their non-durable spending than men. We can also observe that while Democrats are more likely to reduce their durable goods purchases then Republicans when they have higher inflation expectations, they are simultaneously less likely to increase their nondurable good spending. There could also be other explanations that are harder to test given available data. For example, as noted earlier, there is evidence that households associate higher inflation with worse economic outcomes, an effect that has been documented in Kamdar (2018), Binder (2020), and Candia, Coibion, and Gorodnichenko (2020), as well as in Table 2 after the unemployment treatment and in Appendix Table 12. If households associate these worse aggregate outcomes with their own future employment situation, this could make them less willing to commit to large purchases like those covered in our durable goods questions. If this effect were particularly strong for subsets of households such as the less educated, lower income and more financially constrained, then this could potentially explain why these groups tend to reduce their durable goods purchases more when they have higher inflation expectations. Another possibility is if some households with higher inflation expectations believe their real wages will be eroded more, then again this could explain why they could be more reticent to commit to purchases of large durable goods.

In short, we document robust new evidence that U.S. households tend to raise their spending on non-durables and services after they increase their inflation expectations, consistent with an 
intertemporal substitution motive as in the consumption Euler equation, and that this effect is particularly strong for households that are more educated, higher income and financially unconstrained. This complements earlier evidence from Crump et al. (2015), D’Acunto et al. (2016) and Drager and Nghiem (2020) but in a RCT setting combined with both survey and scanner-level data on ex-post spending decisions of households. At the same time, we also find that higher inflation expectations make households less likely to engage in purchases of large durable goods. This is consistent with earlier work using surveys focusing on whether households perceive that now is a good time to buy large durable goods, which concluded that higher inflation expectations were often associated, if at all, with a negative perception of buying houses, cars, etc. (e.g., Bachmann, Berg and Sims 2015).

\section{Conclusion}

In times of low interest rates, central banks have increasingly turned to forward guidance and other communications strategies to affect economic activity. However, these strategies have focused primarily on communicating with financial markets rather than the broader public. Since many expectations channels run through households and firms, central banks could also aim to affect economic conditions via direct communications to the public. The Fed Listens campaign is evidence that monetary policymakers increasingly perceive a need to communicate with the broader public. In this paper, we present new evidence that such communications can change expectations by economically significant magnitudes: simple messages about the central bank's inflation target have implications about real interest rates that dwarf those typically found for monetary policy announcements. Changes in households' inflation expectations in turn affect their spending decisions. However, we find that the effectiveness of these messages to the public is significantly dampened when transmitted via news media: households effectively dismiss much of the information content when presented to them in the form of a news article. This suggests that, if central banks want to add direct communications to the public as a new policy tool, they will have to find new ways to reach the public without relying on traditional media.

\section{References}

Andre, Peter, Carlo Pizzinelli, Chris Roth, and Johannes Wohlfahrt, 2019. "Subjective Models of the Macroeconomy: Evidence from Experts and a Representative Sample," manuscript.

Armona, Luis, Andreas Fuster, and Basit Zafar, 2018. "Home Price Expectations and Behavior: Evidence from a Randomized Information Treatment," forthcoming in Review of Economic Studies. 
Bachmann, Rudi, Tim Berg, and Eric Sims, 2015. "Inflation expectations and readiness to spend: Cross-sectional evidence,” American Economic Journal: Economic Policy 7(1): 1-35.

Bhattarai, Saroj and Christopher J. Neely, 2018. “An Analysis of the Literature on International Unconventional Monetary Policy,” manuscript.

Binder, Carola and Alex Rodrigue, 2018. "Household Informedness and Long-Run Inflation Expectations: Experimental Evidence,” Southern Economic Journal 85(2): 580-598.

Binder, Carola, 2015. “Whose Expectations Augment the Phillips Curve?” Economics Letters 136, 35-38.

Binder, Carola, 2017. "Fed speak on main street: Central bank communication and household expectations,” Journal of Macroeconomics 52(C): 238-251.

Binder, Carola, 2018. “Inflation Expectations and the Price at the Pump.” Journal of Macroeconomics 58(1): 1-18.

Binder, Carola, 2020a. “Long-Run Inflation Expectations in the Shrinking Upper Tail,” Economics Letters, 186(108867).

Binder, Carola, 2020b. “Coronavirus Fears and Macroeconomic Expectations,” Forthcoming in The Review of Economics and Statistics.

Binder, Carola, 2020c. “Presidential Antagonism and Central Bank Credibility,” Manuscript.

Blinder, Alan S. 2018. “Through a Crystal Ball Darkly: The Future of Monetary Policy Communication.” AEA Papers and Proceedings 108: 567-571.

Bordalo, Pedro, Nicola Gennaioli, Yueran Ma, and Andrei Shleifer, 2020. "Overreaction in Macroeconomic Expectations.” American Economic Review 110 (9): 2748-82.

Bryan, Michael F., and Guhan Venkatu, 2001 “The Demographics of Inflation Opinion Surveys.” Economic Commentary, Federal Reserve Bank of Cleveland.

Candia, Bernardo, Olivier Coibion, and Yuriy Gorodnichenko, 2020. "Communication and the Beliefs of Economic Agents,” NBER Working Papers 27800.

Carvalho, Carlos and Fernanda Nechio, 2015. “Do People Understand Monetary Policy?” Journal of Monetary Economics 66, 108-123.

Cavallo, Alberto, Guillermo Cruces, and Ricardo Perez-Truglia, 2017. "Inflation Expectations, Learning, and Supermarket Prices: Evidence from Survey Experiments,” American Economic Journal: Macroeconomics 9(3): 1-35.

Coibion, Olivier, and Yuriy Gorodnichenko, 2015. "Is the Phillips Curve Alive and Well After All? Inflation Expectations and the Missing Disinflation," American Economic Journal: Macroeconomics 7: 197-232. 
Coibion, Olivier, Dimitris Georgarakos, Yuriy Gorodnichenko and Maarten van Rooij, 2019. “How Does Consumption Respond to News about Inflation? Field Evidence from a Randomized Control Trial,” NBER Working Paper w26106.

Coibion, Olivier, Yuriy Gorodnichenko, and Rupal Kamdar, 2018. “The Formation of Expectations, Inflation and the Phillips Curve,” Journal of Economic Literature 56(4): 1447-1491.

Coibion, Olivier, Yuriy Gorodnichenko, Lorenz Kueng, and John Silvia, 2017. “Innocent Bystanders? Monetary policy and inequality,” Journal of Monetary Economics 88: 70-89.

Coibion, Olivier, Yuriy Gorodnichenko, and Saten Kumar, 2018. "How Do Firms Form their Expectations? New Survey Evidence,” American Economic Review 108(9): 2671-2713.

Coibion, Olivier, Yuriy Gorodnichenko, and Tiziano Ropele, 2020. "Inflation Expectations and Firm Decisions: New Causal Evidence,” Quarterly Journal of Economics 135(1), 165-219.

Coibion, Olivier, Yuriy Gorodnichenko, Saten Kumar, and Jane Ryngaert, 2021. "Do you know that I know that you know...? Higher order beliefs in survey data,” forthcoming in Quarterly Journal of Economics.

Coibion, Olivier, Yuriy Gorodnichenko, Saten Kumar and Mathieu Pedemonte, 2020. "Inflation Expectations as a Policy Tool?” Journal of International Economics 124: 103297.

Crump, Richard, Stefano Eusepi, Andrea Tambalotti, and Giorgio Toppa, 2015. “Subjective Intertemporal Substitution,” Federal Reserve Bank of New York Staff Reports N 734.

D’Acunto, Francesco, Daniel Hoang, Maritta Paloviita, and Michael Weber, 2018a. "IQ, Expectations, and Choice,” manuscript.

D’Acunto, Francesco, Daniel Hoang, Maritta Paloviita, and Michael Weber, 2018b. "Human Frictions to the Transmission of Economic Policy,” manuscript.

D’Acunto, Francesco, Daniel Hoang, Maritta Paloviita, and Michael Weber, 2020. "Effective Policy Communication: Targets versus Instruments,” manuscript.

D’Acunto, Francesco, Daniel Hoang, and Michael Weber, 2016. “The Effect of Unconventional Fiscal Policy on Consumption Expenditure,” NBER Working Paper 22563.

D’Acunto, Francesco, Daniel Hoang, and Michael Weber, 2016. “Managing Households' Expectations with Unconventional Policies,” NBER Working Paper 27399.

D’Acunto, Francesco, Andreas Fuster, and Michael Weber, 2021. “Diverse Policy Committees are more effective,” manuscript.

D’Acunto, Francesco, Ulrike Malmendier, and Michael Weber, 2019. “Traditional Gender Norms Distort Women’s Economic Expectations,” manuscript. 
D’Acunto, Francesco, Ulrike Malmendier, Juan Ospina, and Michael Weber, 2020. "Exposure to Grocery Prices and Inflation Expectations,” Journal of Political Economy (forthcoming).

de Quidt, Jonathan, Johannes Haushofer, and Christopher Roth, 2018. "Measuring and Bounding Experimenter Demand,” American Economic Review 108 (11): 3266-3302.

Drager, Lena and Giang Nghiem, 2020. “Are Consumers’ Spending Decisions in Line with an Euler Equation?” Forthcoming in The Review of Economics and Statistics.

Drager, Lena, Michael J. Lamla and Damien Pfajfar, 2016. "Are Survey Expectations Theory Consistent? The Role of Central Bank Communication and News," European Economic Review 85: 84-111.

Fuster, Andreas, Greg Kaplan and Basit Zafar, 2019. "What Would You Do with \$500? Spending Responses to Gains, Losses, News and Loans," manuscript.

Geraats, Petra M., 2007. “The Mystique of Central Bank Speak.” International Journal of Central Banking 3(1): 1-44.

Haldane, Andrew, and Michael McMahon. 2018. "Central Bank Communications and the General Public.” AEA Papers and Proceedings 108: 578-583.

Humziker, Hans-Ueli, Christian Raggi, and Rina Rosenblatt-Wisch, 2018. "The impact of guidance, short-term dynamics and individual characteristics on firms' long-term inflation expectations," manuscript.

Jonung, Lars, 1981 "Perceived and Expected Rates of Inflation in Sweden," American Economic Review 71(5): 961-968.

Kamdar, Rupal, 2018. “The Inattentive Consumer: Sentiment and Expectations” Manuscript.

Kumar, Saten, Hassan Afrouzi, Olivier Coibion, and Yuriy Gorodnichenko, 2015. "Inflation Targeting Does Not Anchor Inflation Expectation: Evidence from Firms in New Zealand,” Brooking Papers on Economic Activity 46(Fall): 151-225.

Roth, Christopher and Johannes Wohfart, 2018. "How do expectations about the economy affect personal expectations and behavior?” manuscript.

Swanson, Eric T., 2018. "Measuring the Effects of Federal Reserve Forward Guidance and Asset Purchases on Financial Markets,” NBER Working Paper 23311.

Weber, Stephen J., and Thomas D. Cook. 1972. "Subject effects in laboratory research: An examination of subject roles, demand characteristics, and valid inference.” Psychological Bulletin 77(4): 273-295. 
Figure 1: Households' Beliefs about the Federal Reserve's Inflation Target.

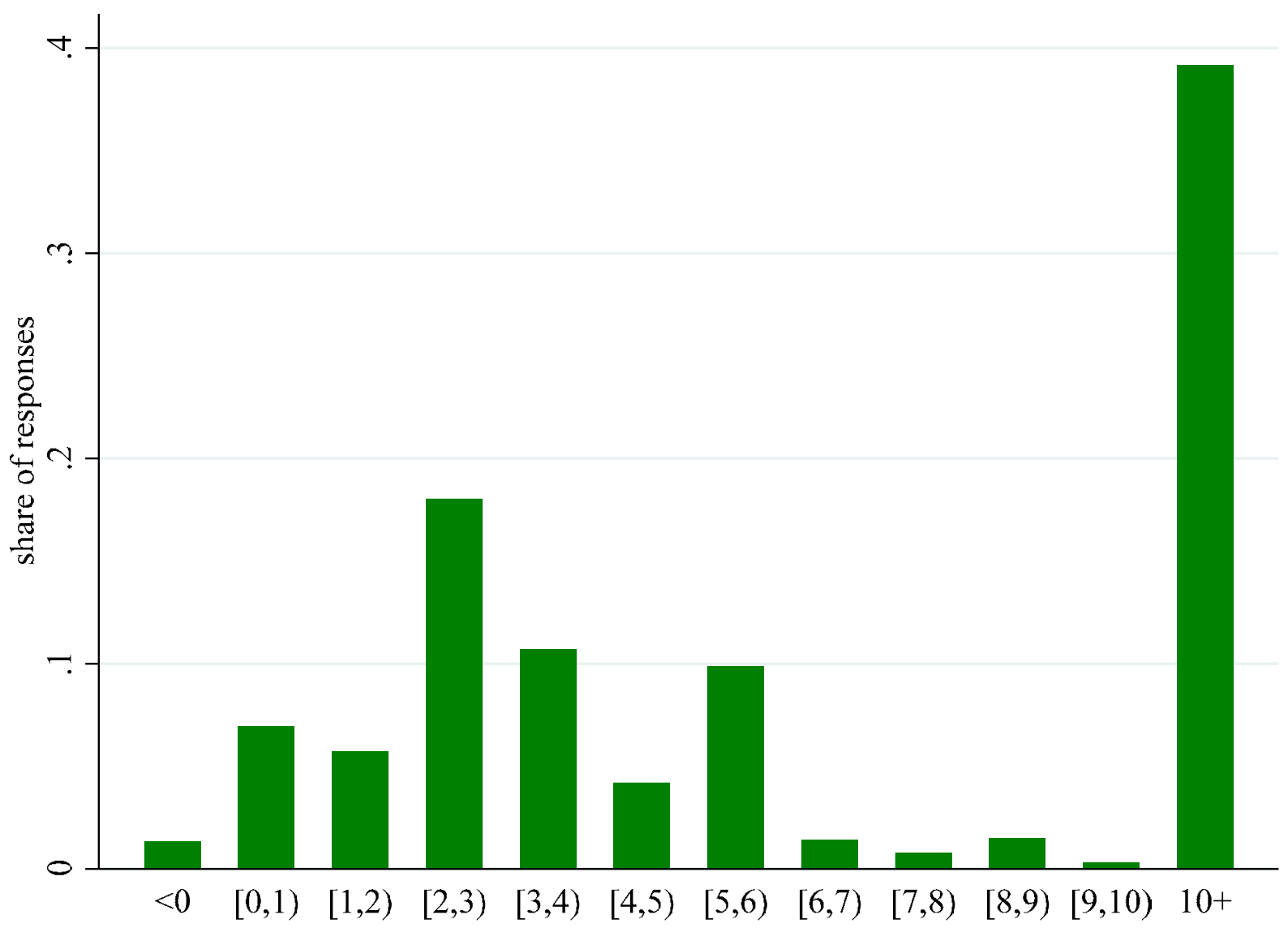

Notes: The figure plots the distribution of responses from individuals about what inflation rate they thought the Federal Reserve was trying to achieve in the long-run. This figure includes only respondents from the May 2018 part of survey wave 1, which did not have a "do not know" option for the question eliciting perceptions of the inflation target. 
Figure 2. Consistency of scanner and survey spending data.

Panel A. Binscatter

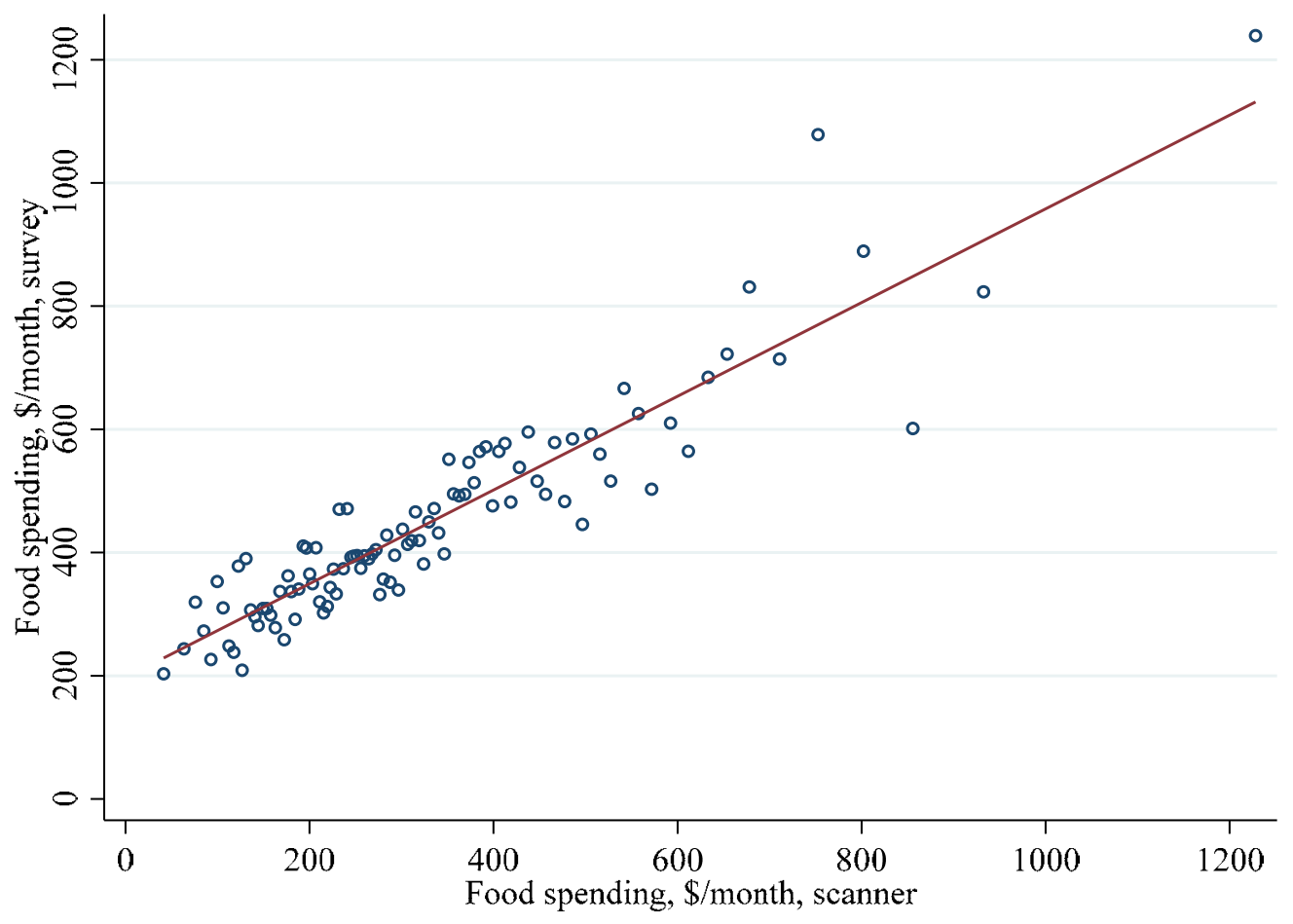

Panel B. Kernel density (notice rounding in the survey = bumps)

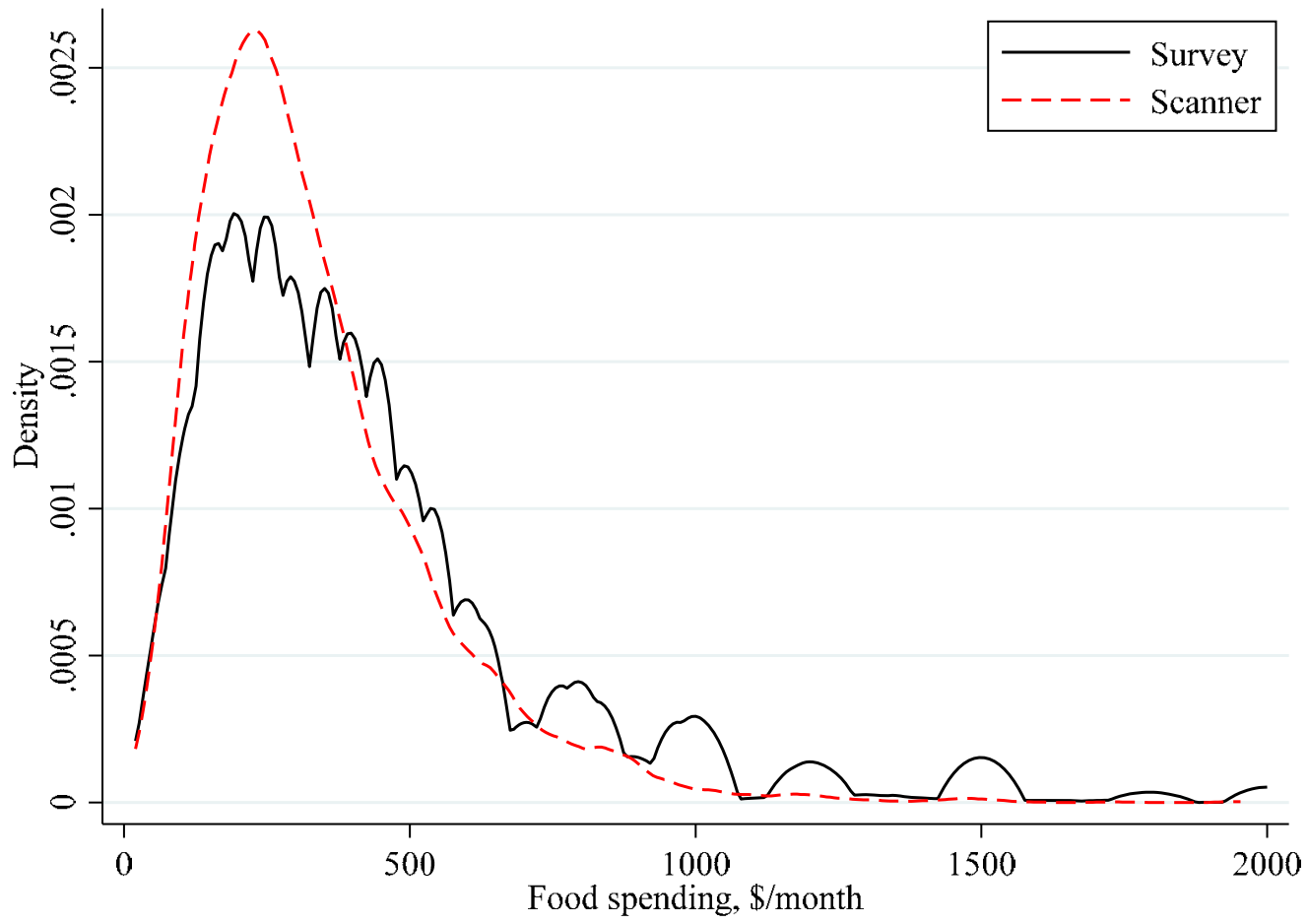

Notes: Panel A shows binscatter plot of monthly food spending reported in Nielsen scanner data and in the survey. Panel B plots kernel densities of these two measures. 
. Table 1: Descriptive Statistics of the Survey

\begin{tabular}{|c|c|c|c|c|c|c|c|c|c|}
\hline \multirow[t]{3}{*}{ Sample } & \multicolumn{3}{|c|}{$\begin{array}{c}\text { Pre-treatment expected } \\
\text { inflation } \\
\end{array}$} & \multicolumn{3}{|c|}{$\begin{array}{c}\text { Pre-treatment perceived } \\
\text { inflation } \\
\end{array}$} & \multicolumn{3}{|c|}{$\begin{array}{c}\text { Pre-treatment perceived } \\
\text { inflation target of the Fed }\end{array}$} \\
\hline & Mean & Median & St.Dev. & Mean & Median & St.Dev. & Mean & Median & St.Dev \\
\hline & $(1)$ & $(2)$ & (3) & $(4)$ & (5) & (6) & $(7)$ & (8) & (9) \\
\hline All & 2.47 & 2.40 & 2.57 & 2.46 & 2.00 & 2.66 & 3.37 & 3.00 & 2.73 \\
\hline Male & 2.43 & 2.70 & 2.12 & 2.50 & 2.00 & 2.10 & 2.89 & 2.30 & 2.08 \\
\hline Female & 2.49 & 2.00 & 2.75 & 2.44 & 2.00 & 2.90 & 3.60 & 3.00 & 2.96 \\
\hline White & 2.50 & 2.45 & 2.59 & 2.54 & 2.00 & 2.71 & 3.36 & 3.00 & 2.74 \\
\hline Non-white & 2.39 & 2.25 & 2.50 & 2.17 & 2.00 & 2.45 & 3.39 & 3.00 & 2.67 \\
\hline Income: tercile 1 (low) & 2.42 & 2.00 & 2.83 & 2.32 & 2.00 & 2.97 & 3.53 & 3.00 & 3.10 \\
\hline Income: tercile 2 & 2.58 & 2.50 & 2.85 & 2.58 & 2.00 & 2.97 & 3.61 & 3.00 & 3.10 \\
\hline Income: tercile 3 & 2.46 & 2.60 & 2.22 & 2.49 & 2.00 & 2.27 & 3.18 & 3.00 & 2.30 \\
\hline Enough credit & 2.54 & 2.66 & 2.44 & 2.61 & 2.00 & 2.52 & 3.28 & 3.00 & 2.57 \\
\hline Not enough credit & 2.55 & 2.50 & 2.72 & 2.38 & 2.00 & 2.86 & 3.55 & 3.00 & 2.90 \\
\hline HTM: less than 1 month in savings & 2.56 & 2.42 & 2.62 & 2.51 & 2.00 & 2.75 & 3.51 & 3.00 & 2.79 \\
\hline HTM: 1-6 months in savings & 2.62 & 2.80 & 2.34 & 2.69 & 2.00 & 2.34 & 3.18 & 3.00 & 2.38 \\
\hline HTM: 6+ months in savings & 2.62 & 3.00 & 2.13 & 2.64 & 2.00 & 2.15 & 3.00 & 2.50 & 2.10 \\
\hline Plan to buy durable & 2.53 & 2.60 & 2.46 & 2.53 & 2.00 & 2.56 & 3.32 & 3.00 & 2.63 \\
\hline No plan to buy durable & 2.46 & 2.20 & 2.60 & 2.44 & 2.00 & 2.69 & 3.38 & 3.00 & 2.76 \\
\hline No financial wealth & 2.22 & 1.20 & 2.82 & 2.12 & 1.00 & 2.90 & 3.48 & 3.00 & 3.07 \\
\hline Positive financial wealth & 2.60 & 2.80 & 2.43 & 2.63 & 2.00 & 2.52 & 3.31 & 3.00 & 2.53 \\
\hline Saving rate: 0 & 2.57 & 2.40 & 2.76 & 2.37 & 2.00 & 2.90 & 3.60 & 3.00 & 2.94 \\
\hline Saving rate: $0-10$ & 2.58 & 2.75 & 2.44 & 2.68 & 2.00 & 2.55 & 3.36 & 3.00 & 2.57 \\
\hline Saving rate: $10+$ & 2.56 & 2.70 & 2.33 & 2.63 & 2.00 & 2.41 & 3.20 & 2.50 & 2.43 \\
\hline Do grocery: me/self & 2.54 & 2.50 & 2.58 & 2.54 & 2.00 & 2.66 & 3.42 & 3.00 & 2.78 \\
\hline Do grocery: share & 2.45 & 2.35 & 2.56 & 2.44 & 2.00 & 2.67 & 3.36 & 3.00 & 2.71 \\
\hline Education: high school or less & 2.22 & 1.50 & 2.52 & 2.06 & 1.00 & 2.60 & 3.52 & 3.00 & 2.85 \\
\hline Education: some college & 2.48 & 2.38 & 2.62 & 2.44 & 2.00 & 2.76 & 3.44 & 3.00 & 2.76 \\
\hline Education: college or more & 2.59 & 2.63 & 2.55 & 2.66 & 2.00 & 2.61 & 3.28 & 3.00 & 2.66 \\
\hline
\end{tabular}

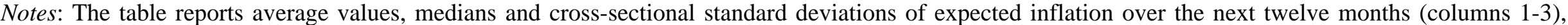

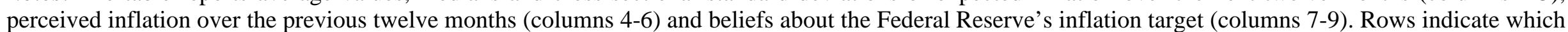

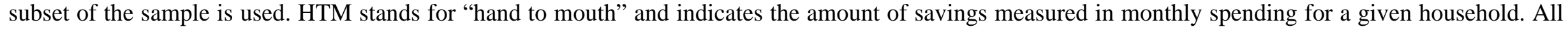

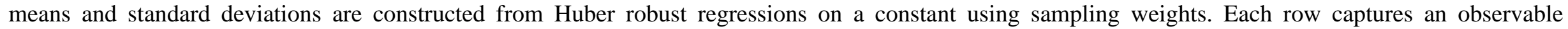
characteristic of the respondent on which we condition. 
Table 2: Average Household Responses to Treatments.

\begin{tabular}{|c|c|c|c|c|c|c|}
\hline \multirow{3}{*}{ Treatments } & \multicolumn{6}{|c|}{ Outcome: forecast revision } \\
\hline & \multicolumn{2}{|c|}{ Immediate revision } & \multicolumn{2}{|c|}{ Revision after 3 months } & \multicolumn{2}{|c|}{ Revision after 6 months } \\
\hline & $(1)$ & $(2)$ & (3) & $(4)$ & (5) & (6) \\
\hline \multirow[t]{2}{*}{ T5 (pop growth) } & $-0.218 * *$ & $-0.229 * *$ & -0.096 & -0.106 & 0.032 & 0.049 \\
\hline & $(0.105)$ & $(0.104)$ & $(0.091)$ & $(0.091)$ & $(0.098)$ & $(0.099)$ \\
\hline \multirow[t]{2}{*}{ T6 (UE) } & $-0.331 * * *$ & $-0.332 * * *$ & $-0.294 * * *$ & $-0.321 * * *$ & -0.131 & -0.133 \\
\hline & $(0.105)$ & $(0.104)$ & $(0.093)$ & $(0.094)$ & $(0.096)$ & $(0.097)$ \\
\hline \multirow[t]{2}{*}{ T4 (gas prices) } & $1.479 * * *$ & $1.474^{* * *}$ & $-0.180 *$ & $-0.174 *$ & -0.151 & $-0.170^{*}$ \\
\hline & $(0.114)$ & $(0.114)$ & $(0.093)$ & $(0.094)$ & $(0.097)$ & $(0.099)$ \\
\hline \multirow[t]{2}{*}{ T2 (past inflation) } & $-1.031 * * *$ & $-1.068 * * *$ & -0.034 & -0.054 & $0.198 * *$ & $0.209 * *$ \\
\hline & $(0.104)$ & $(0.104)$ & $(0.092)$ & $(0.092)$ & $(0.098)$ & $(0.099)$ \\
\hline \multirow[t]{2}{*}{ T3 (inflation target) } & $-0.994 * * *$ & $-0.997 * * *$ & $-0.329 * * *$ & $-0.371^{* * *}$ & 0.028 & 0.047 \\
\hline & $(0.102)$ & $(0.102)$ & $(0.092)$ & $(0.092)$ & $(0.097)$ & $(0.098)$ \\
\hline \multirow[t]{2}{*}{ T7 (Fed inflation forecast) } & $-1.072 * * *$ & $-1.098^{* * *}$ & $-0.235^{* *}$ & $-0.227 * *$ & 0.139 & $0.177^{*}$ \\
\hline & $(0.102)$ & $(0.103)$ & $(0.094)$ & $(0.094)$ & $(0.096)$ & $(0.098)$ \\
\hline \multirow[t]{2}{*}{ T8 (FOMC statement) } & $-1.193 * * *$ & $-1.218 * * *$ & -0.107 & -0.127 & -0.012 & 0.028 \\
\hline & $(0.103)$ & $(0.103)$ & $(0.091)$ & $(0.092)$ & $(0.099)$ & $(0.101)$ \\
\hline \multirow[t]{2}{*}{ T9 (USA today coverage) } & $-0.444 * * *$ & $-0.475 * * *$ & -0.120 & $-0.154^{*}$ & 0.087 & 0.086 \\
\hline & $(0.105)$ & $(0.105)$ & $(0.093)$ & $(0.093)$ & $(0.097)$ & $(0.098)$ \\
\hline Remove outliers & Yes & Yes & Yes & Yes & Yes & Yes \\
\hline Using sampling weights & Yes & Yes & Yes & Yes & Yes & Yes \\
\hline Controls for demographics & No & Yes & No & Yes & No & Yes \\
\hline Observations & 19,222 & 19,210 & 12,882 & 12,872 & 12,619 & 12,406 \\
\hline $\mathrm{R}^{2}$ & 0.047 & 0.061 & 0.002 & 0.017 & 0.002 & 0.015 \\
\hline
\end{tabular}

Notes: The table reports the average change in inflation expectations of individuals in each treatment group relative to those in the control group. Columns (1) and (2) consider the immediate change in expectations after the treatment, columns (3) and (4) consider the changes in beliefs after three months, columns (5) and (6) report changes in beliefs over a six month horizon. In each case, differences in beliefs are measured relative to initial beliefs from the first wave measured before all treatments. Treatments are described in detail in the text. For each time horizon, the second column uses the same specification as in the first column but augmented with respondentspecific controls. Results are from Huber robust regressions to control for outliers and influential observations. Robust standard errors are reported in parentheses. 
Table 3: Average Effects of Treatments over Time on Specific Variables being Treated.

\begin{tabular}{|c|c|c|c|c|}
\hline \multirow[t]{3}{*}{ Treatments } & \multicolumn{4}{|c|}{ Outcome: forecast revision } \\
\hline & \multicolumn{2}{|c|}{ Revisions after 3 months } & \multicolumn{2}{|c|}{ Revision after 6 months } \\
\hline & $(1)$ & $(2)$ & $(3)$ & $(4)$ \\
\hline \multicolumn{5}{|c|}{ Panel A: Treatment effect on perceptions of the Fed's inflation target } \\
\hline T3 (inflation target) & $\begin{array}{l}-0.343^{* * *} \\
(0.107)\end{array}$ & $\begin{array}{l}-0.356^{* * *} \\
(0.116)\end{array}$ & $\begin{array}{l}-0.123 \\
(0.118)\end{array}$ & $\begin{array}{l}-0.198 \\
(0.129)\end{array}$ \\
\hline \multicolumn{5}{|c|}{ Panel B: Treatment effect on perceptions past inflation } \\
\hline T2 (past inflation) & $\begin{array}{l}-0.208^{* *} \\
(0.097)\end{array}$ & $\begin{array}{l}-0.170^{*} \\
(0.102)\end{array}$ & $\begin{array}{l}-0.206^{* *} \\
(0.103)\end{array}$ & $\begin{array}{l}-0.201 * \\
(0.107)\end{array}$ \\
\hline \multicolumn{5}{|c|}{ Panel C: Treatment effect on perceptions of unemployment rate } \\
\hline T6 (UE) & $\begin{array}{l}-0.224^{* *} \\
(0.107)\end{array}$ & $\begin{array}{l}-0.236^{* *} \\
(0.112)\end{array}$ & $\begin{array}{l}-0.166 \\
(0.109)\end{array}$ & $\begin{array}{l}-0.213^{*} \\
(0.115)\end{array}$ \\
\hline Controls for demographics & No & Yes & No & Yes \\
\hline
\end{tabular}

Notes: The table reports the average changes in beliefs about variables being treated after 3 months (columns 1-2) and 6 months (3-4) relative to changes reported in the control group. In Panel A, we report how respondents in the group that received information about the Fed's inflation target revised their beliefs about the inflation target over time. In Panel B, we report how respondents in the group that received information about recent inflation revised their beliefs about recent inflation rates over time. In Panel C, we report how respondents in the group that received information about recent unemployment revised their beliefs about the unemployment rate over time. For each time horizon, the second column uses the same specification as in the first column but augmented with respondentspecific controls. Results are from Huber robust regressions to control for outliers and influential observations. Robust standard errors are reported in parentheses. 
Table 4: Sensitivity to Differential Language in FOMC and USA Today Treatments.

\begin{tabular}{|c|c|c|c|c|c|c|}
\hline \multirow{3}{*}{ Treatments } & \multicolumn{6}{|c|}{ Outcome: immediate forecast revision } \\
\hline & \multicolumn{2}{|c|}{ Pooled sample } & \multicolumn{2}{|c|}{ May sample } & \multicolumn{2}{|c|}{ June sample } \\
\hline & $(1)$ & $(2)$ & (3) & $(4)$ & (5) & $(6)$ \\
\hline T8 (FOMC statement) & $\begin{array}{l}-1.193 * * * \\
(0.103)\end{array}$ & $\begin{array}{l}-1.218 * * * \\
(0.103)\end{array}$ & $\begin{array}{l}-1.092 * * * \\
(0.150)\end{array}$ & $\begin{array}{l}-1.104 * * * \\
(0.151)\end{array}$ & $\begin{array}{l}-1.291 * * * \\
(0.141)\end{array}$ & $\begin{array}{c}-1.314^{* * *} \\
(0.141)\end{array}$ \\
\hline T9 (USA Today coverage) & $\begin{array}{l}-0.444^{* * *} \\
(0.105)\end{array}$ & $\begin{array}{l}-0.475^{* * *} \\
(0.105)\end{array}$ & $\begin{array}{l}-0.581^{* * *} \\
(0.152)\end{array}$ & $\begin{array}{l}-0.618^{* * * *} \\
(0.152)\end{array}$ & $\begin{array}{l}-0.325^{* *} \\
(0.145)\end{array}$ & $\begin{array}{l}-0.338^{* *} \\
(0.145)\end{array}$ \\
\hline Remove outliers & Yes & Yes & Yes & Yes & Yes & Yes \\
\hline Using sampling weights & Yes & Yes & Yes & Yes & Yes & Yes \\
\hline Controls for demographics & No & Yes & No & Yes & No & Yes \\
\hline
\end{tabular}

Notes: The table reports the average change in inflation expectations of individuals in each treatment group relative to those in the control group. Columns (1) and (2) consider the immediate change in expectations after the treatment, columns (3) and (4) consider the changes in beliefs for those taking the survey in May of 2018, columns (5) and (6) report changes in beliefs for those participating in June 2018. Differences in information treatments between May and June waves are described in detail in section 3.2. For each time horizon, the second column uses the same specification as in the first column but augmented with respondent-specific controls. Results are from Huber robust regressions to control for outliers and influential observations. Robust standard errors are reported in parentheses. 
Table 5: Credibility of Different News Sources

\begin{tabular}{|c|c|c|c|}
\hline & \multicolumn{2}{|c|}{ Score } & \multirow{2}{*}{$\begin{array}{c}\text { Share of people } \\
\text { choosing "do not } \\
\text { know" }\end{array}$} \\
\hline & mean & st.dev. & \\
\hline & $(1)$ & $(2)$ & $(3)$ \\
\hline \multicolumn{4}{|c|}{ Credibility of news sources (lower score means more credibility) } \\
\hline Newspapers & 3.07 & 1.16 & 0.11 \\
\hline TV & 2.87 & 1.12 & 0.08 \\
\hline Social media & 2.12 & 1.08 & 0.09 \\
\hline Friends and coworker & 2.83 & 1.02 & 0.10 \\
\hline Government & 2.84 & 1.14 & 0.11 \\
\hline \multicolumn{4}{|c|}{ Credibility of newspapers (lower score means more credibility) } \\
\hline New York Times & 3.20 & 1.42 & 0.36 \\
\hline Wall Street Journal & 3.45 & 1.31 & 0.35 \\
\hline USA Today & 3.05 & 1.26 & 0.36 \\
\hline Washington Post & 3.14 & 1.40 & 0.39 \\
\hline Chicago Tribune & 2.91 & 1.34 & 0.48 \\
\hline Los Angeles Times & 2.92 & 1.36 & 0.47 \\
\hline
\end{tabular}

Notes: The table reports scores to questions about the credibility of news sources (top panel) and the credibility of specific newspapers (bottom panel). In each case, respondents were asked to rate credibility on a scale of 1 (very credible) to 5 (not credible). Column (1) reports mean credibility scores across all respondents, column (2) reports the standard deviation of those scores across respondents, while column (3) reports the fraction of respondents who claimed that they did not know about the credibility of each source. 28,507 respondents provided their assessments. 
Table 6: Posterior Beliefs by Treatments.

\begin{tabular}{|c|c|c|c|c|c|c|}
\hline \multirow{3}{*}{ Treatments } & \multicolumn{2}{|c|}{ Immediate revision } & \multicolumn{2}{|c|}{ Revision after 3 months } & \multicolumn{2}{|c|}{ Revision after 6 months } \\
\hline & $\begin{array}{l}\text { Intercept } \\
(b)\end{array}$ & $\begin{array}{c}\text { Slope } \\
(\gamma)\end{array}$ & $\begin{array}{c}\text { Intercept } \\
(b)\end{array}$ & $\begin{array}{c}\text { Slope } \\
(\gamma)\end{array}$ & $\begin{array}{c}\text { Intercept } \\
(b)\end{array}$ & $\begin{array}{c}\text { Slope } \\
(\gamma)\end{array}$ \\
\hline & $(1)$ & $(2)$ & $(3)$ & $(4)$ & $(5)$ & $(6)$ \\
\hline T1 (control) & $\begin{array}{l}2.235^{* * *} \\
(0.088)\end{array}$ & $\begin{array}{l}0.662 \text { *** } \\
(0.021)\end{array}$ & $\begin{array}{l}2.281^{* * * *} \\
(0.074)\end{array}$ & $\begin{array}{l}0.268 * * * \\
(0.016)\end{array}$ & $\begin{array}{l}2.399 * * * \\
(0.089)\end{array}$ & $\begin{array}{l}0.261^{* * *} \\
(0.020)\end{array}$ \\
\hline \multicolumn{7}{|l|}{ Relative to control group } \\
\hline T5 (pop growth) & $\begin{array}{l}0.290^{* *} \\
(0.121)\end{array}$ & $\begin{array}{l}-0.228^{* * *} \\
(0.029)\end{array}$ & $\begin{array}{l}-0.670^{* * *} \\
(0.106)\end{array}$ & $\begin{array}{l}0.202^{* * *} \\
(0.025)\end{array}$ & $\begin{array}{l}-0.835^{* * *} \\
(0.122)\end{array}$ & $\begin{array}{l}0.256^{* * *} \\
(0.029)\end{array}$ \\
\hline T6 (UE) & $\begin{array}{l}0.412^{* * *} \\
(0.120)\end{array}$ & $\begin{array}{l}-0.277^{* * *} \\
(0.027)\end{array}$ & $\begin{array}{l}-0.186^{*} \\
(0.107)\end{array}$ & $\begin{array}{c}0.029 \\
(0.023)\end{array}$ & $\begin{array}{l}-0.195 \\
(0.126)\end{array}$ & $\begin{array}{c}0.005 \\
(0.027)\end{array}$ \\
\hline T4 (gas prices) & $\begin{array}{l}2.183^{* * *} \\
(0.132)\end{array}$ & $\begin{array}{l}-0.209 * * * \\
(0.028)\end{array}$ & $\begin{array}{l}-0.185^{*} \\
(0.106)\end{array}$ & $\begin{array}{l}0.061^{* *} \\
(0.024)\end{array}$ & $\begin{array}{l}-0.276^{* *} \\
(0.122)\end{array}$ & $\begin{array}{c}0.034 \\
(0.028)\end{array}$ \\
\hline T2 (past inflation) & $\begin{array}{l}0.408^{* * *} \\
(0.110)\end{array}$ & $\begin{array}{l}-0.505^{* * * *} \\
(0.025)\end{array}$ & $\begin{array}{l}-0.027 \\
(0.103)\end{array}$ & $\begin{array}{l}-0.028 \\
(0.022)\end{array}$ & $\begin{array}{l}-0.031 \\
(0.121)\end{array}$ & $\begin{array}{l}-0.047^{*} \\
(0.026)\end{array}$ \\
\hline T3 (inflation target) & $\begin{array}{l}0.238^{* *} \\
(0.109)\end{array}$ & $\begin{array}{l}-0.444^{* * *} \\
(0.025)\end{array}$ & $\begin{array}{l}-0.488^{* * * *} \\
(0.105)\end{array}$ & $\begin{array}{l}0.049^{* *} \\
(0.023)\end{array}$ & $\begin{array}{l}-0.511^{* * * *} \\
(0.123)\end{array}$ & $\begin{array}{c}0.045 \\
(0.028)\end{array}$ \\
\hline T7 (Fed inflation forecast) & $\begin{array}{c}0.102 \\
(0.107)\end{array}$ & $\begin{array}{l}-0.458^{* * *} \\
(0.025)\end{array}$ & $\begin{array}{l}-0.197^{*} \\
(0.107)\end{array}$ & $\begin{array}{l}0.090^{* * *} \\
(0.024)\end{array}$ & $\begin{array}{l}-0.254 * * \\
(0.128)\end{array}$ & $\begin{array}{l}0.122^{* * * *} \\
(0.028)\end{array}$ \\
\hline T8 (FOMC statement) & $\begin{array}{c}0.044 \\
(0.110)\end{array}$ & $\begin{array}{l}-0.488^{* * * *} \\
(0.026)\end{array}$ & $\begin{array}{l}-0.206^{* *} \\
(0.103)\end{array}$ & $\begin{array}{l}-0.012 \\
(0.023)\end{array}$ & $\begin{array}{l}-0.275^{* *} \\
(0.119)\end{array}$ & $\begin{array}{l}-0.006 \\
(0.027)\end{array}$ \\
\hline T9 (USA Today coverage) & $\begin{array}{l}0.288^{* *} \\
(0.115)\end{array}$ & $\begin{array}{l}-0.369 * * * \\
(0.028)\end{array}$ & $\begin{array}{l}-0.260^{* *} \\
(0.104)\end{array}$ & $\begin{array}{l}0.077^{* * *} \\
(0.024)\end{array}$ & $\begin{array}{l}-0.394^{* * *} \\
(0.123)\end{array}$ & $\begin{array}{l}0.126^{* * *} \\
(0.028)\end{array}$ \\
\hline Remove outliers & & & & & & \\
\hline Using sampling weights & & & & & & \\
\hline Controls for demographics & & & & & & \\
\hline Observations & & & & & & \\
\hline $\mathrm{R}^{2}$ & & & & & & \\
\hline
\end{tabular}

Notes: The table reports the slope and intercept in the following regression: $E_{i}^{\text {post }} \pi=a+b * \operatorname{Treat}_{i}+\gamma * \operatorname{Treat}_{i} *$ $E_{i}^{p r e} \pi+\psi * E_{i}^{p r e} \pi$. Columns (1) and (2) consider the immediate change in expectations after the treatment, columns (3) and (4) are for beliefs after three months, columns (5) and (6) are for beliefs after six months. Results are from Huber robust regressions to control for outliers and influential observations. Robust standard errors are reported in parentheses. 
Table 7: Heterogeneity in Treatment Effects.

\begin{tabular}{|c|c|c|c|c|c|c|c|c|c|c|c|}
\hline \multirow[t]{2}{*}{ Breakdown of Sample: } & \multicolumn{2}{|c|}{ By Gender } & \multicolumn{3}{|c|}{ By Income } & \multicolumn{3}{|c|}{ By Education } & \multicolumn{3}{|c|}{ Political affiliation } \\
\hline & Female & Male & $\begin{array}{l}\text { Bottom } \\
\text { Tercile }\end{array}$ & $\begin{array}{l}\text { Middle } \\
\text { Tercile }\end{array}$ & $\begin{array}{l}\text { Highest } \\
\text { Tercile }\end{array}$ & $\begin{array}{l}\text { High } \\
\text { school of } \\
\text { less }\end{array}$ & $\begin{array}{l}\text { Assoc. } \\
\text { degree or } \\
\text { some } \\
\text { college }\end{array}$ & $\begin{array}{l}\text { College } \\
\text { or more }\end{array}$ & Democrat & Republican & Other \\
\hline Treatment Group: & $(1)$ & $(2)$ & (3) & (4) & $(5)$ & $(6)$ & $(7)$ & (8) & (9) & $(10)$ & $(11)$ \\
\hline T5 (pop growth) & $\begin{array}{l}-0.31 * * \\
(0.13)\end{array}$ & $\begin{array}{l}-0.06 \\
(0.17)\end{array}$ & $\begin{array}{l}-0.04 \\
(0.21)\end{array}$ & $\begin{array}{l}-0.52 * * \\
(0.23)\end{array}$ & $\begin{array}{l}-0.19 \\
(0.14)\end{array}$ & $\begin{array}{l}-0.06 \\
(0.24)\end{array}$ & $\begin{array}{l}-0.40^{* *} \\
(0.20)\end{array}$ & $\begin{array}{l}-0.18 \\
(0.14)\end{array}$ & $\begin{array}{l}-0.65 * * * \\
(0.24)\end{array}$ & $\begin{array}{l}-0.01 \\
(0.22)\end{array}$ & $\begin{array}{l}-0.08 \\
(0.25)\end{array}$ \\
\hline T6 (UE) & $\begin{array}{l}-0.54 * * * \\
(0.13)\end{array}$ & $\begin{array}{c}0.05 \\
(0.17)\end{array}$ & $\begin{array}{l}-0.19 \\
(0.20)\end{array}$ & $\begin{array}{l}-0.63 * * * \\
(0.23)\end{array}$ & $\begin{array}{l}-0.28 * * \\
(0.14)\end{array}$ & $\begin{array}{l}-0.30 \\
(0.24)\end{array}$ & $\begin{array}{l}-0.28 \\
(0.19)\end{array}$ & $\begin{array}{l}-0.39 * * * \\
(0.14)\end{array}$ & $\begin{array}{l}-0.75 * * * \\
(0.25)\end{array}$ & $\begin{array}{l}-0.28 \\
(0.22)\end{array}$ & $\begin{array}{c}0.04 \\
(0.25)\end{array}$ \\
\hline T4 (gas prices) & $\begin{array}{l}1.52^{* * *} \\
(0.15)\end{array}$ & $\begin{array}{l}1.38 * * * \\
(0.18)\end{array}$ & $\begin{array}{l}1.62 * * * \\
(0.22)\end{array}$ & $\begin{array}{l}1.06 * * * \\
(0.25)\end{array}$ & $\begin{array}{l}1.57 * * * \\
(0.16)\end{array}$ & $\begin{array}{l}1.40 * * * \\
(0.26)\end{array}$ & $\begin{array}{l}1.58^{* * *} \\
(0.21)\end{array}$ & $\begin{array}{l}1.45^{* * *} \\
(0.16)\end{array}$ & $\begin{array}{l}1.15^{* * *} \\
(0.26)\end{array}$ & $\begin{array}{l}1.19 * * * \\
(0.24)\end{array}$ & $\begin{array}{l}1.72 * * * \\
(0.27)\end{array}$ \\
\hline T2 (past inflation) & $\begin{array}{l}-1.29 * * * \\
(0.13)\end{array}$ & $\begin{array}{l}-0.53 * * * \\
(0.17)\end{array}$ & $\begin{array}{l}-1.10^{* * * *} \\
(0.20)\end{array}$ & $\begin{array}{l}-1.57 * * * \\
(0.23)\end{array}$ & $\begin{array}{l}-0.76^{* * * *} \\
(0.14)\end{array}$ & $\begin{array}{l}-0.96 * * * \\
(0.25)\end{array}$ & $\begin{array}{l}-1.37 * * * \\
(0.19)\end{array}$ & $\begin{array}{l}-0.85^{* * * *} \\
(0.14)\end{array}$ & $\begin{array}{l}-1.49 * * * \\
(0.24)\end{array}$ & $\begin{array}{l}-0.73 * * * \\
(0.22)\end{array}$ & $\begin{array}{c}-0.90^{* * * *} \\
(0.25)\end{array}$ \\
\hline T3 (inflation target) & $\begin{array}{l}-1.27^{* * * *} \\
(0.13)\end{array}$ & $\begin{array}{l}-0.47^{* * * *} \\
(0.16)\end{array}$ & $\begin{array}{l}-0.83^{* * *} \\
(0.19)\end{array}$ & $\begin{array}{l}-1.66^{* * * *} \\
(0.23)\end{array}$ & $\begin{array}{l}-0.80^{* * *} \\
(0.14)\end{array}$ & $\begin{array}{l}-0.64^{* * *} \\
(0.23)\end{array}$ & $\begin{array}{l}-1.21^{* * *} \\
(0.19)\end{array}$ & $\begin{array}{l}-1.03^{* * *} \\
(0.14)\end{array}$ & $\begin{array}{l}-1.30 * * * \\
(0.24)\end{array}$ & $\begin{array}{l}-0.76^{* * *} \\
(0.21)\end{array}$ & $\begin{array}{c}-0.72^{* * *} \\
(0.24)\end{array}$ \\
\hline T7 (Fed inflation forecast) & $\begin{array}{l}-1.25 * * * \\
(0.13)\end{array}$ & $\begin{array}{l}-0.75 * * * \\
(0.16)\end{array}$ & $\begin{array}{l}-1.29 * * * \\
(0.20)\end{array}$ & $\begin{array}{l}-1.52 * * * \\
(0.22)\end{array}$ & $\begin{array}{l}-0.74 * * * \\
(0.14)\end{array}$ & $\begin{array}{l}-1.21 * * * \\
(0.24)\end{array}$ & $\begin{array}{l}-1.10^{* * *} \\
(0.19)\end{array}$ & $\begin{array}{l}-1.01 * * * \\
(0.14)\end{array}$ & $\begin{array}{l}-1.64 * * * \\
(0.24)\end{array}$ & $\begin{array}{l}-0.75 * * * \\
(0.21)\end{array}$ & $\begin{array}{c}-0.96^{* * * *} \\
(0.25)\end{array}$ \\
\hline T8 (FOMC statement) & $\begin{array}{l}-1.43^{* * *} \\
(0.13)\end{array}$ & $\begin{array}{l}-0.74 * * * \\
(0.17)\end{array}$ & $\begin{array}{l}-1.08^{* * * *} \\
(0.19)\end{array}$ & $\begin{array}{l}-1.78 * * * \\
(0.23)\end{array}$ & $\begin{array}{l}-1.00 * * * \\
(0.14)\end{array}$ & $\begin{array}{l}-1.16^{* * * *} \\
(0.24)\end{array}$ & $\begin{array}{l}-1.21 * * * \\
(0.18)\end{array}$ & $\begin{array}{l}-1.21^{* * * *} \\
(0.14)\end{array}$ & $\begin{array}{l}-1.57 * * * \\
(0.24)\end{array}$ & $\begin{array}{l}-1.01 * * * \\
(0.22)\end{array}$ & $\begin{array}{c}-1.05^{* * * *} \\
(0.24)\end{array}$ \\
\hline T9 (USA Today coverage) & $\begin{array}{l}-0.59 * * * \\
(0.13)\end{array}$ & $\begin{array}{l}-0.20 \\
(0.17)\end{array}$ & $\begin{array}{l}-0.24 \\
(0.20)\end{array}$ & $\begin{array}{l}-0.84^{* * *} \\
(0.23)\end{array}$ & $\begin{array}{l}-0.40^{* * *} \\
(0.14)\end{array}$ & $\begin{array}{l}-0.17 \\
(0.24)\end{array}$ & $\begin{array}{l}-0.53^{* * * *} \\
(0.20)\end{array}$ & $\begin{array}{l}-0.52^{* * *} \\
(0.14)\end{array}$ & $\begin{array}{l}-0.86 * * * \\
(0.25)\end{array}$ & $\begin{array}{l}-0.46^{* *} \\
(0.21)\end{array}$ & $\begin{array}{l}-0.19 \\
(0.25)\end{array}$ \\
\hline Observations & 14,225 & 4,997 & 5,902 & 5,676 & 7,644 & 2,748 & 5,177 & 11,297 & 3,882 & 4,320 & 3,439 \\
\hline R-squared & 0.05 & 0.04 & 0.05 & 0.05 & 0.05 & 0.05 & 0.06 & 0.04 & 0.05 & 0.03 & 0.05 \\
\hline
\end{tabular}

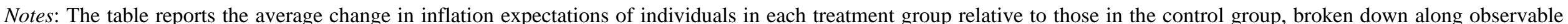

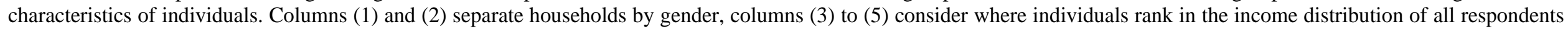

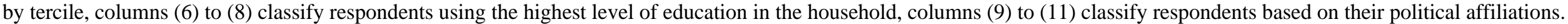

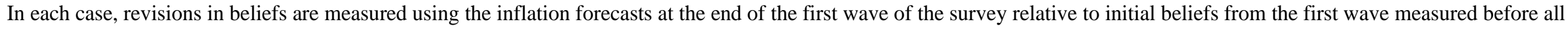

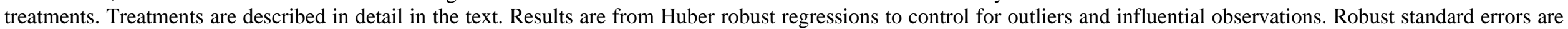
reported in parentheses. 
Table 8: Effect of Inflation Expectations on Spending Decisions.

\begin{tabular}{|c|c|c|}
\hline \multirow{3}{*}{ Dep. var. is indicated in the title of the panel } & \multicolumn{2}{|c|}{ Actual spending, horizon, month } \\
\hline & $1^{\text {st }}$ follow-up wave & $2^{\text {nd }}$ follow-up wave \\
\hline & $(1)$ & $(2)$ \\
\hline \multicolumn{3}{|l|}{ Panel A. Total Spending, survey } \\
\hline Posterior inflation expectations & $\begin{array}{l}1.826^{* * * *} \\
(0.690)\end{array}$ & $\begin{array}{c}1.015 \\
(0.638)\end{array}$ \\
\hline Observations & 6,459 & 6,570 \\
\hline R-squared & 0.414 & 0.414 \\
\hline $1^{\text {st }}$ stage F-stat & 46.97 & 60.06 \\
\hline \multicolumn{3}{|l|}{ Panel B. Total Spending, scanner } \\
\hline Posterior inflation expectations & $\begin{array}{l}0.950 * * * \\
(0.286)\end{array}$ & $\begin{array}{c}0.864^{* *} \\
(0.336)\end{array}$ \\
\hline Observations & 13,170 & 13,132 \\
\hline R-squared & 0.751 & 0.696 \\
\hline $1^{\text {st }}$ stage F-stat & 134.8 & 128.1 \\
\hline \multicolumn{3}{|l|}{ Panel C. Spending on food items, survey } \\
\hline Posterior inflation expectations & $\begin{array}{c}1.299^{*} \\
(0.775)\end{array}$ & $\begin{array}{c}0.873 \\
(0.640)\end{array}$ \\
\hline Observations & 6,626 & 6,748 \\
\hline R-squared & 0.460 & 0.473 \\
\hline $1^{\text {st }}$ stage F-stat & 50.36 & 63.81 \\
\hline \multicolumn{3}{|l|}{ Panel D. Spending on food items, scanner } \\
\hline Posterior inflation expectations & $\begin{array}{l}0.568 * * \\
(0.266)\end{array}$ & $\begin{array}{c}0.237 \\
(0.313)\end{array}$ \\
\hline Observations & 13,170 & 13,136 \\
\hline R-squared & 0.773 & 0.708 \\
\hline $1^{\text {st }}$ stage F-stat & 136.3 & 132.8 \\
\hline
\end{tabular}

\begin{tabular}{lcc} 
Panel E. Spending on any durable good, survey, extensive margin & \\
Posterior inflation expectations & $-1.472^{* * *}$ & $-1.743^{* * *}$ \\
& $(0.263)$ & $(0.403)$ \\
\hline Observations & 11,080 & 9,755 \\
R-squared & 0.06 & 0.08 \\
$1^{\text {st }}$ stage F-stat & 110.6 & 86.54 \\
\hline \hline
\end{tabular}

Notes: The table reports estimates from regressing spending measures (indicated by each panel) on household inflation expectations and household controls as described in section 5. Inflation expectations are instrumented using information treatments, as described in section 5. Dependent variables are as follows: Panel A is total monthly spending reported by households in the follow-up waves of the survey, Panel B is total spending measured in Nielsen scanner data, Panels C and D are total spending on food as measured in survey and scanner data respectively, while Panel $\mathrm{E}$ is an indicator variable for whether individuals reported purchasing any large durable good in follow-up survey waves. Panels A-D include controls for past spending levels while Panel E includes a control for any intended purchase of durable good reported in the first wave of the survey. Households controls include gender of the respondent, age and age squared of the respondent, presence and number of children, education of household head (a set of indicator variables), log household income, and household size. Robust standard errors are in parentheses. $* * * * * *$ denote statistical significance at 1, 5 and 10 percent level. For each regression, we use Huber regressions in the first stage and jack-knife procedure in the second stage, as described in Coibion, Georgarakos, Gorodnichenko and van Rooij (2019). 
Table 9: Heterogeneity in Spending Effects of Inflation Expectations.

\begin{tabular}{|c|c|c|c|c|c|c|c|c|}
\hline & \multicolumn{4}{|c|}{ Total Spending, scanner data } & \multicolumn{4}{|c|}{ Extensive margin for purchases of any durable good } \\
\hline & coef./(s.e.) & Obs. & $\mathrm{R}^{2}$ & $\begin{array}{c}\text { 1st stage } \\
\text { F-stat }\end{array}$ & coef./(s.e.) & Obs. & $\mathrm{R}^{2}$ & $\begin{array}{c}\text { 1st stage } \\
\text { F-stat }\end{array}$ \\
\hline & $(1)$ & $(2)$ & (3) & $(4)$ & (5) & $(6)$ & $(7)$ & $(8)$ \\
\hline \multicolumn{9}{|l|}{$\overline{\text { Gender }}$} \\
\hline Female & $\begin{array}{l}0.986 * * * \\
(0.306)\end{array}$ & 9,491 & 0.736 & 106 & $\begin{array}{l}-1.170 * * * \\
(0.296)\end{array}$ & 8,087 & 0.065 & 86.72 \\
\hline Male & $\begin{array}{c}0.541 \\
(0.657)\end{array}$ & 3,679 & 0.765 & 34.81 & $\begin{array}{l}-2.247^{* * * *} \\
(0.572)\end{array}$ & 2,993 & 0.063 & 27.11 \\
\hline \multicolumn{9}{|l|}{ Income } \\
\hline Tercile 1 (lowest) & $\begin{array}{c}0.842 * \\
(0.436)\end{array}$ & 3,928 & 0.726 & 50.52 & $\begin{array}{l}-1.234 * * * \\
(0.317)\end{array}$ & 3,612 & 0.031 & 48.67 \\
\hline Tercile 2 & $\begin{array}{c}0.325 \\
(0.554)\end{array}$ & 3,988 & 0.753 & 32.99 & $\begin{array}{l}-0.320 \\
(0.606)\end{array}$ & 3,307 & 0.043 & 29.48 \\
\hline Tercile 3 & $\begin{array}{l}1.423^{* * *} \\
(0.505)\end{array}$ & 5,254 & 0.727 & 51.79 & $\begin{array}{l}-2.842 * * * \\
(0.551)\end{array}$ & 4,161 & 0.07 & 33.12 \\
\hline \multicolumn{9}{|l|}{ Education } \\
\hline High school or less & $\begin{array}{c}0.561 \\
(0.545)\end{array}$ & 1,942 & 0.788 & 33.05 & $\begin{array}{l}-0.400 \\
(0.418)\end{array}$ & 1,691 & 0.065 & 31.03 \\
\hline Associate degree or some college & $\begin{array}{l}1.408^{* * * *} \\
(0.477)\end{array}$ & 3,561 & 0.748 & 43.91 & $\begin{array}{l}-1.699 * * * \\
(0.471)\end{array}$ & 3,036 & 0.028 & 35.02 \\
\hline College diploma or more & $\begin{array}{c}0.853^{*} \\
(0.464)\end{array}$ & 7,667 & 0.735 & 61.78 & $\begin{array}{l}-2.009 * * * \\
(0.459)\end{array}$ & 6,353 & 0.077 & 46.88 \\
\hline \multicolumn{9}{|l|}{ Liquidity status } \\
\hline Hand-to-mouth (HTM) & $\begin{array}{c}0.894 * \\
(0.512)\end{array}$ & 3,661 & 0.721 & 39.19 & $\begin{array}{l}-1.658 * * * \\
(0.425)\end{array}$ & 3,185 & 0.067 & 33.12 \\
\hline Non-HTM & $\begin{array}{c}1.081^{*} \\
(0.646)\end{array}$ & 4,121 & 0.759 & 32.79 & $\begin{array}{l}-1.528^{* *} \\
(0.672)\end{array}$ & 3,511 & 0.083 & 28.36 \\
\hline \multicolumn{9}{|l|}{ Political affiliation } \\
\hline Democrat & $\begin{array}{l}-0.263 \\
(0.583)\end{array}$ & 3,093 & 0.734 & 33.27 & $\begin{array}{l}-1.630 * * * \\
(0.421)\end{array}$ & 2,927 & 0.066 & 37.45 \\
\hline Republican & $\begin{array}{l}1.663^{* *} \\
(0.728)\end{array}$ & 3,550 & 0.758 & 24.42 & $\begin{array}{l}-0.748 \\
(0.708)\end{array}$ & 3,350 & 0.106 & 20.69 \\
\hline Other & $\begin{array}{l}1.132 * \\
(0.605)\end{array}$ & 2,590 & 0.783 & 29.76 & $\begin{array}{l}-1.312^{* * *} \\
(0.477)\end{array}$ & 2,423 & 0.06 & 31.31 \\
\hline
\end{tabular}

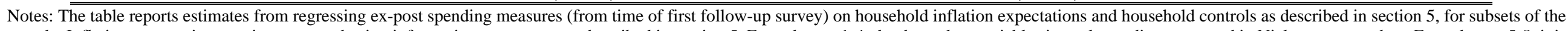

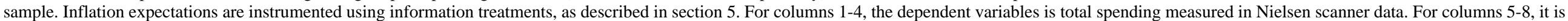

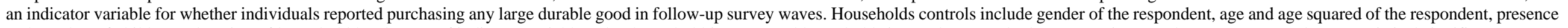

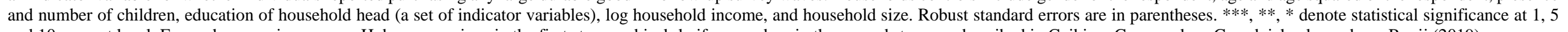

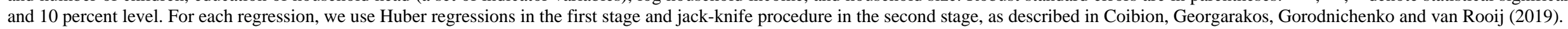




\section{Online Appendix}




\section{Appendix 1: Surveys and Treatments}

First wave of the survey: May-June 2018

This survey is about your household's finances and opinions about the economy. As with any of our surveys, the information you provide is confidential and is only shared in an aggregate (not individual) level.

Please tell us about yourself...

1. What is your date of birth?

2. What is your gender?

() Male () Female

3. Do you have any credit cards?

() Yes () No () Prefer to not answer

ASK IF: Q3=YES

4. Suppose that you had to make an unexpected payment equal to one month of your income, would you have sufficient credit on your credit card(s) to charge the entire amount?

() Yes () No () Don’t know/prefer to not answer

5. How much money did you have in your checking and savings accounts and in cash the day before your last regular paycheck arrived? Please do not include fixed term deposits, stocks, bonds, mutual funds, or retirement accounts, etc.

(Please enter dollars and cents)

\section{$\$$}

[] Don't know/prefer to not answer

6. Approximately how many times per month do you go to a gas station to buy gasoline or for other reasons? (Please enter a number) times [RANGE: 0-999]

7. Who typically does the grocery shopping in your household? (Select one)

() I do all of the grocery shopping in the household

() I share the grocery shopping with others in the household

() Someone else does the grocery shopping in the household

8. Over the last three months on average, how much did your household spend (per month) on goods and services in total and for each of the individual components listed below?

Please enter a number between 0 and 99,999 for each category. The sum of the expenditures for the individual categories should add up to the total amount. (Enter a "0" if you did not purchase anything in a given category)

Total monthly spending TOTAL [AUTOSUM] [RANGE: 0-99,999]

[HAVE THIS AUTOMATICALLY SUM]

Debt payments (mortgages, auto loans, student loans,...)

$\$$

Housing (including rent, maintenance and home owner/renter insurance but not including mortgage payments) $\$$

Utilities (including water, sewer, electricity, gas, heating oil, phone, internet)

Food (including groceries, dining out, and beverages)

Clothing, footwear, and personal care

Gasoline

Other regular transportation costs (including public transportation fares and car maintenance)

Medical care (including health insurance, medical bills, prescription drugs)

Travel, Recreation, and entertainment

Education and child care

Furniture, jewelry, small appliances and other small durable goods

$\$$

$\$$

$\$$

$\$$

$\$$

$\$$

$\$$

$\$$

Other (including gifts, child support or alimony, charitable giving, and other miscellaneous) \$

Prefer not to answer

9. Saving is income that is neither spent nor used to make payments on debt. Methods of saving include putting money aside in, for example, a deposit account, a pension account, an investment fund, or as cash.

What percentage of your monthly income, on average, did you save during the last 12 months? (Please enter a number. The number you enter should be greater than or equal to 0 . If you did not save any money, please enter a "0". If you went into debt, enter a negative value)

(Please enter a percent) [RANGE: -100-100]

Prefer not to answer

10. What percent of your financial wealth (excluding housing) do you invest in the following categories? (enter a " 0 ” if you do not invest in a given category) 
Checking and Savings Account

percent

Cash percent

US Bonds percent

US Stocks percent

Foreign Stocks and Bonds percent

Gold and precious metals percent

Bitcoin and other cryptocurrencies percent

Other percent

\% Total 100 PN: TOTAL FOR RESPONDENT

[] I have no financial investments $>$ EXCLUSIVE

11. Do you plan to buy a new home in the next 6 months?

() Yes () No

ASK IF: Q12=YES

12. What price do you expect/plan to pay for a new house?

$\$$ [] Don't know/Won't answer

13. Do you plan to purchase a car in the next 6 months?

() Yes () No

ASK IF: Q13=YES

14. What price do you expect/plan to pay for this car?

$\$$ [] Don't know/Won't answer

15. Do you plan to purchase any other big-ticket household items (TV, fridge, furniture, and similar items) over the next 6 months?
() Yes
() No

ASK IF: Q15=YES

16. How much do you expect to spend on these big-ticket household items over the next 6 months?

$\$$

[] Don't know/Won't answer

17. How much higher or lower do you think your household's total after-tax income will be over the next six months compared to the last twelve months?

Please provide an answer in percents. If you think that your household's total after-tax income will decrease, please fill in a negative percent (insert a minus sign for the number). If you think that your household's total aftertax income will increase, please fill in a positive percent. If you think that your household's total net income will not change, please fill in 0 (zero). $\%$

18. In THIS question, you will be asked about the PERCENT CHANCE of something happening. The percent chance must be a number between 0 and 100 and the sum of your answers must add up to 100 .

Nondurable goods and services include for instance food, tobacco, alcohol, gasoline, clothing, haircuts, transportation, and other small services and nondurable goods that do not last in time. What do you think is the percent chance that, over the next six months, your spending on non-durable goods and services will... (assign probabilities to each outcome; probabilities should sum to 100)

Increase by $10 \%$ or more

Increase between 5\% and 10\%

Increase between 2\% and 5\%

Increase by $2 \%$ or less

Stay the same

Decrease 2\% or less

Decrease between 2\% and 5\%

Decrease between 5\% and 10\%

Decrease by $10 \%$ or more

\% Total

100 PN: TOTAL FOR RESPONDENT

19. How many total hours per week do you and other members of your household work in a typical week? Please do not include volunteer hours or hours that are unpaid.

You: hours per week 
All others in household: hours per week

20. Do you expect the hours for you or other people in your household will be the same over the next 6 months or not? Please do not include volunteer hours or hours that are unpaid.

() Yes, the same over the next 6 months

() No, not the same over the next 6 months

ASK IF: Q20=NO

23. How many hours per week do you expect to be working in 6 months and how many hours do you expect all other members of your household to be working in 6 months? Please do not include volunteer hours or hours that are unpaid.

You: hours per week

All others in household: hours per week

[Everyone who did not answer [] I have no financial investments in Q10 should get this question]

24. What do you think the rate of return will be on your financial investments over the next twelve months? Please provide a quantitative answer in percentage terms.
$\%$
[] I have no financial investments

25. We would like to ask you about the rate of inflation/deflation (Note: inflation is the percentage rise in overall prices in the economy, most commonly measured by the Consumer Price Index and deflation corresponds to when prices are falling).

Please enter a number in the box below. If you do not think there was any inflation/deflation in the last 12 months, please enter a "0". If you think there was deflation, enter a negative value. If you think there was inflation, enter a positive value. Over the last 12 months, the rate of inflation/deflation was percent

26. In THIS question, you will be asked about the PERCENT CHANCE of something happening. The percent chance must be a number between 0 and 100 and the sum of your answers must add up to 100 .

What do you think is the percent chance that, over the next 12 months...

the rate of inflation will be $12 \%$ or more

the rate of inflation will be between $8 \%$ and $12 \%$

the rate of inflation will be between $4 \%$ and 8

the rate of inflation will be between $2 \%$ and 4

the rate of inflation will be between $0 \%$ and $2 \%$

the rate of deflation (opposite of inflation) will be between $0 \%$ and $2 \%$

the rate of deflation (opposite of inflation) will be between $2 \%$ and $4 \%$

the rate of deflation (opposite of inflation) will be between $4 \%$ and $8 \%$

the rate of deflation (opposite of inflation) will be between $8 \%$ and $12 \%$

the rate of deflation (opposite of inflation) will be $12 \%$ or more

\% Total

FROM ABOVE]

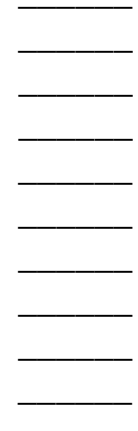

[PN: TOTAL ANSWERS

\section{[Half of respondents get this question]}

27. In THIS question, you will be asked about the probability (PERCENT CHANCE) of something being true. The percent chance must be a number between 0 and 100 and the sum of your answers must add up to 100 .

What is the probability that the average American believes inflation or deflation over the next 12 months will be...

The average American expects the rate of inflation will be $12 \%$ or more

The average American expects the rate of inflation will be between $8 \%$ and $12 \%$

The average American expects the rate of inflation will be between $4 \%$ and 8

The average American expects the rate of inflation will be between $2 \%$ and 4

The average American expects the rate of inflation will be between $0 \%$ and $2 \%$

The average American expects the rate of deflation (opposite of inflation) will be between $0 \%$ and $2 \%$

The average American expects the rate of deflation (opposite of inflation) will be between $2 \%$ and $4 \%$

The average American expects the rate of deflation (opposite of inflation) will be between $4 \%$ and $8 \%$

The average American expects the rate of deflation (opposite of inflation) will be between $8 \%$ and $12 \%$

The average American expects the rate of deflation (opposite of inflation) will be $12 \%$ or more 
[Other half of respondents get the next two question]

28. What do you think the current overall level of prices in the economy (as measured by the Consumer Price Index) relative to the level of prices 5 years ago?

Please provide an answer in percentage terms. If you think there was deflation (that is, prices fell), enter a negative value. If you think there was inflation (that is, prices rose), enter a positive value. If you do not think there was any inflation/deflation in the last 5 years, please enter a " 0 ".

overall percent change for last 5 years [RANGE: -100-100 Whole numbers only]

29. In THIS question, you will be asked about the probability (PERCENT CHANCE) of something happening. The percent chance must be a number between 0 and 100 and the sum of your answers must add up to 100 .

What do you think is the probability that, over the next 5 years, the overall level of prices in the economy (as measured by the Consumer Price Index) relative to the current level of prices will...

$$
\begin{aligned}
& \text { rise by } 50 \% \text { or more } \\
& \text { rise from } 25 \% \text { to } 50 \% \\
& \text { rise from } 15 \% \text { to } 25 \% \\
& \text { rise from } 5 \% \text { to } 15 \% \\
& \text { rise less than } 5 \% \\
& \text { stay about the same } \\
& \text { fall by less than } 5 \% \\
& \text { fall from } 5 \% \text { to } 15 \% \\
& \text { fall from } 15 \% \text { to } 25 \% \\
& \text { fall from } 25 \% \text { to } 50 \% \\
& \text { fall by } 50 \% \text { or more } \\
& \% \text { Total }
\end{aligned}
$$

[75\% of respondents get this question]

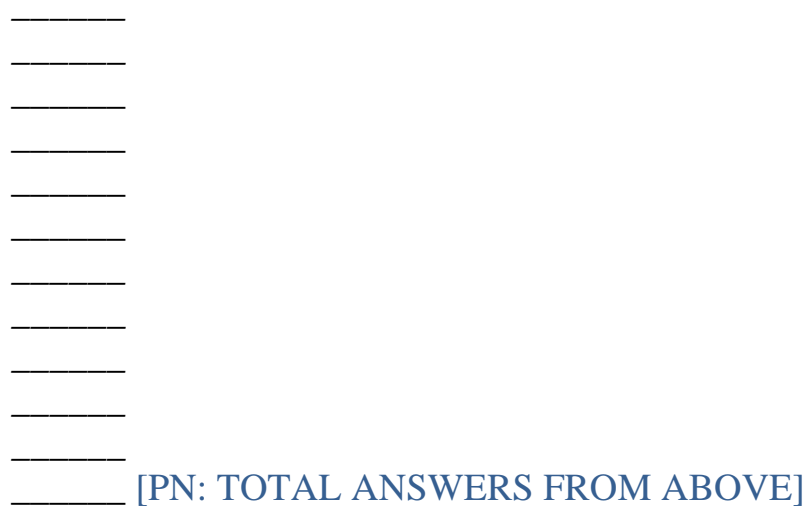

30. What is your best guess about the annual inflation rate that the Federal Reserve tries to achieve on average over long periods of time? Please use a percent between -100 and 100)

$$
\% \text { per year }
$$

[25\% of respondents get this question instead]

30. What is your best guess about the annual inflation rate that the Federal Reserve tries to achieve on average over long periods of time? Please use a percent between -100 and 100)

$$
\text { \% per year [] Prefer to not answer }
$$

31. What is your best guess about the current unemployment rate in the U.S.? (Please use a percent between 0 and 100) $\%$

32. What is your best guess at the current unleaded gas price in your area? (Please enter dollars and cents) $\$$

33. What is your best guess about the dollar change in gas prices over the next six months? (Please enter dollars and cents) $\$$

34. In THIS question, you will be asked about the PERCENT CHANCE of something happening. The percent chance must be a number between 0 and 100 and the sum of your answers must add up to 100 .

What do you think the average unemployment rate will be over the next 12 months:

The average unemployment rate will be $10 \%$ or more

The average unemployment rate will be between $8.0 \%$ and $9.9 \%$

The average unemployment rate will be between $7.0 \%$ and $7.9 \%$

The average unemployment rate will be between $6.0 \%$ and $6.9 \%$

The average unemployment rate will be between $5.0 \%$ and $5.9 \%$

The average unemployment rate will be between $4.0 \%$ and $4.9 \%$

The average unemployment rate will be $4.0 \%$ or less

\% Total

[PN: TOTAL ANSWERS FROM ABOVE]

\section{[INFORMATION TREATMENTS]}


You are almost done with the survey. We have just a few more questions. But before you give us your responses, we would like you to know the following.

SHOW IF Group 1: Over the last twelve months, the inflation rate in the U.S. (as measured by the Consumer Price Index) was $2.3 \%$.

SHOW IF Group 2: The inflation target of the Federal Reserve is $2 \%$ per year.

SHOW IF Group 3: The price of gasoline (national average) rose by $6.4 \%$ over the last three months.

SHOW IF Group 4: The U.S. population grew $2 \%$ over the last three years.

SHOW IF Group 5: The current rate of unemployment in the U.S. is 4.1\%.

SHOW IF Group 6: The U.S. Federal Open Market Committee (which sets short-term interest rates) forecasts $1.9 \%$ inflation rate in 2018.

SHOW IF Group 7 [May 2018 version]: Please read the most recent policy statement by the U.S. Federal Open Market Committee.

Information received since the Federal Open Market Committee met in January indicates that the labor market has continued to strengthen and that economic activity has been rising at a moderate rate. Job gains have been strong in recent months, and the unemployment rate has stayed low. Recent data suggest that growth rates of household spending and business fixed investment have moderated from their strong fourth-quarter readings. On a 12-month basis, both overall inflation and inflation for items other than food and energy have continued to run below 2 percent. Market-based measures of inflation compensation have increased in recent months but remain low; survey-based measures of longerterm inflation expectations are little changed, on balance.

Consistent with its statutory mandate, the Committee seeks to foster maximum employment and price stability. The economic outlook has strengthened in recent months. The Committee expects that, with further gradual adjustments in the stance of monetary policy, economic activity will expand at a moderate pace in the medium term and labor market conditions will remain strong. Inflation on a 12-month basis is expected to move up in coming months and to stabilize around the Committee's 2 percent objective over the medium term. Near-term risks to the economic outlook appear roughly balanced, but the Committee is monitoring inflation developments closely.

In view of realized and expected labor market conditions and inflation, the Committee decided to raise the target range for the federal funds rate to 1-1/2 to 1-3/4 percent. The stance of monetary policy remains accommodative, thereby supporting strong labor market conditions and a sustained return to 2 percent inflation.

In determining the timing and size of future adjustments to the target range for the federal funds rate, the Committee will assess realized and expected economic conditions relative to its objectives of maximum employment and 2 percent inflation. This assessment will take into account a wide range of information, including measures of labor market conditions, indicators of inflation pressures and inflation expectations, and readings on financial and international developments. The Committee will carefully monitor actual and expected inflation developments relative to its symmetric inflation goal. The Committee expects that economic conditions will evolve in a manner that will warrant further gradual increases in the federal funds rate; the federal funds rate is likely to remain, for some time, below levels that are expected to prevail in the longer run. However, the actual path of the federal funds rate will depend on the economic outlook as informed by incoming data.

SHOW IF Group 7 [June 2018 version]: Please read the most recent policy statement by the U.S. Federal Open Market Committee. 
Information received since the Federal Open Market Committee met in March indicates that the labor market has continued to strengthen and that economic activity has been rising at a moderate rate. Job gains have been strong, on average, in recent months, and the unemployment rate has stayed low. Recent data suggest that growth of household spending moderated from its strong fourth-quarter pace, while business fixed investment continued to grow strongly. On a 12-month basis, both overall inflation and inflation for items other than food and energy have moved close to 2 percent. Market-based measures of inflation compensation remain low; survey-based measures of longer-term inflation expectations are little changed, on balance.

Consistent with its statutory mandate, the Committee seeks to foster maximum employment and price stability. The Committee expects that, with further gradual adjustments in the stance of monetary policy, economic activity will expand at a moderate pace in the medium term and labor market conditions will remain strong. Inflation on a 12-month basis is expected to run near the Committee's symmetric 2 percent objective over the medium term. Risks to the economic outlook appear roughly balanced.

In view of realized and expected labor market conditions and inflation, the Committee decided to maintain the target range for the federal funds rate at 1-1/2 to 1-3/4 percent. The stance of monetary policy remains accommodative, thereby supporting strong labor market conditions and a sustained return to 2 percent inflation.

In determining the timing and size of future adjustments to the target range for the federal funds rate, the Committee will assess realized and expected economic conditions relative to its objectives of maximum employment and 2 percent inflation. This assessment will take into account a wide range of information, including measures of labor market conditions, indicators of inflation pressures and inflation expectations, and readings on financial and international developments. The Committee will carefully monitor actual and expected inflation developments relative to its symmetric inflation goal. The Committee expects that economic conditions will evolve in a manner that will warrant further gradual increases in the federal funds rate; the federal funds rate is likely to remain, for some time, below levels that are expected to prevail in the longer run. However, the actual path of the federal funds rate will depend on the economic outlook as informed by incoming data.

SHOW IF Group 8 [May 2018 version]: On March 21, 2018, USA Today summarized the most recent decision of the U.S. Federal Open Market Committee (which sets short-term interest rates) as follows:

"Citing a brighter economic outlook, the Federal Reserve raised its key short-term interest rate Wednesday but maintained its forecast for a total of three hikes this year amid still-modest inflation.

The move is expected to ripple through the economy, nudging consumer and business borrowing costs higher, especially for variable-rate loans such as adjustable-rate mortgages and credit cards.

Investors cheered the unchanged rate forecast for 2018, pushing up the Dow Jones industrial average about 250 points initially before stocks pared their gains.

The Fed's policymaking committee, as widely anticipated, lifted the federal funds rate — what banks charge each other for overnight loans - by a quarter percentage point to a range of $1 \frac{1}{2} \%$ to $13 / 4 \%$.

That's still low by historical standards but it marks the central bank's fourth rate increase in the past 12 months and another vote of confidence in an economy that's picking up steam nearly nine years after the Great Recession ended.

"We're trying to take that middle ground" on rate hikes, boosting rates enough to head off an eventual spike in inflation without derailing the economic expansion, Fed Chairman Jerome Powell said at a news conference. The meeting was the first led by Powell, a Republican and Trump appointee, who took the reins from Democrat Janet Yellen last month." SHOW IF Group 8 [June 2018 version]: On May 2, 2018, USA Today summarized the most recent decision of the U.S. Federal Open Market Committee (which sets short-term interest rates) as follows: 
WASHINGTON — Inflation is creeping higher, and that's making the Federal Reserve more confident about raising interest rates.

The Fed held its key interest rate steady Wednesday but noted that inflation has climbed close to its 2\% goal, paving the way for another rate hike in June.

As expected, the Fed kept its benchmark short-term interest rate at a range of $1 \frac{1 / 2}{2} \%$ to $13 / 4 \%$. The central bank's policymaking committee lifted the rate by a quarter percentage point in March for the sixth time since late 2015 after holding it near zero for years following the 2008 financial crisis and recession.

In a statement after a two-day meeting, the Fed reiterated that it plans to continue to raise rates gradually, a pace that economists have interpreted as roughly every other meeting.

Fed policymakers have forecast two more rate increases this year, according to their median estimate, but faster inflation could trigger three additional moves. Before the statement release, Fed fund futures indicated a $90 \%$ chance of a hike in June, according to CME Group.

35. By how much do you expect prices in the economy (as measured by the Consumer Price Index) to change over the next 12 months? Please provide an answer as a percentage change from current prices. Please use a percent between -100 and 100, if no change please enter a " 0 ”. You may enter a percent)

$\%$

[PN: ONLY THOSE THAT ANSWERED Q28 AND Q29 SHOULD ANSWER Q36]

36. By how much do you expect prices in the economy (as measured by the Consumer Price Index) to change over the next five years? Please provide an answer as a cumulative percentage change from the current level of prices. Please use a percent between -100 and 100, if no change please enter a “0”.)

$\%$

[PN: ONLY THOSE THAT ANSWERED Q27 SHOULD ANSWER Q37]

37. What inflation rate do you think the average American would predict for the next twelve months? (Please enter a number in one of the boxes below. If you think that the average American predicts no inflation or deflation, please enter a " 0 ". If you think the average American expects deflation, enter a negative value. If you expect, inflation, enter a positive value)

38. What do you think the unemployment rate in the U.S. economy will be in twelve months? Please provide a quantitative answer in percentage terms. (Please use a percent between 0 and 100)

$\%$

39. What do you think the rate of return will be on your financial investments over the next twelve months? Please provide a quantitative answer in percentage terms.

$\% \quad$ [] I have no financial investments

40. How much higher or lower do you think your household's total after-tax income will be over the next six months compared to the last twelve months?

Please provide an answer in percents. If you think that your household's total after-tax income will decrease, please fill in a negative percent (insert a minus sign for the number). If you think that your household's total aftertax income will increase, please fill in a positive percent. If you think that your household's total net income will not change, please fill in 0 (zero). $\%$

41. How much higher or lower do you think your household's spending on non-durable goods and services will be over the next six months compared to the last six months?

Please provide an answer in percentage terms. If you think that your household's spending on non-durable goods and services will decrease, please fill in a negative percentage (insert a minus sign for the number). If you think that your household's spending on non-durable goods and services will increase, please fill in a positive percentage. If you think that your household's spending on non-durable goods and services will not change, please fill in 0 (zero). (You are able to enter a percent up to two decimal places)

$\%$ 
This survey is about your household's finances and opinions about the economy. As with any of our surveys, the information you provide is confidential and is only shared in an aggregate (not individual) level.

Please tell us about yourself...

1. What is your date of birth? (Please select the month, day and year)

Month: January, February... December

Day: $1,2,3 \ldots 31$

Year: 1916, 1917... 2000

2. Over the last three months on average, how much did your household spend (per month) on goods and services in total and for each of the individual components listed below?

Please enter a number between 0 and 99,999 for each category. The sum of the expenditures for the individual categories should add up to the total amount. (Enter a "0" if you did not purchase anything in a given category)

Total monthly spending TOTAL [AUTOSUM] [RANGE: 0-99,999]

[PN: HAVE THIS AUTOMATICALLY SUM]

Debt payments (mortgages, auto loans, student loans,...)

Housing (including rent, maintenance and home owner/renter insurance but not including mortgage payments)

Utilities (including water, sewer, electricity, gas, heating oil, phone, internet)

Food (including groceries, dining out, and beverages)

Clothing, footwear, and personal care

Gasoline

Other regular transportation costs (including public transportation fares and car maintenance)

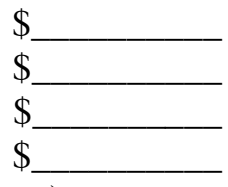

$\$$

Medical care (including health insurance, medical bills, prescription drugs)

Travel, Recreation, and entertainment

Education and child care

Furniture, jewelry, small appliances and other small durable goods

\section{$\$$}

$\$$

$\$$

$\$$

Other (including gifts, child support or alimony, charitable giving, and other miscellaneous)

Prefer not to answer

$\$$

3. What percent of your financial wealth (excluding housing) do you invest in the following categories? (Please enter a whole number if you invest in a given category. Percents should total 100\%.)

$\begin{array}{lc}\text { Checking and Savings Account } & \ldots \ldots \ldots \ldots \text { percent } \\ \text { Cash } & \ldots \ldots \ldots \ldots \text { percent } \\ \text { US Bonds } & \ldots \ldots \ldots \ldots \text { percent } \\ \text { US Stocks } & \ldots \ldots \ldots \ldots \text { percent } \\ \text { Foreign Stocks and Bonds } & \ldots \ldots \ldots \ldots \text { percent } \\ \text { Gold and precious metals } & \ldots \ldots \ldots \ldots \text { percent } \\ \text { Bitcoin and other cryptocurrencies } & \ldots \ldots \ldots \ldots \text { percent } \\ \text { Other } & \ldots \ldots \ldots \ldots \text { percent } \\ \text { \% Total } & \end{array}$

[] I have no financial investments

4. Did you buy a new home in the last 3 months?

() Yes

() No

ASK IF: Q4=YES

4a. What price did you pay for the new house?

$\$$ 
[] Don't know/Won't answer

ASK IF: Q4=NO

4b. Do you plan to buy a new home in the next 3 months?

() Yes () No

ASK IF: Q4b=YES

4c. What price do you expect/plan to pay for a new house?

$\$$

[] Don’t know/Won’t answer

5. Did you buy a new car in the last 3 months?

() Yes () No

ASK IF: Q5=YES

5a. What price did you pay for this car?

$\$$

ASK IF: Q5=NO

[] Don’t know/Won’t answer

5b. Do you plan to purchase a car in the next 3 months?

() Yes () No

ASK IF: Q5b=YES

5c. What price do you expect/plan to pay for this car?

$\$$

[] Don’t know/Won’t answer

6. Did you purchase any other big-ticket household items (TV, fridge, furniture, and similar items) in the last 3 months?

() Yes () No

ASK IF: Q6=YES

6a. How much did you spend on these big-ticket household items over the last 3 months?

$\$$

[] Don't know/Won't answer

6b. Do you plan to purchase any other big-ticket household items (TV, fridge, furniture, and similar items) over the next 3 months?

() Yes () No

ASK IF: Q6b=YES

6c. How much do you expect to spend on these big-ticket household items over the next 3 months?

$\$$

[] Don’t know/Won’t answer

7. How much higher or lower do you think your household's total after-tax income will be over the next three months compared to the last three months?

Please provide an answer in percent. If you think that your household's total after-tax income will decrease, please fill in a negative percent (insert a minus sign for the number). If you think that your household's total aftertax income will increase, please fill in a positive percent. If you think that your household's total net income will not change, please fill in 0 (zero). $\%$

8. How many total hours per week do you and other members of your household work in a typical week? Please do not include volunteer hours or hours that are unpaid.
You: hours per week
All others in household: hours per week

9. Do you expect the hours for you or other people in your household will be the same over the next 3 months or not? Please do not include volunteer hours or hours that are unpaid.

() Yes, the same over the next 3 months

() No, not the same over the next 3 months

ASK IF: Q9=NO

10. How many hours per week do you expect to be working in 3 months and how many hours do you expect all other members of your household to be working in 3 months? Please do not include volunteer hours or hours that are unpaid.

You: hours per week

All others in household: hours per week 
11. We would like to ask you about the rate of inflation/deflation (Note: inflation is the percentage rise in overall prices in the economy, most commonly measured by the Consumer Price Index and deflation corresponds to when prices are falling).

Please enter a number in the box below. If you do not think there was any inflation/deflation in the last 12 months, please enter a " 0 ”. If you think there was deflation, enter a negative value. If you think there was inflation, enter a positive value.

Over the last 12 months, the rate of inflation/deflation was percent

12. In THIS question, you will be asked about the PERCENT CHANCE of something happening. The percent chance must be a number between 0 and 100 and the sum of your answers must add up to 100 .

What do you think is the percent chance that, over the next 12 months...

the rate of inflation will be $12 \%$ or more

the rate of inflation will be between $8 \%$ and $12 \%$

the rate of inflation will be between $4 \%$ and 8

the rate of inflation will be between $2 \%$ and 4

the rate of inflation will be between $0 \%$ and $2 \%$

the rate of deflation (opposite of inflation) will be between $0 \%$ and $2 \%$

the rate of deflation (opposite of inflation) will be between $2 \%$ and $4 \%$

the rate of deflation (opposite of inflation) will be between $4 \%$ and $8 \%$

the rate of deflation (opposite of inflation) will be between $8 \%$ and $12 \%$

the rate of deflation (opposite of inflation) will be $12 \%$ or more

$\%$ Total

13. What is your best guess about the annual inflation rate that the Federal Reserve tries to achieve on average over long periods of time? Please use a percent between -100 and 100)

$\%$ per year

14. What is your best guess about the current unemployment rate in the U.S.? (Please use a percent between 0 and 100) $\%$

15. What is your best guess at the current unleaded gas price in your area? (Please enter dollars and cents)

$\$$

16. Are you? (Select one)

()Male ()Female

17. What is your first name?

18. Are there any members of your household aged 18 or older who have not yet taken this survey?
() Yes
() No 


\section{Third wave of the survey: December 2018}

This survey is about your household's finances and opinions about the economy. As with any of our surveys, the information you provide is confidential and is only shared in an aggregate (not individual) level.

\section{Please tell us about yourself...}

1. What is your date of birth? (Please select the month, day and year)

2. Which political party do you lean towards?
() Democrats
() Republication party
() Green party
() Libertarian party
() Other
() Prefer not to answer

3. Over the last three months on average, how much did your household spend (per month) on goods and services in total and for each of the individual components listed below?

Please enter a number between 0 and 99,999 for each category. The sum of the expenditures for the individual categories should add up to the total amount. (Enter a "0" if you did not purchase anything in a given category)

Total monthly spending TOTAL [AUTOSUM] [RANGE: 0-99,999]

[PN: HAVE THIS AUTOMATICALLY SUM]

\section{$\$$}

Debt payments (mortgages, auto loans, student loans,...)

$\$$

Housing (including rent, maintenance and home owner/renter insurance but not including mortgage payments)

\section{$\$$}

Utilities (including water, sewer, electricity, gas, heating oil, phone, internet)

Food (including groceries, dining out, and beverages)

Clothing, footwear, and personal care

Gasoline

Other regular transportation costs (including public transportation fares and car maintenance)

$\$$

\section{$\$$}

Medical care (including health insurance, medical bills, prescription drugs)

Travel, Recreation, and entertainment

Education and child care

Furniture, jewelry, small appliances and other small durable goods

$\$$

$\$$

$\$$

Other (including gifts, child support or alimony, charitable giving, and other miscellaneous)

Prefer not to answer

$\$$

4. What percent of your financial wealth (excluding housing) do you invest in the following categories? (Please enter a whole number if you invest in a given category. Percents should total 100\%.)

Checking and Savings Account

percent

Cash

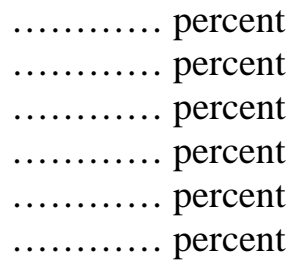

US Bonds

US Stocks

Foreign Stocks and Bonds

percent

Gold and precious metals 
Bitcoin and other cryptocurrencies percent

Other

\section{\% Total}

[] I have no financial investments

\section{Consumption Plans:}

5. Did you buy a new home in the last 6 months?

() Yes

() No

\section{ASK IF: Q5=YES}

5 a. What price did you pay for the new house?

$\$$ [PN: MAX=10,000,000]

[] Don’t know/Prefer not to answer

6. Did you buy a new car in the last 6 months?

() Yes

() No

ASK IF: Q6=YES

6a. What price did you pay for this car?

$\$$ [PN: MAX=100,000]

[] Don’t know/Prefer not to answer

7. Did you purchase any other big-ticket household items (TV, fridge, furniture, and similar items) in the last 6 months?

() Yes

() No

\section{ASK IF: Q7=YES}

7a. How much did you spend on these big-ticket household items over the last 6 months?

$\$$

[] Don’t know/Prefer not to answer

8. How much higher or lower do you think your household's total after-tax income will be over the next six months compared to the last six months?

Please provide an answer with a percent. If you think that your household's total after-tax income will decrease, please fill in a negative percent (insert a minus sign before the number). If you think that your household's total after-tax income will increase, please fill in a positive percent. If you think that your household's total net income will not change, please fill in 0 (zero).

$\%$ [RANGE: (-100) to 100]

9. How many total hours per week do you and other members of your household work in a typical week? Please do not include volunteer hours or hours that are unpaid. (Please enter a zero if you or others do not work)

You: hours per week

All others in household: hours per week

\section{;Inflation and Aggregate Expectations - DON'T SHOW}

10. We would like to ask you about the rate of inflation/deflation (Note: Deflation is the opposite of inflation).

Over the last 12 months... 
(Please enter a number in one of the boxes below. The number you enter should be greater than 0 or equal to 0 . If you do not think there was any inflation/deflation in the last 12 months, please enter a " 0 " in one of the boxes.)

The rate of inflation was

..... percent [RANGE: 0-100]

The rate of deflation (the opposite of inflation) was

..... percent [RANGE: 0-100]

11. In THIS question, you will be asked about the PERCENT CHANCE of something happening. The percent chance must be a number between 0 and 100 . Numbers like $2 \%$ or $5 \%$ indicate "almost no chance," $19 \%$ or so may mean "not much chance," a $47 \%$ or $55 \%$ chance may be a "pretty even chance," $82 \%$ indicates a "very good chance," and 95\% or 98\% mean "almost certain."

What do you think is the percent chance that, over the next 12 months...

[RANGE OF EACH OPTION BELOW: 0-100] the rate of inflation will be $12 \%$ or more the rate of inflation will be between $8 \%$ and $12 \%$ the rate of inflation will be between $4 \%$ and 8 the rate of inflation will be between $2 \%$ and 4 the rate of inflation will be between $0 \%$ and $2 \%$ the rate of deflation (opposite of inflation) will be between $0 \%$ and $2 \%$ the rate of deflation(opposite of inflation) will be between $2 \%$ and $4 \%$ the rate of deflation(opposite of inflation) will be between $4 \%$ and $8 \%$ the rate of deflation(opposite of inflation) will be between $8 \%$ and $12 \%$ $\%$ Total the rate of deflation(opposite of inflation) will be $12 \%$ or more

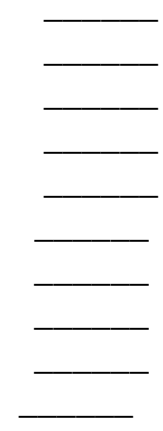

12. What do you think is the probability that, in $\mathbf{1 0}$ years from now, the overall level of prices in the economy (as measured by the Consumer Price Index) will...

[RANGE OF EACH OPTION BELOW: 0-100 ALLOW FOR UP TO 2 DECIMAL POINTS]

fall by $50 \%$ or more

fall by $25 \%$ to $50 \%$

fall by $15 \%$ to $25 \%$

fall by $5 \%$ to $15 \%$

fall but by less than $5 \%$

stay about the same

grow but at less than $5 \%$

grow by $5 \%$ to $15 \%$

grow by $15 \%$ to $25 \%$

grow by $25 \%$ to $50 \%$

grow by $50 \%$ to $100 \%$

grow by $100 \%$ or more

$\%$ Total [PN: TOTAL ANSWERS FROM ABOVE]

13. What is your best guess about the annual inflation rate that the Federal Reserve tries to achieve on average over long periods of time? Please use a percent between -100 to 100)

\% per year [RANGE: -100 to 100 Whole numbers]

14. What is your best guess about the current unemployment rate in the U.S.? (Please use a percent between 0 and 100 , may enter up to 2 decimal points)

$\%$ [RANGE: 0-100]

15. What is your best guess at the current unleaded gas price in your area? (Please enter dollars and cents)

$\$$

[PN: ADD two DECIMAL FOR DOLLARS AND CENTS] 


\section{Appendix 2: Additional Results}

\section{Appendix Table 1: Heterogeneous Contemporaneous Effects of Treatments on Inflation Expectation}

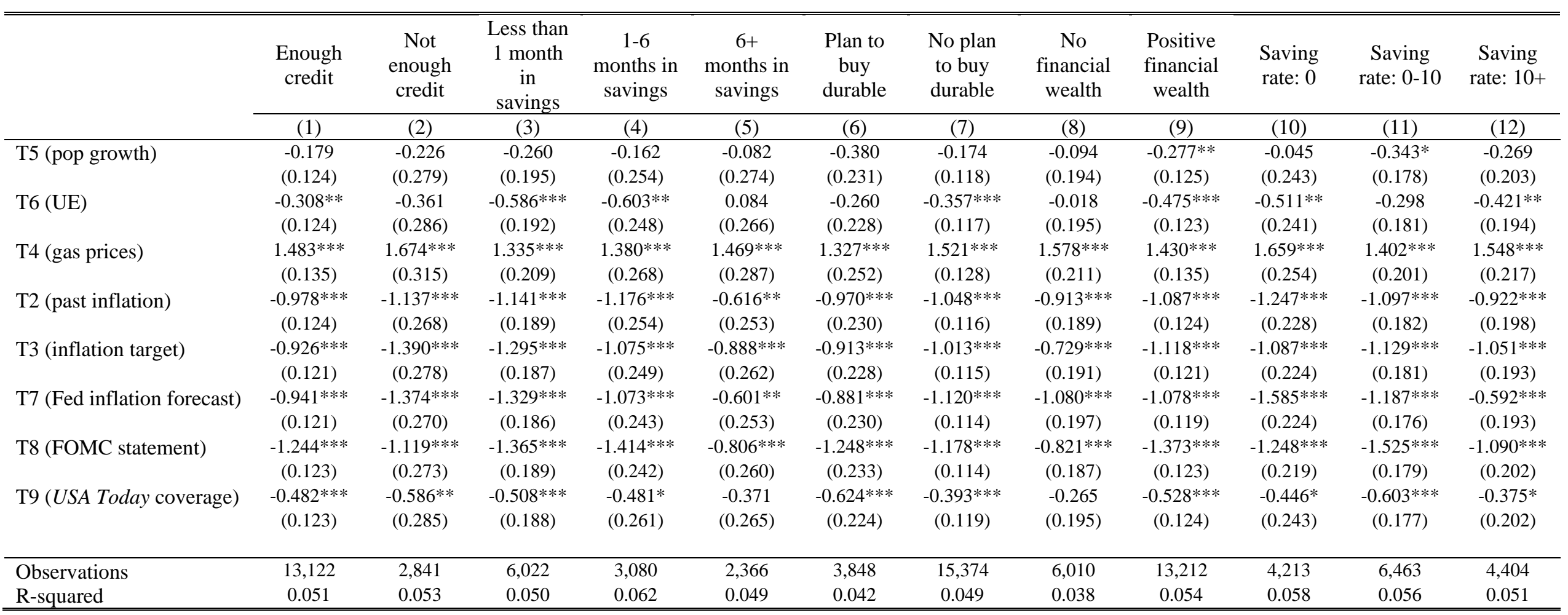

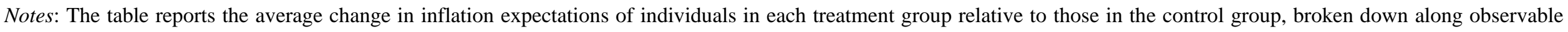

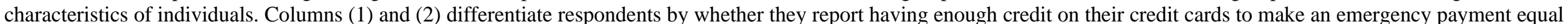

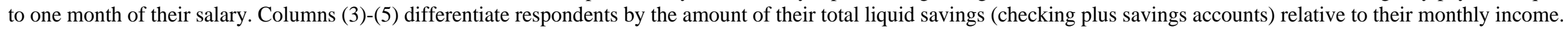

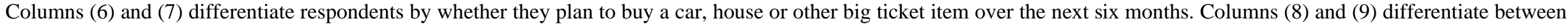

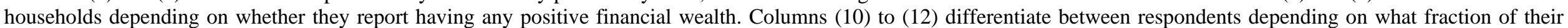

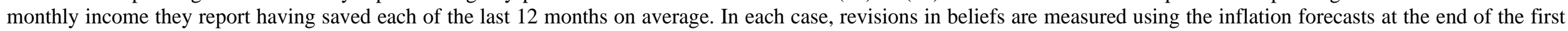

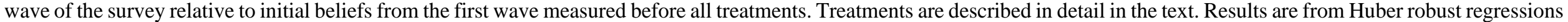
to control for outliers. Robust standard errors are reported in parentheses. 
Appendix Table 1 (continued): Heterogeneous Contemporaneous Effects of Treatments on Inflation Expectation

\begin{tabular}{|c|c|c|c|c|c|c|c|c|c|c|}
\hline & \multicolumn{2}{|c|}{ Race } & \multicolumn{2}{|c|}{ Who does groceries: } & \multicolumn{3}{|c|}{$\begin{array}{l}\text { Number of bins used in inflation } \\
\text { expectations distribution question }\end{array}$} & \multicolumn{3}{|c|}{$\begin{array}{l}\text { Time spent answering inflation } \\
\text { expectations distribution question }\end{array}$} \\
\hline & White & Non-White & Just me & Shared & $1 \mathrm{bin}$ & 2 bins & $3+$ bins & $<20$ sec. & 20-120 sec. & $120+$ sec. \\
\hline & $(1)$ & $(2)$ & (3) & $(4)$ & $(5)$ & $(6)$ & $(7)$ & $(8)$ & $(9)$ & $(10)$ \\
\hline \multirow[t]{2}{*}{ T5 (pop growth) } & $-0.191^{*}$ & -0.327 & $-0.348 *$ & -0.193 & -0.218 & -0.218 & -0.188 & -0.014 & -0.099 & 0.376 \\
\hline & $(0.116)$ & $(0.246)$ & $(0.209)$ & $(0.123)$ & $(0.134)$ & $(0.257)$ & $(0.225)$ & $(0.285)$ & $(0.171)$ & $(0.615)$ \\
\hline \multirow[t]{2}{*}{ T6 (UE) } & $-0.287 * *$ & $-0.490 * *$ & -0.160 & $-0.439 * * *$ & $-0.265 * *$ & -0.269 & $-0.544 * *$ & -0.100 & -0.256 & 0.008 \\
\hline & $(0.115)$ & $(0.244)$ & $(0.201)$ & $(0.124)$ & $(0.134)$ & $(0.247)$ & $(0.223)$ & $(0.275)$ & $(0.175)$ & $(0.658)$ \\
\hline \multirow[t]{2}{*}{ T4 (gas prices) } & $1.508^{* * *}$ & $1.349 * * *$ & $1.531 * * *$ & $1.439 * * *$ & $1.414^{* * *}$ & $1.686 * * *$ & $1.568 * * *$ & $1.658 * * *$ & $1.928 * * *$ & $2.570 * * *$ \\
\hline & $(0.125)$ & $(0.274)$ & $(0.228)$ & $(0.134)$ & $(0.146)$ & $(0.264)$ & $(0.252)$ & $(0.327)$ & $(0.193)$ & $(0.658)$ \\
\hline \multirow[t]{2}{*}{ T2 (past inflation) } & $-0.977 * * *$ & $-1.236^{* * *}$ & $-0.852 * * *$ & $-1.105^{* * *}$ & $-0.937 * * *$ & $-1.094 * * *$ & $-1.239 * * *$ & $-0.929 * * *$ & $-1.095^{* * *}$ & -0.726 \\
\hline & $(0.115)$ & $(0.242)$ & $(0.201)$ & $(0.123)$ & $(0.135)$ & $(0.236)$ & $(0.222)$ & $(0.282)$ & $(0.169)$ & $(0.610)$ \\
\hline \multirow[t]{2}{*}{ T3 (inflation target) } & $-1.034 * * *$ & $-0.851 * * *$ & $-1.181^{* * *}$ & $-0.953 * * *$ & $-0.902 * * *$ & $-1.046 * * *$ & $-1.209 * * *$ & $-0.985 * * *$ & $-1.002 * * *$ & -0.792 \\
\hline & $(0.112)$ & $(0.241)$ & $(0.200)$ & $(0.120)$ & $(0.134)$ & $(0.234)$ & $(0.212)$ & $(0.280)$ & $(0.169)$ & $(0.556)$ \\
\hline \multirow[t]{2}{*}{ T7 (Fed inflation forecast) } & $-1.102 * * *$ & $-0.956 * * *$ & $-1.208 * * *$ & $-1.050 * * *$ & $-1.013 * * *$ & $-0.857 * * *$ & $-1.385 * * *$ & $-0.772 * * *$ & $-1.085 * * *$ & -0.811 \\
\hline & $(0.112)$ & $(0.246)$ & $(0.200)$ & $(0.120)$ & $(0.133)$ & $(0.228)$ & $(0.223)$ & $(0.286)$ & $(0.167)$ & $(0.551)$ \\
\hline \multirow[t]{2}{*}{ T8 (FOMC statement) } & $-1.186^{* * *}$ & $-1.213^{* * *}$ & $-1.268 * * *$ & $-1.197 * * *$ & $-1.109 * * *$ & $-1.121 * * *$ & $-1.475^{* * *}$ & $-1.093 * * *$ & $-1.381 * * *$ & $-1.194 * *$ \\
\hline & $(0.114)$ & $(0.232)$ & $(0.200)$ & $(0.121)$ & $(0.133)$ & $(0.230)$ & $(0.226)$ & $(0.278)$ & $(0.171)$ & $(0.557)$ \\
\hline \multirow[t]{2}{*}{ T9 (USA Today coverage) } & $-0.437 * * *$ & $-0.477^{*}$ & $-0.410 * *$ & $-0.477 * * *$ & $-0.354 * * *$ & $-0.683 * * *$ & $-0.535 * *$ & $-0.525^{*}$ & $-0.298 *$ & 0.311 \\
\hline & $(0.115)$ & $(0.249)$ & $(0.202)$ & $(0.124)$ & $(0.134)$ & $(0.252)$ & $(0.226)$ & $(0.280)$ & $(0.176)$ & $(0.643)$ \\
\hline Observations & 16,285 & 2,937 & 5,614 & 13,285 & 12,163 & 2,977 & 4,081 & 2,525 & 6,937 & 792 \\
\hline R-squared & 0.049 & 0.044 & 0.049 & 0.047 & 0.041 & 0.066 & 0.060 & 0.047 & 0.064 & 0.068 \\
\hline
\end{tabular}

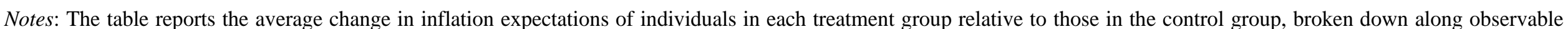

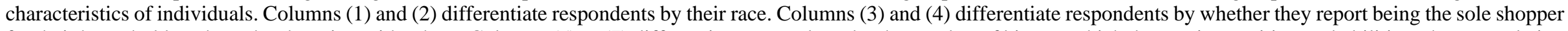

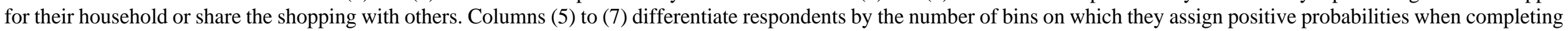

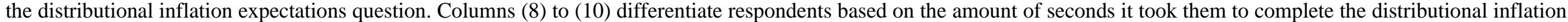

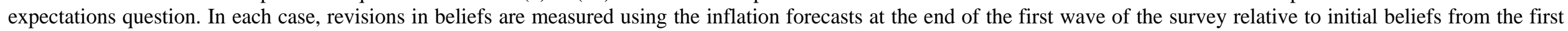

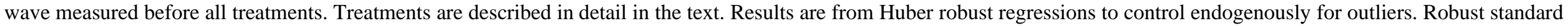
errors are reported in parentheses. 
Appendix Table 1 (continued): Heterogeneous Contemporaneous Effects of Treatments on Inflation Expectation

\begin{tabular}{|c|c|c|c|}
\hline & \multicolumn{3}{|c|}{ Age } \\
\hline & 40 or less & {$[41,60]$} & 61 or more \\
\hline & $(1)$ & $(2)$ & (3) \\
\hline T5 (pop growth) & $\begin{array}{l}-0.100 \\
(0.213)\end{array}$ & $\begin{array}{l}-0.360 * * \\
(0.168)\end{array}$ & $\begin{array}{l}-0.139 \\
(0.173)\end{array}$ \\
\hline T6 (UE) & $\begin{array}{l}-0.514^{* *} \\
(0.206)\end{array}$ & $\begin{array}{l}-0.277 \\
(0.169)\end{array}$ & $\begin{array}{l}-0.256 \\
(0.174)\end{array}$ \\
\hline T4 (gas prices) & $\begin{array}{l}1.465^{* * *} \\
(0.241)\end{array}$ & $\begin{array}{l}1.437 * * * \\
(0.186)\end{array}$ & $\begin{array}{l}1.542^{* * *} \\
(0.180)\end{array}$ \\
\hline T2 (past inflation) & $\begin{array}{l}-0.852^{* * *} \\
(0.209)\end{array}$ & $\begin{array}{l}-1.145^{* * *} \\
(0.166)\end{array}$ & $\begin{array}{l}-1.028 * * * \\
(0.174)\end{array}$ \\
\hline T3 (inflation target) & $\begin{array}{l}-1.052 * * * \\
(0.202)\end{array}$ & $\begin{array}{l}-1.012^{* * *} \\
(0.169)\end{array}$ & $\begin{array}{l}-0.927^{* * *} \\
(0.166)\end{array}$ \\
\hline T7 (Fed inflation forecast) & $\begin{array}{l}-0.950 * * * \\
(0.203)\end{array}$ & $\begin{array}{l}-1.161 * * * \\
(0.168)\end{array}$ & $\begin{array}{l}-1.059 * * * \\
(0.167)\end{array}$ \\
\hline T8 (FOMC statement) & $\begin{array}{l}-1.307 * * * \\
(0.203)\end{array}$ & $\begin{array}{l}-1.103^{* * *} \\
(0.166)\end{array}$ & $\begin{array}{l}-1.211 * * * \\
(0.170)\end{array}$ \\
\hline T9 (USA Today coverage) & $\begin{array}{l}-0.526^{* * *} \\
(0.201)\end{array}$ & $\begin{array}{l}-0.540^{* * *} \\
(0.173)\end{array}$ & $\begin{array}{l}-0.263 \\
(0.174)\end{array}$ \\
\hline Observations & 3,634 & 7,024 & 8,564 \\
\hline R-squared & 0.053 & 0.048 & 0.045 \\
\hline
\end{tabular}

Notes: The table reports the average change in inflation expectations of individuals in each treatment group relative to those in the control group, broken down by age of the respondent. Column (1) uses individuals aged 40 or less, column (2) uses individuals with ages from 41 to 60 , and column (3) uses individuals aged 61 or more. In each case, revisions in beliefs are measured using the inflation forecasts at the end of the first wave of the survey relative to initial beliefs from the first wave measured before all treatments. Treatments are described in detail in the text. Results are from Huber robust regressions to control endogenously for outliers. Robust standard errors are reported in parentheses. 
Appendix Table 2: Heterogeneous Three-Month Effects of Treatments on Inflation Expectation

\begin{tabular}{|c|c|c|c|c|c|c|c|c|c|c|c|c|}
\hline & $\begin{array}{c}\text { Enough } \\
\text { credit }\end{array}$ & $\begin{array}{c}\text { Not } \\
\text { enough } \\
\text { credit }\end{array}$ & $\begin{array}{l}\text { Less than } \\
1 \text { month } \\
\text { in } \\
\text { savings }\end{array}$ & $\begin{array}{c}1-6 \\
\text { months in } \\
\text { savings }\end{array}$ & $\begin{array}{c}6^{6+} \\
\text { months in } \\
\text { savings }\end{array}$ & $\begin{array}{c}\text { Plan to } \\
\text { buy } \\
\text { durable }\end{array}$ & $\begin{array}{l}\text { No plan } \\
\text { to buy } \\
\text { durable }\end{array}$ & $\begin{array}{c}\text { No } \\
\text { financial } \\
\text { wealth }\end{array}$ & $\begin{array}{c}\text { Positive } \\
\text { financial } \\
\text { wealth }\end{array}$ & $\begin{array}{l}\text { Saving } \\
\text { rate: } 0\end{array}$ & $\begin{array}{l}\text { Saving } \\
\text { rate: } 0-10\end{array}$ & $\begin{array}{l}\text { Saving } \\
\text { rate: } 10^{+}\end{array}$ \\
\hline T5 (pop growth) & $\begin{array}{l}-0.014 \\
(0.109)\end{array}$ & $\begin{array}{c}-0.072 \\
(0.244)\end{array}$ & $\begin{array}{c}-0.078 \\
(0.175)\end{array}$ & $\begin{array}{l}-0.020 \\
(0.210)\end{array}$ & $\begin{array}{c}0.044 \\
(0.231)\end{array}$ & $\begin{array}{l}-0.271 \\
(0.210)\end{array}$ & $\begin{array}{l}-0.060 \\
(0.101)\end{array}$ & $\begin{array}{l}-0.304^{*} \\
(0.174)\end{array}$ & $\begin{array}{c}-0.012 \\
(0.106)\end{array}$ & $\begin{array}{c}0.026 \\
(0.203)\end{array}$ & $\begin{array}{c}0.086 \\
(0.160)\end{array}$ & $\begin{array}{c}-0.353^{* *} \\
(0.170)\end{array}$ \\
\hline T6 (UE) & $\begin{array}{c}-0.228 * * \\
(0.110)\end{array}$ & $\begin{array}{c}-0.490^{*} \\
(0.272)\end{array}$ & $\begin{array}{c}-0.442^{* *} \\
(0.181)\end{array}$ & $\begin{array}{l}-0.274 \\
(0.227)\end{array}$ & $\begin{array}{l}-0.142 \\
(0.233)\end{array}$ & $\begin{array}{l}-0.110 \\
(0.211)\end{array}$ & $\begin{array}{c}-0.343^{* * *} \\
(0.104)\end{array}$ & $\begin{array}{c}-0.501 * * * \\
(0.181)\end{array}$ & $\begin{array}{c}-0.209 * \\
(0.109)\end{array}$ & $\begin{array}{c}-0.797 * * * \\
(0.203)\end{array}$ & $\begin{array}{c}0.006 \\
(0.173)\end{array}$ & $\begin{array}{c}-0.348 * * \\
(0.174)\end{array}$ \\
\hline T4 (gas prices) & $\begin{array}{c}-0.192 * \\
(0.110)\end{array}$ & $\begin{array}{l}-0.093 \\
(0.257)\end{array}$ & $\begin{array}{l}-0.239 \\
(0.178)\end{array}$ & $\begin{array}{l}-0.062 \\
(0.221)\end{array}$ & $\begin{array}{l}-0.150 \\
(0.216)\end{array}$ & $\begin{array}{l}-0.045 \\
(0.212)\end{array}$ & $\begin{array}{c}-0.214 * * \\
(0.104)\end{array}$ & $\begin{array}{c}-0.323^{*} \\
(0.182)\end{array}$ & $\begin{array}{l}-0.123 \\
(0.107)\end{array}$ & $\begin{array}{l}-0.381^{*} \\
(0.200)\end{array}$ & $\begin{array}{c}0.085 \\
(0.167)\end{array}$ & $\begin{array}{l}-0.310^{*} \\
(0.173)\end{array}$ \\
\hline T2 (past inflation) & $\begin{array}{c}0.032 \\
(0.107)\end{array}$ & $\begin{array}{l}-0.109 \\
(0.267)\end{array}$ & $\begin{array}{l}-0.118 \\
(0.176)\end{array}$ & $\begin{array}{l}-0.010 \\
(0.220)\end{array}$ & $\begin{array}{l}-0.093 \\
(0.226)\end{array}$ & $\begin{array}{c}-0.198 \\
(0.205)\end{array}$ & $\begin{array}{c}0.006 \\
(0.103)\end{array}$ & $\begin{array}{c}-0.112 \\
(0.177)\end{array}$ & $\begin{array}{l}-0.005 \\
(0.107)\end{array}$ & $\begin{array}{l}-0.135 \\
(0.203)\end{array}$ & $\begin{array}{c}0.177 \\
(0.161)\end{array}$ & $\begin{array}{l}-0.225 \\
(0.177)\end{array}$ \\
\hline T3 (inflation target) & $\begin{array}{c}-0.282 * * \\
(0.111)\end{array}$ & $\begin{array}{l}-0.177 \\
(0.253)\end{array}$ & $\begin{array}{c}-0.303^{*} \\
(0.173)\end{array}$ & $\begin{array}{l}-0.207 \\
(0.232)\end{array}$ & $\begin{array}{c}-0.458^{*} \\
(0.241)\end{array}$ & $\begin{array}{c}-0.406^{*} \\
(0.210)\end{array}$ & $\begin{array}{c}-0.312^{* * *} \\
(0.103)\end{array}$ & $\begin{array}{c}-0.688^{* * *} \\
(0.175)\end{array}$ & $\begin{array}{c}-0.178^{*} \\
(0.108)\end{array}$ & $\begin{array}{c}-0.388^{*} \\
(0.200)\end{array}$ & $\begin{array}{c}0.001 \\
(0.166)\end{array}$ & $\begin{array}{c}-0.470^{* * *} \\
(0.175)\end{array}$ \\
\hline T7 (Fed inflation forecast) & $\begin{array}{l}-0.169 \\
(0.112)\end{array}$ & $\begin{array}{c}-0.201 \\
(0.252)\end{array}$ & $\begin{array}{c}-0.144 \\
(0.177)\end{array}$ & $\begin{array}{c}-0.178 \\
(0.229)\end{array}$ & $\begin{array}{l}-0.050 \\
(0.231)\end{array}$ & $\begin{array}{c}-0.054 \\
(0.221)\end{array}$ & $\begin{array}{c}-0.278^{* * *} \\
(0.103)\end{array}$ & $\begin{array}{c}-0.567 * * * \\
(0.180)\end{array}$ & $\begin{array}{l}-0.100 \\
(0.109)\end{array}$ & $\begin{array}{c}-0.493^{* *} \\
(0.215)\end{array}$ & $\begin{array}{c}-0.033 \\
(0.162)\end{array}$ & $\begin{array}{c}-0.238 \\
(0.173)\end{array}$ \\
\hline T8 (FOMC statement) & $\begin{array}{c}-0.131 \\
(0.108)\end{array}$ & $\begin{array}{l}-0.020 \\
(0.272)\end{array}$ & $\begin{array}{l}-0.106 \\
(0.174)\end{array}$ & $\begin{array}{l}-0.237 \\
(0.216)\end{array}$ & $\begin{array}{c}0.120 \\
(0.228)\end{array}$ & $\begin{array}{c}-0.190 \\
(0.210)\end{array}$ & $\begin{array}{l}-0.087 \\
(0.101)\end{array}$ & $\begin{array}{l}-0.265 \\
(0.173)\end{array}$ & $\begin{array}{l}-0.043 \\
(0.107)\end{array}$ & $\begin{array}{c}0.064 \\
(0.205)\end{array}$ & $\begin{array}{c}-0.280^{*} \\
(0.162)\end{array}$ & $\begin{array}{l}-0.032 \\
(0.172)\end{array}$ \\
\hline T9 (USA Today coverage) & $\begin{array}{l}-0.148 \\
(0.109)\end{array}$ & $\begin{array}{c}0.006 \\
(0.269)\end{array}$ & $\begin{array}{l}-0.117 \\
(0.177)\end{array}$ & $\begin{array}{l}-0.117 \\
(0.227)\end{array}$ & $\begin{array}{c}0.139 \\
(0.227)\end{array}$ & $\begin{array}{c}0.053 \\
(0.208)\end{array}$ & $\begin{array}{c}-0.161 \\
(0.103)\end{array}$ & $\begin{array}{c}-0.299 * \\
(0.176)\end{array}$ & $\begin{array}{l}-0.047 \\
(0.108)\end{array}$ & $\begin{array}{c}0.001 \\
(0.214)\end{array}$ & $\begin{array}{c}-0.118 \\
(0.165)\end{array}$ & $\begin{array}{l}-0.219 \\
(0.170)\end{array}$ \\
\hline Observations & 8,782 & 1,853 & 3,963 & 2,100 & 1,696 & 2,434 & 10,448 & 4,070 & 8,812 & 2,885 & 4,179 & 3,013 \\
\hline R-squared & 0.002 & 0.003 & 0.002 & 0.002 & 0.006 & 0.003 & 0.002 & 0.005 & 0.001 & 0.011 & 0.003 & 0.004 \\
\hline
\end{tabular}

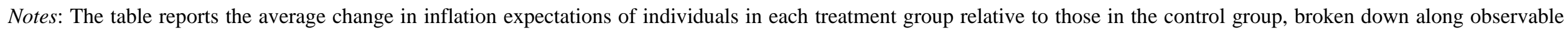

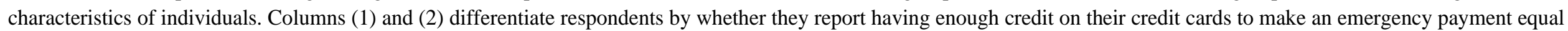

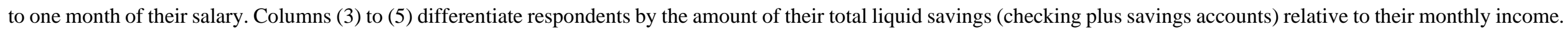

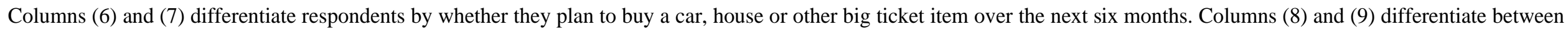

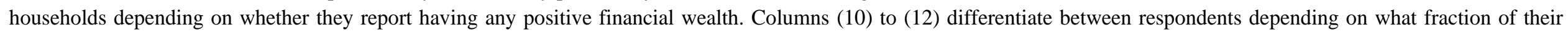

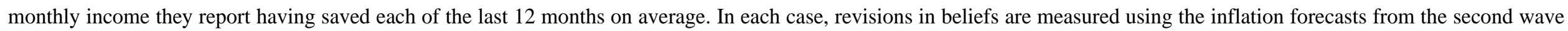

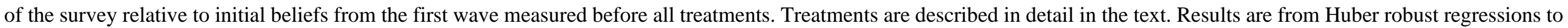
control endogenously for outliers. Robust standard errors are reported in parentheses. 
Appendix Table 2 (continued): Heterogeneous Three-Month Effects of Treatments on Inflation Expectation

\begin{tabular}{|c|c|c|c|c|c|c|c|c|c|c|}
\hline & \multicolumn{2}{|c|}{ Race } & \multicolumn{2}{|c|}{ Who does groceries: } & \multicolumn{3}{|c|}{$\begin{array}{l}\text { Number of bins used in inflation } \\
\text { expectations distribution question }\end{array}$} & \multicolumn{3}{|c|}{$\begin{array}{l}\text { Time spent answering inflation } \\
\text { expectations distribution question }\end{array}$} \\
\hline & White & Non-White & Just me & Shared & 1 bin & 2 bins & $3+$ bins & $<20$ sec. & 20-120 sec. & $120+$ sec. \\
\hline & $(1)$ & $(2)$ & (3) & (4) & $(5)$ & $(6)$ & $(7)$ & (8) & $(9)$ & $(10)$ \\
\hline \multirow[t]{2}{*}{ T5 (pop growth) } & -0.154 & 0.137 & 0.063 & -0.137 & -0.080 & -0.129 & -0.113 & -0.023 & -0.030 & -0.425 \\
\hline & $(0.100)$ & $(0.214)$ & $(0.185)$ & $(0.106)$ & $(0.117)$ & $(0.213)$ & $(0.194)$ & $(0.272)$ & $(0.156)$ & $(0.472)$ \\
\hline \multirow[t]{2}{*}{ T6 (UE) } & $-0.370 * * *$ & 0.014 & -0.107 & $-0.356 * * *$ & $-0.430 * * *$ & -0.171 & 0.025 & $-0.465^{*}$ & $-0.419 * * *$ & -0.393 \\
\hline & $(0.104)$ & $(0.217)$ & $(0.182)$ & $(0.110)$ & $(0.121)$ & $(0.220)$ & $(0.200)$ & $(0.273)$ & $(0.153)$ & $(0.496)$ \\
\hline \multirow[t]{2}{*}{ T4 (gas prices) } & $-0.170 *$ & -0.292 & 0.130 & $-0.256^{* *}$ & -0.174 & -0.308 & -0.111 & -0.118 & -0.177 & -0.750 \\
\hline & $(0.103)$ & $(0.226)$ & $(0.182)$ & $(0.109)$ & $(0.122)$ & $(0.218)$ & $(0.192)$ & $(0.287)$ & $(0.154)$ & $(0.480)$ \\
\hline \multirow[t]{2}{*}{ T2 (past inflation) } & -0.088 & 0.183 & 0.285 & -0.129 & -0.072 & -0.066 & 0.104 & -0.167 & -0.064 & -0.667 \\
\hline & $(0.102)$ & $(0.210)$ & $(0.181)$ & $(0.107)$ & $(0.119)$ & $(0.220)$ & $(0.192)$ & $(0.264)$ & $(0.154)$ & $(0.510)$ \\
\hline \multirow[t]{2}{*}{ T3 (inflation target) } & $-0.300 * * *$ & $-0.451 * *$ & -0.165 & $-0.360 * * *$ & $-0.414 * * *$ & -0.268 & -0.137 & $-0.549 *$ & $-0.306 * *$ & 0.272 \\
\hline & $(0.103)$ & $(0.207)$ & $(0.182)$ & $(0.108)$ & $(0.120)$ & $(0.200)$ & $(0.202)$ & $(0.280)$ & $(0.151)$ & $(0.514)$ \\
\hline \multirow[t]{2}{*}{ T7 (Fed inflation forecast) } & $-0.315^{* * *}$ & 0.094 & -0.292 & $-0.204 *$ & $-0.309 * *$ & -0.284 & 0.008 & -0.293 & -0.242 & -0.427 \\
\hline & $(0.105)$ & $(0.204)$ & $(0.188)$ & (0.109) & $(0.123)$ & $(0.213)$ & (0.193) & $(0.295)$ & $(0.157)$ & $(0.473)$ \\
\hline \multirow[t]{2}{*}{ T8 (FOMC statement) } & $-0.171^{*}$ & 0.148 & 0.151 & $-0.192 *$ & -0.049 & -0.125 & -0.260 & -0.325 & -0.184 & -0.541 \\
\hline & $(0.102)$ & $(0.203)$ & $(0.182)$ & $(0.107)$ & $(0.118)$ & $(0.222)$ & $(0.189)$ & $(0.265)$ & $(0.156)$ & $(0.481)$ \\
\hline \multirow[t]{2}{*}{ T9 (USA Today coverage) } & $-0.175^{*}$ & 0.100 & -0.188 & -0.066 & -0.136 & -0.334 & 0.075 & -0.164 & -0.149 & 0.062 \\
\hline & $(0.103)$ & $(0.209)$ & $(0.181)$ & (0.109) & $(0.122)$ & $(0.216)$ & $(0.185)$ & $(0.268)$ & $(0.150)$ & $(0.496)$ \\
\hline Observations & 10,920 & 1,962 & 3,612 & 9,048 & 8,158 & 1,984 & 2,739 & 1,558 & 4,356 & 509 \\
\hline R-squared & 0.002 & 0.007 & 0.005 & 0.002 & 0.003 & 0.002 & 0.002 & 0.005 & 0.002 & 0.015 \\
\hline
\end{tabular}

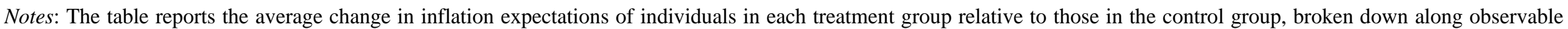

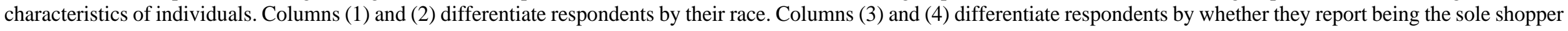

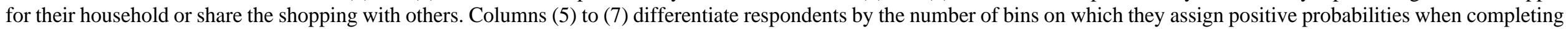

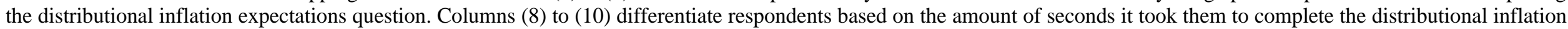

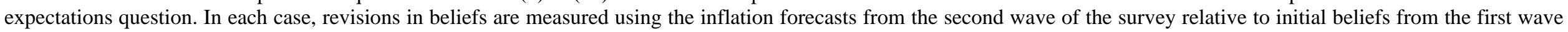

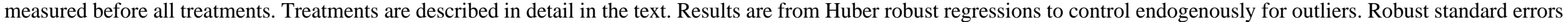
are reported in parentheses. 
Appendix Table 2 (continued): Heterogeneous Three-Month Effects of Treatments on Inflation Expectation

\begin{tabular}{|c|c|c|c|c|c|c|c|c|}
\hline \multirow[t]{2}{*}{ Breakdown of Sample: } & \multicolumn{2}{|c|}{ By Gender } & \multicolumn{3}{|c|}{ By Income } & \multicolumn{3}{|c|}{ By Education } \\
\hline & Female & Male & $\begin{array}{l}\text { Bottom } \\
\text { Tercile }\end{array}$ & $\begin{array}{l}\text { Middle } \\
\text { Tercile }\end{array}$ & $\begin{array}{l}\text { Highest } \\
\text { Tercile }\end{array}$ & $\begin{array}{c}\text { High school } \\
\text { of less }\end{array}$ & $\begin{array}{l}\text { Assoc. } \\
\text { degree or } \\
\text { some } \\
\text { college }\end{array}$ & $\begin{array}{l}\text { College or } \\
\text { more }\end{array}$ \\
\hline Treatment Group: & $(1)$ & $(2)$ & (3) & $(4)$ & (5) & $(6)$ & $(7)$ & $(8)$ \\
\hline T5 (pop growth) & $\begin{array}{l}-0.091 \\
(0.116)\end{array}$ & $\begin{array}{l}-0.104 \\
(0.147)\end{array}$ & $\begin{array}{l}-0.164 \\
(0.170)\end{array}$ & $\begin{array}{l}-0.081 \\
(0.191)\end{array}$ & $\begin{array}{l}-0.060 \\
(0.129)\end{array}$ & $\begin{array}{l}-0.173 \\
(0.196)\end{array}$ & $\begin{array}{l}-0.088 \\
(0.170)\end{array}$ & $\begin{array}{l}-0.063 \\
(0.127)\end{array}$ \\
\hline T6 (UE) & $\begin{array}{l}-0.311^{* * *} \\
(0.118)\end{array}$ & $\begin{array}{l}-0.256^{*} \\
(0.154)\end{array}$ & $\begin{array}{l}-0.442 * * * \\
(0.171)\end{array}$ & $\begin{array}{l}-0.108 \\
(0.203)\end{array}$ & $\begin{array}{l}-0.283^{* *} \\
(0.134)\end{array}$ & $\begin{array}{l}-0.562 * * * \\
(0.205)\end{array}$ & $\begin{array}{l}-0.324^{*} \\
(0.169)\end{array}$ & $\begin{array}{l}-0.126 \\
(0.133)\end{array}$ \\
\hline T4 (gas prices) & $\begin{array}{l}-0.122 \\
(0.122)\end{array}$ & $\begin{array}{l}-0.272^{*} \\
(0.143)\end{array}$ & $\begin{array}{l}-0.294^{*} \\
(0.169)\end{array}$ & $\begin{array}{l}-0.018 \\
(0.193)\end{array}$ & $\begin{array}{l}-0.189 \\
(0.137)\end{array}$ & $\begin{array}{l}-0.252 \\
(0.208)\end{array}$ & $\begin{array}{c}0.109 \\
(0.176)\end{array}$ & $\begin{array}{l}-0.304^{* *} \\
(0.127)\end{array}$ \\
\hline T2 (past inflation) & $\begin{array}{l}-0.040 \\
(0.119)\end{array}$ & $\begin{array}{l}-0.021 \\
(0.145)\end{array}$ & $\begin{array}{l}-0.156 \\
(0.176)\end{array}$ & $\begin{array}{c}0.082 \\
(0.195)\end{array}$ & $\begin{array}{l}-0.008 \\
(0.128)\end{array}$ & $\begin{array}{l}-0.310 \\
(0.214)\end{array}$ & $\begin{array}{c}0.005 \\
(0.172)\end{array}$ & $\begin{array}{c}0.077 \\
(0.124)\end{array}$ \\
\hline T3 (inflation target) & $\begin{array}{l}-0.339 * * * \\
(0.118)\end{array}$ & $\begin{array}{l}-0.308 * * \\
(0.148)\end{array}$ & $\begin{array}{l}-0.476 * * * \\
(0.166)\end{array}$ & $\begin{array}{l}-0.347^{*} \\
(0.198)\end{array}$ & $\begin{array}{l}-0.224^{*} \\
(0.134)\end{array}$ & $\begin{array}{l}-0.307 \\
(0.201)\end{array}$ & $\begin{array}{l}-0.349 * * \\
(0.173)\end{array}$ & $\begin{array}{l}-0.329 * * * \\
(0.128)\end{array}$ \\
\hline T7 (Fed inflation forecast) & $\begin{array}{l}-0.275^{* *} \\
(0.120)\end{array}$ & $\begin{array}{l}-0.168 \\
(0.149)\end{array}$ & $\begin{array}{l}-0.479 * * * \\
(0.176)\end{array}$ & $\begin{array}{l}-0.153 \\
(0.197)\end{array}$ & $\begin{array}{l}-0.106 \\
(0.132)\end{array}$ & $\begin{array}{l}-0.724 * * * \\
(0.218)\end{array}$ & $\begin{array}{l}-0.247 \\
(0.177)\end{array}$ & $\begin{array}{l}-0.004 \\
(0.126)\end{array}$ \\
\hline T8 (FOMC statement) & $\begin{array}{l}-0.106 \\
(0.118)\end{array}$ & $\begin{array}{l}-0.108 \\
(0.143)\end{array}$ & $\begin{array}{l}-0.209 \\
(0.171)\end{array}$ & $\begin{array}{l}-0.050 \\
(0.192)\end{array}$ & $\begin{array}{l}-0.066 \\
(0.131)\end{array}$ & $\begin{array}{l}-0.340 * \\
(0.198)\end{array}$ & $\begin{array}{l}-0.114 \\
(0.173)\end{array}$ & $\begin{array}{c}0.018 \\
(0.127)\end{array}$ \\
\hline T9 (USA Today coverage) & $\begin{array}{l}-0.135 \\
(0.117)\end{array}$ & $\begin{array}{l}-0.090 \\
(0.152)\end{array}$ & $\begin{array}{l}-0.280 \\
(0.172)\end{array}$ & $\begin{array}{l}-0.132 \\
(0.194)\end{array}$ & $\begin{array}{l}-0.010 \\
(0.133)\end{array}$ & $\begin{array}{l}-0.128 \\
(0.198)\end{array}$ & $\begin{array}{l}-0.152 \\
(0.174)\end{array}$ & $\begin{array}{l}-0.098 \\
(0.130)\end{array}$ \\
\hline Observations & 9,608 & 3,274 & 4,160 & 3,859 & 4,863 & 1,953 & 3,496 & 7,433 \\
\hline R-squared & 0.002 & 0.003 & 0.003 & 0.002 & 0.002 & 0.007 & 0.003 & 0.003 \\
\hline
\end{tabular}

Notes: The table reports the average change in inflation expectations of individuals in each treatment group relative to those in the control group, broken down along observable characteristics of individuals. Columns (1) and (2) separate households by gender, columns (3) to (5) consider where individuals rank in the income distribution of all respondents by tercile, columns (6) to (8) classify respondents using the highest level of education in the household. In each case, revisions in beliefs are measured using the inflation forecasts from the second wave of the survey relative to initial beliefs from the first wave measured before all treatments. Treatments are described in detail in the text. Results are from Huber robust regressions to control endogenously for outliers. Robust standard errors are reported in parentheses. 
Appendix Table 3: Treatment effects by initial inflation expectations.

\begin{tabular}{lcccc}
\hline \hline & \multicolumn{3}{c}{ Outcome: forecast revision immediately after treatment } \\
\cline { 2 - 5 } & \multicolumn{2}{c}{ Pre-treatment expected } & \multicolumn{2}{c}{$\begin{array}{c}\text { Pre-treatment expected } \\
\text { inflation }\end{array}$} \\
& $(1)$ & $(2)$ & $(3)$ & $(4)$ \\
\cline { 2 - 5 } & 0.195 & 0.099 & $-0.584^{* * *}$ & $-0.584^{* * *}$ \\
\hline \hline T5 (pop growth) & $(0.143)$ & $(0.143)$ & $(0.139)$ & $(0.139)$ \\
T6 (UE) & 0.022 & 0.030 & $-0.615^{* * *}$ & $-0.640^{* * *}$ \\
& $(0.144)$ & $(0.144)$ & $(0.139)$ & $(0.141)$ \\
T4 (gas prices) & $1.959^{* * *}$ & $1.864^{* * *}$ & $1.263^{* * *}$ & $1.278^{* * *}$ \\
& $(0.167)$ & $(0.165)$ & $(0.147)$ & $(0.148)$ \\
T2 (past inflation) & $0.238^{*}$ & 0.175 & $-2.039^{* * *}$ & $-2.078^{* * *}$ \\
& $(0.141)$ & $(0.140)$ & $(0.135)$ & $(0.136)$ \\
T3 (inflation target) & 0.141 & 0.064 & $-1.774^{* * *}$ & $-1.743^{* * *}$ \\
& $(0.139)$ & $(0.139)$ & $(0.133)$ & $(0.134)$ \\
T7 (Fed inflation forecast) & -0.110 & -0.135 & $-1.863^{* * *}$ & $-1.872^{* * *}$ \\
& $(0.135)$ & $(0.134)$ & $(0.135)$ & $(0.136)$ \\
T8 (FOMC statement) & -0.098 & -0.164 & $-1.978^{* * *}$ & $-1.965^{* * *}$ \\
& $(0.137)$ & $(0.138)$ & $(0.134)$ & $(0.135)$ \\
T9 (USA Today coverage) & 0.052 & -0.029 & $-0.872^{* * *}$ & $-0.904^{* * *}$ \\
& $(0.143)$ & $(0.143)$ & $(0.139)$ & $(0.140)$ \\
\hline Remove outliers & Yes & Yes & Yes & Yes \\
Using sampling weights & Yes & Yes & Yes & Yes \\
Controls for demographics & No & Yes & No & Yes \\
\hline Observations & 7,136 & 7,133 & 11,993 & 11,998 \\
$\mathrm{R}^{2}$ & 0.040 & 0.072 & 0.081 & 0.102 \\
\hline \hline
\end{tabular}

Notes: the table reports estimated treatment effects for respondents who report pre-treatment expected inflation above $2 \%$ (columns 3 and 4) and 2\% or below (columns 1 and 2). See notes to Table 2 for more details. 
Appendix Table 4: Descriptive Statistics of the Survey, Unfiltered Data

\begin{tabular}{|c|c|c|c|c|c|c|c|c|c|}
\hline & \multicolumn{3}{|c|}{$\begin{array}{l}\text { Pre-treatment expected } \\
\text { inflation }\end{array}$} & \multicolumn{3}{|c|}{$\begin{array}{l}\text { Pre-treatment perceived } \\
\text { inflation }\end{array}$} & \multicolumn{3}{|c|}{$\begin{array}{l}\text { Pre-treatment perceived } \\
\text { inflation target of the Fed }\end{array}$} \\
\hline & Mean & Median & St.Dev. & Mean & Median & St.Dev. & Mean & Median & St.Dev. \\
\hline & $(1)$ & $(2)$ & $(3)$ & $(4)$ & (5) & (6) & $(7)$ & (8) & $(9)$ \\
\hline All & 3.62 & 3.00 & 5.12 & 7.77 & 3.00 & 15.56 & 16.95 & 5.00 & 29.48 \\
\hline Male & 3.20 & 3.00 & 4.34 & 5.36 & 3.00 & 11.24 & 10.31 & 3.00 & 23.94 \\
\hline Female & 3.79 & 3.00 & 5.41 & 8.77 & 3.00 & 16.93 & 19.55 & 5.00 & 31.00 \\
\hline White & 3.55 & 3.00 & 4.94 & 7.16 & 3.00 & 14.07 & 15.10 & 4.00 & 27.69 \\
\hline Non-white & 3.83 & 3.00 & 5.64 & 9.60 & 3.00 & 19.22 & 22.77 & 8.00 & 33.85 \\
\hline Income: tercile 1 (low) & 3.87 & 3.00 & 5.92 & 10.06 & 3.00 & 18.95 & 23.29 & 8.00 & 35.31 \\
\hline Income: tercile 2 & 3.73 & 3.00 & 4.98 & 8.05 & 3.00 & 16.04 & 18.40 & 5.00 & 30.04 \\
\hline Income: tercile 3 & 3.37 & 3.00 & 4.48 & 5.88 & 3.00 & 11.71 & 11.70 & 3.00 & 22.90 \\
\hline Enough credit & 3.44 & 3.00 & 4.49 & 6.26 & 3.00 & 12.46 & 12.66 & 3.00 & 25.02 \\
\hline Not enough credit & 4.19 & 3.00 & 5.59 & 9.55 & 4.00 & 17.76 & 20.11 & 6.00 & 31.00 \\
\hline HTM: less than 1 month in savings & 4.03 & 3.00 & 5.29 & 8.57 & 3.00 & 16.10 & 17.97 & 5.00 & 29.48 \\
\hline HTM: $1-6$ months in savings & 3.53 & 3.00 & 4.13 & 5.30 & 3.00 & 10.09 & 9.30 & 3.00 & 20.91 \\
\hline HTM: $6+$ months in savings & 3.11 & 3.00 & 3.52 & 4.17 & 3.00 & 6.90 & 7.78 & 3.00 & 17.27 \\
\hline Plan to buy durable & 3.63 & 3.00 & 4.82 & 8.29 & 3.00 & 16.37 & 15.66 & 5.00 & 27.29 \\
\hline No plan to buy durable & 3.61 & 3.00 & 5.21 & 7.63 & 3.00 & 15.32 & 17.37 & 5.00 & 30.14 \\
\hline No financial wealth & 3.60 & 3.00 & 5.97 & 10.22 & 3.00 & 19.43 & 23.95 & 10.00 & 34.90 \\
\hline Positive financial wealth & 3.63 & 3.00 & 4.55 & 6.33 & 3.00 & 12.52 & 12.39 & 3.00 & 24.27 \\
\hline Saving rate: 0 & 4.30 & 3.00 & 5.72 & 9.67 & 3.00 & 18.00 & 20.35 & 6.00 & 31.28 \\
\hline Saving rate: $0-10$ & 3.69 & 3.00 & 4.39 & 6.19 & 3.00 & 11.56 & 11.63 & 3.75 & 23.33 \\
\hline Saving rate: $10+$ & 3.40 & 3.00 & 4.30 & 6.43 & 3.00 & 12.46 & 12.47 & 3.00 & 23.91 \\
\hline Do grocery: me/self & 3.57 & 3.00 & 4.95 & 7.03 & 3.00 & 14.16 & 15.46 & 5.00 & 27.35 \\
\hline Do grocery: share & 3.65 & 3.00 & 5.17 & 8.01 & 3.00 & 15.94 & 17.43 & 5.00 & 30.04 \\
\hline Education: high school or less & 3.67 & 3.00 & 5.83 & 10.00 & 3.00 & 19.13 & 26.22 & 10.00 & 36.83 \\
\hline Education: some college & 3.76 & 3.00 & 5.31 & 8.16 & 3.00 & 15.93 & 17.22 & 5.00 & 28.95 \\
\hline Education: college or more & 3.48 & 3.00 & 4.46 & 6.08 & 3.00 & 12.22 & 11.44 & 3.00 & 23.09 \\
\hline
\end{tabular}

Notes: The table reports average values and cross-sectional deviations of expected inflation over the next twelve months (columns 1-3), perceived inflation over the previous twelve months (columns 4-6) and beliefs about the Federal Reserve's inflation target (columns 7-9). Data are not restricted/filtered in any way. Rows indicate which subset of the sample is used. Each row captures an observable characteristic of the respondent on which we condition. 
Appendix Table 5: Treatment Effects over Time using only Repeat Participants

\begin{tabular}{|c|c|c|c|c|c|c|}
\hline \multirow{3}{*}{ Treatments } & \multicolumn{6}{|c|}{ Outcome: forecast revision } \\
\hline & \multicolumn{2}{|c|}{ Immediate revision } & \multicolumn{2}{|c|}{ Revision after 3 months } & \multicolumn{2}{|c|}{ Revision after 6 months } \\
\hline & $(1)$ & $(2)$ & (3) & $(4)$ & $(5)$ & $(6)$ \\
\hline \multirow[t]{2}{*}{ T5 (pop growth) } & $-0.415 * * *$ & $-0.464 * * *$ & -0.138 & -0.134 & 0.126 & 0.153 \\
\hline & $(0.150)$ & $(0.149)$ & $(0.104)$ & $(0.104)$ & $(0.111)$ & $(0.113)$ \\
\hline T6 (UE) & $-0.629 * * *$ & $-0.649 * * *$ & $-0.375 * * *$ & $-0.374 * * *$ & -0.019 & -0.014 \\
\hline \multirow[t]{2}{*}{ T4 (gas prices) } & $1.066 * * *$ & $1.037 * * *$ & $-0.187 *$ & $-0.191 *$ & 0.057 & 0.061 \\
\hline & $(0.159)$ & $(0.157)$ & $(0.107)$ & $(0.108)$ & $(0.110)$ & $(0.112)$ \\
\hline \multirow[t]{2}{*}{ T2 (past inflation) } & $-1.199 * * *$ & $-1.299 * * *$ & -0.030 & -0.032 & $0.193 *$ & $0.219 *$ \\
\hline & $(0.148)$ & $(0.148)$ & $(0.106)$ & $(0.106)$ & $(0.111)$ & $(0.112)$ \\
\hline T3 (inflation target) & $-0.967 * * *$ & $-0.990 * * *$ & $-0.300 * * *$ & $-0.329 * * *$ & 0.109 & 0.155 \\
\hline T8 (FOMC statement) & $(0.144)$ & $(0.144)$ & $(0.104)$ & $(0.104)$ & $(0.111)$ & $(0.113)$ \\
\hline \multirow[t]{2}{*}{ T9 (USA Today coverage) } & $-0.644 * * *$ & $-0.648 * * *$ & $-0.182 *$ & -0.169 & 0.120 & 0.123 \\
\hline & $(0.146)$ & $(0.147)$ & $(0.106)$ & $(0.106)$ & $(0.110)$ & $(0.111)$ \\
\hline Remove outliers & Yes & Yes & Yes & Yes & Yes & Yes \\
\hline Using sampling weights & Yes & Yes & Yes & Yes & Yes & Yes \\
\hline Controls for demographics & No & Yes & No & Yes & No & Yes \\
\hline Observations & 8,921 & 8,927 & 9,681 & 9,669 & 9,763 & 9,592 \\
\hline $\mathrm{R}^{2}$ & 0.043 & 0.072 & 0.002 & 0.020 & 0.001 & 0.018 \\
\hline
\end{tabular}

Notes: The table reports the average change in inflation expectations of individuals in each treatment group relative to those in the control group. Columns (1) and (2) consider the immediate change in expectations after the treatment, columns (3) and (4) consider the changes in beliefs after three months, columns (5) and (6) report changes in beliefs over a six month horizon. In each case, differences in beliefs are measured relative to initial beliefs from the first wave measured before all treatments. Treatments are described in detail in the text. For each time horizon, the second column uses the same specification as in the first column but augmented with respondent-specific controls. Results are from Huber robust regressions to control for outliers and influential observations. Robust standard errors are reported in parentheses. Only respondents who participate in all waves are included. 
Appendix Table 6: Balancedness across Treatment Arms

\begin{tabular}{|c|c|c|c|c|c|c|c|c|c|}
\hline & \multicolumn{9}{|c|}{ Treatment } \\
\hline & $\begin{array}{c}\mathrm{T} 1 \\
\text { (control) }\end{array}$ & $\begin{array}{c}\text { T2 } \\
\text { (past } \\
\text { inflation) }\end{array}$ & $\begin{array}{c}\text { T3 } \\
\text { (inflation } \\
\text { target) }\end{array}$ & $\begin{array}{c}\mathrm{T} 4 \\
\text { (gas prices) }\end{array}$ & $\begin{array}{c}\text { T5 } \\
\text { (pop } \\
\text { growth) }\end{array}$ & $\begin{array}{c}\text { T6 } \\
\text { (UE) }\end{array}$ & $\begin{array}{c}\text { T7 } \\
\text { (Fed } \\
\text { inflation } \\
\text { forecast) } \\
\end{array}$ & $\begin{array}{c}\text { T8 } \\
\text { (FOMC } \\
\text { statement) }\end{array}$ & $\begin{array}{c}\text { T9 } \\
\text { (USA } \\
\text { Today } \\
\text { coverage) } \\
\end{array}$ \\
\hline Age & $\begin{array}{c}51.08 \\
(15.02)\end{array}$ & $\begin{array}{c}51.57 \\
(14.87)\end{array}$ & $\begin{array}{c}51.95 \\
(14.97)\end{array}$ & $\begin{array}{c}52.54 \\
(15.29)\end{array}$ & $\begin{array}{c}51.42 \\
(15.07)\end{array}$ & $\begin{array}{c}51.08 \\
(14.82)\end{array}$ & $\begin{array}{c}51.26 \\
(14.89)\end{array}$ & $\begin{array}{c}51.86 \\
(14.55)\end{array}$ & $\begin{array}{c}50.96 \\
(14.99)\end{array}$ \\
\hline White share & $\begin{array}{c}0.74 \\
(0.44)\end{array}$ & $\begin{array}{c}0.74 \\
(0.44)\end{array}$ & $\begin{array}{c}0.75 \\
(0.43)\end{array}$ & $\begin{array}{c}0.76 \\
(0.43)\end{array}$ & $\begin{array}{c}0.76 \\
(0.42)\end{array}$ & $\begin{array}{c}0.74 \\
(0.44)\end{array}$ & $\begin{array}{c}0.77 \\
(0.42)\end{array}$ & $\begin{array}{c}0.73 \\
(0.45)\end{array}$ & $\begin{array}{c}0.75 \\
(0.43)\end{array}$ \\
\hline Household size & $\begin{array}{c}2.55 \\
(1.35)\end{array}$ & $\begin{array}{c}2.51 \\
(1.29)\end{array}$ & $\begin{array}{c}2.49 \\
(1.34)\end{array}$ & $\begin{array}{c}2.50 \\
(1.31)\end{array}$ & $\begin{array}{c}2.44 \\
(1.29)\end{array}$ & $\begin{array}{c}2.55 \\
(1.31)\end{array}$ & $\begin{array}{c}2.47 \\
(1.31)\end{array}$ & $\begin{array}{c}2.48 \\
(1.30)\end{array}$ & $\begin{array}{c}2.52 \\
(1.34)\end{array}$ \\
\hline Employed share & $\begin{array}{c}0.57 \\
(0.50)\end{array}$ & $\begin{array}{c}0.56 \\
(0.50)\end{array}$ & $\begin{array}{c}0.54 \\
(0.50)\end{array}$ & $\begin{array}{c}0.52 \\
(0.50)\end{array}$ & $\begin{array}{c}0.57 \\
(0.49)\end{array}$ & $\begin{array}{c}0.56 \\
(0.50)\end{array}$ & $\begin{array}{c}0.54 \\
(0.50)\end{array}$ & $\begin{array}{c}0.53 \\
(0.50)\end{array}$ & $\begin{array}{c}0.57 \\
(0.50)\end{array}$ \\
\hline Income ('000) & $\begin{array}{c}64.10 \\
(37.41)\end{array}$ & $\begin{array}{c}67.48 \\
(36.92)\end{array}$ & $\begin{array}{c}63.91 \\
(37.63)\end{array}$ & $\begin{array}{c}63.53 \\
(37.54)\end{array}$ & $\begin{array}{c}64.38 \\
(37.43)\end{array}$ & $\begin{array}{c}65.84 \\
(37.65)\end{array}$ & $\begin{array}{c}64.24 \\
(36.99)\end{array}$ & $\begin{array}{c}64.52 \\
(37.29)\end{array}$ & $\begin{array}{c}65.21 \\
(36.98)\end{array}$ \\
\hline Saving rate & $\begin{array}{c}10.39 \\
(14.88)\end{array}$ & $\begin{array}{c}10.39 \\
(14.08)\end{array}$ & $\begin{array}{c}10.13 \\
(14.32)\end{array}$ & $\begin{array}{c}10.46 \\
(15.19)\end{array}$ & $\begin{array}{c}10.04 \\
(14.77)\end{array}$ & $\begin{array}{c}10.84 \\
(15.20)\end{array}$ & $\begin{array}{c}10.09 \\
(13.91)\end{array}$ & $\begin{array}{c}9.36 \\
(13.19)\end{array}$ & $\begin{array}{c}10.94 \\
(15.19)\end{array}$ \\
\hline $\begin{array}{l}\text { Pre-treatment inflation } \\
\text { expectations }\end{array}$ & $\begin{array}{c}3.53 \\
(5.17) \\
\end{array}$ & $\begin{array}{c}3.63 \\
(5.27) \\
\end{array}$ & $\begin{array}{r}3.59 \\
(5.19) \\
\end{array}$ & $\begin{array}{r}3.55 \\
(5.12) \\
\end{array}$ & $\begin{array}{c}3.77 \\
(4.99) \\
\end{array}$ & $\begin{array}{c}3.70 \\
(5.06) \\
\end{array}$ & $\begin{array}{c}3.47 \\
(5.23) \\
\end{array}$ & $\begin{array}{c}3.86 \\
(4.97) \\
\end{array}$ & $\begin{array}{c}3.47 \\
(5.11) \\
\end{array}$ \\
\hline
\end{tabular}

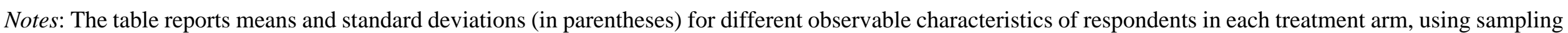
weights. The first row of the table indicates treatment arms for which moments are reported. 
Appendix Table 7: Average Household Responses to Treatments, median regression.

\begin{tabular}{|c|c|c|c|c|c|c|}
\hline \multirow{3}{*}{ Treatments } & \multicolumn{6}{|c|}{ Outcome: forecast revision } \\
\hline & \multicolumn{2}{|c|}{ Immediate revision } & \multicolumn{2}{|c|}{ Revision after 3 months } & \multicolumn{2}{|c|}{ Revision after 6 months } \\
\hline & $(1)$ & $(2)$ & (3) & $(4)$ & (5) & $(6)$ \\
\hline \multirow[t]{2}{*}{ T5 (pop growth) } & -0.350 & -0.431 & -0.150 & -0.076 & 0.050 & 0.138 \\
\hline & $(0.316)$ & $(0.305)$ & $(0.131)$ & $(0.084)$ & $(0.124)$ & $(0.108)$ \\
\hline \multirow[t]{2}{*}{ T6 (UE) } & -0.350 & $-0.575 * *$ & -0.150 & -0.132 & 0.000 & -0.013 \\
\hline & $(0.331)$ & $(0.262)$ & $(0.119)$ & $(0.086)$ & $(0.068)$ & $(0.081)$ \\
\hline \multirow[t]{2}{*}{ T4 (gas prices) } & $1.650 * * *$ & $1.615^{* * *}$ & -0.050 & 0.037 & 0.000 & 0.076 \\
\hline & $(0.333)$ & $(0.320)$ & $(0.152)$ & $(0.107)$ & $(0.107)$ & $(0.089)$ \\
\hline \multirow[t]{2}{*}{ T2 (past inflation) } & $-1.350 * * *$ & $-1.445 * * *$ & -0.100 & -0.045 & $0.190 *$ & 0.112 \\
\hline & $(0.277)$ & $(0.218)$ & $(0.136)$ & $(0.087)$ & $(0.109)$ & $(0.094)$ \\
\hline \multirow[t]{2}{*}{ T3 (inflation target) } & $-1.350 * * *$ & $-1.498 * * *$ & -0.150 & -0.061 & 0.100 & $0.193^{*}$ \\
\hline & $(0.270)$ & $(0.218)$ & $(0.136)$ & $(0.093)$ & $(0.176)$ & $(0.109)$ \\
\hline \multirow[t]{2}{*}{ T7 (Fed inflation forecast) } & $-1.350 * * *$ & $-1.318 * * *$ & -0.150 & -0.043 & 0.150 & $0.250 * *$ \\
\hline & $(0.273)$ & $(0.235)$ & $(0.136)$ & $(0.110)$ & $(0.171)$ & $(0.126)$ \\
\hline \multirow[t]{2}{*}{ T8 (FOMC statement) } & -1.350 & $-1.506 * * *$ & -0.150 & -0.067 & 0.000 & 0.130 \\
\hline & $(0.000)$ & $(0.224)$ & $(0.119)$ & $(0.095)$ & $(0.098)$ & $(0.100)$ \\
\hline \multirow[t]{2}{*}{ T9 (USA Today coverage) } & -0.350 & $-0.577 * *$ & 0.050 & 0.029 & 0.240 & 0.233 \\
\hline & $(0.397)$ & $(0.294)$ & $(0.167)$ & $(0.102)$ & $(0.153)$ & $(0.153)$ \\
\hline Remove outliers & Yes & Yes & Yes & Yes & Yes & Yes \\
\hline Using sampling weights & Yes & Yes & Yes & Yes & Yes & Yes \\
\hline Controls for demographics & No & Yes & No & Yes & No & Yes \\
\hline Observations & 22,582 & 22,582 & 14,003 & 14,001 & 13,580 & 13,369 \\
\hline
\end{tabular}

Notes: The table reports the average change in inflation expectations of individuals in each treatment group relative to those in the control group. Columns (1) and (2) consider the immediate change in expectations after the treatment, columns (3) and (4) consider the changes in beliefs after three months, columns (5) and (6) report changes in beliefs over a six month horizon. In each case, differences in beliefs are measured relative to initial beliefs from the first wave measured before all treatments. Treatments are described in detail in the text. For each time horizon, the second column uses the same specification as in the first column but augmented with respondent-specific controls. Results are from median regressions. Robust standard errors are reported in parentheses. 
Appendix Table 8: Average Household Responses to Treatments, OLS regression.

\begin{tabular}{|c|c|c|c|c|c|c|}
\hline \multirow{3}{*}{ Treatments } & \multicolumn{6}{|c|}{ Outcome: forecast revision } \\
\hline & \multicolumn{2}{|c|}{ Immediate revision } & \multicolumn{2}{|c|}{ Revision after 3 months } & \multicolumn{2}{|c|}{ Revision after 6 months } \\
\hline & $(1)$ & $(2)$ & (3) & $(4)$ & (5) & $(6)$ \\
\hline \multirow[t]{2}{*}{ T5 (pop growth) } & -1.304 & -1.220 & -0.436 & -0.466 & 0.029 & 0.041 \\
\hline & $(0.886)$ & $(0.857)$ & $(0.308)$ & $(0.307)$ & $(0.320)$ & $(0.322)$ \\
\hline \multirow[t]{2}{*}{ T6 (UE) } & $-2.742 * * *$ & $-2.748 * * *$ & -0.458 & -0.503 & -0.201 & -0.210 \\
\hline & $(0.891)$ & $(0.866)$ & $(0.317)$ & $(0.313)$ & $(0.317)$ & $(0.317)$ \\
\hline \multirow[t]{2}{*}{ T4 (gas prices) } & 0.084 & 0.214 & -0.302 & -0.314 & -0.062 & -0.028 \\
\hline & $(0.919)$ & $(0.892)$ & $(0.315)$ & $(0.315)$ & $(0.329)$ & $(0.332)$ \\
\hline \multirow[t]{2}{*}{ T2 (past inflation) } & $-3.632 * * *$ & $-3.376 * * *$ & -0.124 & -0.154 & -0.046 & -0.027 \\
\hline & $(0.880)$ & $(0.851)$ & $(0.312)$ & $(0.310)$ & $(0.326)$ & $(0.327)$ \\
\hline \multirow[t]{2}{*}{ T3 (inflation target) } & $-3.813 * * *$ & $-3.805 * * *$ & 0.005 & 0.007 & 0.400 & 0.472 \\
\hline & $(0.898)$ & $(0.870)$ & $(0.308)$ & $(0.306)$ & $(0.318)$ & $(0.320)$ \\
\hline \multirow[t]{2}{*}{ T7 (Fed inflation forecast) } & $-3.542 * * *$ & $-3.452 * * *$ & -0.088 & -0.109 & 0.374 & 0.459 \\
\hline & $(0.861)$ & $(0.835)$ & $(0.306)$ & $(0.304)$ & $(0.313)$ & $(0.317)$ \\
\hline \multirow[t]{2}{*}{ T8 (FOMC statement) } & $-2.645^{* * *}$ & $-2.622 * * *$ & -0.083 & -0.106 & 0.118 & 0.235 \\
\hline & $(0.906)$ & $(0.878)$ & $(0.308)$ & $(0.307)$ & $(0.311)$ & $(0.314)$ \\
\hline \multirow[t]{2}{*}{ T9 (USA Today coverage) } & -0.148 & 0.005 & 0.212 & 0.229 & 0.301 & 0.354 \\
\hline & $(0.933)$ & $(0.896)$ & $(0.312)$ & $(0.310)$ & $(0.327)$ & $(0.327)$ \\
\hline Remove outliers & Yes & Yes & Yes & Yes & Yes & Yes \\
\hline Using sampling weights & Yes & Yes & Yes & Yes & Yes & Yes \\
\hline Controls for demographics & No & Yes & No & Yes & No & Yes \\
\hline Observations & 22,582 & 22,582 & 14,003 & 14,001 & 13,580 & 13,369 \\
\hline $\mathrm{R}^{2}$ & 0.005 & 0.052 & 0.001 & 0.013 & 0.001 & 0.013 \\
\hline
\end{tabular}

Notes: The table reports the average change in inflation expectations of individuals in each treatment group relative to those in the control group. Columns (1) and (2) consider the immediate change in expectations after the treatment, columns (3) and (4) consider the changes in beliefs after three months, columns (5) and (6) report changes in beliefs over a six month horizon. In each case, differences in beliefs are measured relative to initial beliefs from the first wave measured before all treatments. Treatments are described in detail in the text. For each time horizon, the second column uses the same specification as in the first column but augmented with respondent-specific controls. Results are from median regressions. Robust standard errors are reported in parentheses. 
Appendix Table 9: Average Household Responses to Treatments, OLS regression, revisions trimmed at bottom and top $10 \%$.

\begin{tabular}{|c|c|c|c|c|c|c|}
\hline \multirow{3}{*}{ Treatments } & \multicolumn{6}{|c|}{ Outcome: forecast revision } \\
\hline & \multicolumn{2}{|c|}{ Immediate revision } & \multicolumn{2}{|c|}{ Revision after 3 months } & \multicolumn{2}{|c|}{ Revision after 6 months } \\
\hline & $(1)$ & $(2)$ & $(3)$ & $(4)$ & $(5)$ & $(6)$ \\
\hline \multirow[t]{2}{*}{ T5 (pop growth) } & -0.170 & -0.208 & -0.175 & -0.177 & 0.052 & 0.088 \\
\hline & $(0.263)$ & $(0.257)$ & $(0.144)$ & $(0.144)$ & $(0.162)$ & $(0.163)$ \\
\hline \multirow[t]{2}{*}{ T6 (UE) } & -0.299 & -0.346 & -0.122 & -0.123 & -0.080 & -0.061 \\
\hline & $(0.263)$ & $(0.259)$ & $(0.148)$ & $(0.146)$ & $(0.151)$ & $(0.151)$ \\
\hline \multirow[t]{2}{*}{ T4 (gas prices) } & $1.124 * * *$ & $1.071 * * *$ & -0.125 & -0.124 & 0.007 & 0.003 \\
\hline & $(0.267)$ & $(0.260)$ & $(0.150)$ & $(0.148)$ & $(0.159)$ & $(0.159)$ \\
\hline \multirow[t]{2}{*}{ T2 (past inflation) } & $-1.087 * * *$ & $-1.052 * * *$ & -0.052 & -0.043 & $0.261^{*}$ & $0.300 *$ \\
\hline & $(0.265)$ & $(0.260)$ & $(0.147)$ & $(0.146)$ & $(0.156)$ & $(0.157)$ \\
\hline \multirow[t]{2}{*}{ T3 (inflation target) } & $-1.439 * * *$ & $-1.460 * * *$ & -0.172 & -0.163 & 0.215 & 0.239 \\
\hline & $(0.252)$ & $(0.247)$ & $(0.147)$ & $(0.147)$ & $(0.158)$ & $(0.158)$ \\
\hline \multirow[t]{2}{*}{ T7 (Fed inflation forecast) } & $-0.838 * * *$ & $-0.878 * * *$ & -0.037 & -0.022 & $0.256^{*}$ & $0.303^{* *}$ \\
\hline & $(0.276)$ & $(0.270)$ & $(0.150)$ & $(0.149)$ & $(0.154)$ & $(0.154)$ \\
\hline \multirow[t]{2}{*}{ T8 (FOMC statement) } & $-1.153^{* * *}$ & $-1.197 * * *$ & -0.078 & -0.063 & 0.177 & 0.236 \\
\hline & $(0.264)$ & $(0.258)$ & $(0.157)$ & $(0.155)$ & $(0.162)$ & $(0.162)$ \\
\hline \multirow[t]{2}{*}{ T9 (USA Today coverage) } & -0.221 & -0.207 & -0.124 & -0.117 & 0.143 & 0.180 \\
\hline & $(0.275)$ & $(0.270)$ & $(0.149)$ & $(0.148)$ & $(0.158)$ & $(0.158)$ \\
\hline Remove outliers & Yes & Yes & Yes & Yes & Yes & Yes \\
\hline Using sampling weights & Yes & Yes & Yes & Yes & Yes & Yes \\
\hline Controls for demographics & No & Yes & No & Yes & No & Yes \\
\hline Observations & 18,415 & 18,415 & 9,717 & 9,716 & 9,511 & 9,376 \\
\hline $\mathrm{R}^{2}$ & 0.014 & 0.052 & 0.000 & 0.012 & 0.002 & 0.016 \\
\hline
\end{tabular}

Notes: The table reports the average change in inflation expectations of individuals in each treatment group relative to those in the control group. Columns (1) and (2) consider the immediate change in expectations after the treatment, columns (3) and (4) consider the changes in beliefs after three months, columns (5) and (6) report changes in beliefs over a six month horizon. In each case, differences in beliefs are measured relative to initial beliefs from the first wave measured before all treatments. Treatments are described in detail in the text. For each time horizon, the second column uses the same specification as in the first column but augmented with respondent-specific controls. Results are from OLS regressions. The dependent variable is trimmed at bottom and top 10 percent. Robust standard errors are reported in parentheses. 


\begin{tabular}{|c|c|c|c|c|c|c|}
\hline \multirow{3}{*}{ Treatments } & \multicolumn{2}{|c|}{ Immediate revision } & \multicolumn{2}{|c|}{ Revision after 3 months } & \multicolumn{2}{|c|}{ Revision after 6 months } \\
\hline & $\begin{array}{c}\text { Intercept } \\
(b)\end{array}$ & $\begin{array}{c}\text { Slope } \\
(\gamma)\end{array}$ & $\begin{array}{c}\text { Intercept } \\
(b)\end{array}$ & $\begin{array}{c}\text { Slope } \\
(\gamma)\end{array}$ & $\begin{array}{c}\text { Intercept } \\
(b)\end{array}$ & $\begin{array}{c}\text { Slope } \\
(\gamma)\end{array}$ \\
\hline & $(1)$ & $(2)$ & (3) & $(4)$ & (5) & $(6)$ \\
\hline T1 (control) & & $\begin{array}{l}0.627^{* * *} \\
(0.021)\end{array}$ & & $\begin{array}{l}0.265^{* * *} \\
(0.016)\end{array}$ & & $\begin{array}{l}0.305^{* * *} \\
(0.017)\end{array}$ \\
\hline \multicolumn{7}{|l|}{ Relative to control group } \\
\hline T5 (pop growth) & $\begin{array}{c}0.203^{*} \\
(0.119)\end{array}$ & $\begin{array}{l}-0.200^{* * *} \\
(0.028)\end{array}$ & $\begin{array}{l}-0.687^{* * *} \\
(0.104)\end{array}$ & $\begin{array}{l}0.198^{* * *} \\
(0.024)\end{array}$ & $\begin{array}{l}-0.263^{* *} \\
(0.110)\end{array}$ & $\begin{array}{l}0.135 * * * \\
(0.025)\end{array}$ \\
\hline T6 (UE) & $\begin{array}{l}0.380^{* * *} \\
(0.118)\end{array}$ & $\begin{array}{l}-0.262 * * * \\
(0.027)\end{array}$ & $\begin{array}{l}-0.210^{* *} \\
(0.105)\end{array}$ & $\begin{array}{c}0.007 \\
(0.023)\end{array}$ & $\begin{array}{l}-0.351^{* * * *} \\
(0.110)\end{array}$ & $\begin{array}{l}0.099 * * * \\
(0.026)\end{array}$ \\
\hline T4 (gas prices) & $\begin{array}{l}2.007^{* * * *} \\
(0.131)\end{array}$ & $\begin{array}{l}-0.177^{* * * *} \\
(0.028)\end{array}$ & $\begin{array}{l}-0.250 * * \\
(0.106)\end{array}$ & $\begin{array}{l}0.072^{* * * *} \\
(0.024)\end{array}$ & $\begin{array}{c}0.005 \\
(0.109)\end{array}$ & $\begin{array}{l}-0.046^{*} \\
(0.025)\end{array}$ \\
\hline T2 (past inflation) & $\begin{array}{l}0.330 * * * \\
(0.109)\end{array}$ & $\begin{array}{l}-0.480 * * * \\
(0.024)\end{array}$ & $\begin{array}{l}-0.064 \\
(0.101)\end{array}$ & $\begin{array}{l}-0.032 \\
(0.022)\end{array}$ & $\begin{array}{c}0.182 * \\
(0.107)\end{array}$ & $\begin{array}{c}-0.063^{* * *} \\
(0.024)\end{array}$ \\
\hline T3 (inflation target) & $\begin{array}{c}0.164 \\
(0.107)\end{array}$ & $\begin{array}{l}-0.420^{* * *} \\
(0.025)\end{array}$ & $\begin{array}{l}-0.500^{* * *} \\
(0.103)\end{array}$ & $\begin{array}{l}0.046^{* *} \\
(0.023)\end{array}$ & $\begin{array}{l}-0.188^{*} \\
(0.107)\end{array}$ & $\begin{array}{l}0.088 * * * \\
(0.024)\end{array}$ \\
\hline T7 (Fed inflation forecast) & $\begin{array}{c}0.048 \\
(0.106)\end{array}$ & $\begin{array}{l}-0.443^{* * *} \\
(0.025)\end{array}$ & $\begin{array}{l}-0.191^{*} \\
(0.104)\end{array}$ & $\begin{array}{l}0.075^{* * * *} \\
(0.023)\end{array}$ & $\begin{array}{c}0.167 \\
(0.112)\end{array}$ & $\begin{array}{l}0.055^{* *} \\
(0.025)\end{array}$ \\
\hline T8 (FOMC statement) & $\begin{array}{l}-0.053 \\
(0.109)\end{array}$ & $\begin{array}{l}-0.457 * * * \\
(0.026)\end{array}$ & $\begin{array}{l}-0.297 * * * \\
(0.101)\end{array}$ & $\begin{array}{c}0.008 \\
(0.023)\end{array}$ & $\begin{array}{c}0.140 \\
(0.110)\end{array}$ & $\begin{array}{l}-0.040^{*} \\
(0.024)\end{array}$ \\
\hline T9 (USA Today coverage) & $\begin{array}{c}0.216^{*} \\
(0.113)\end{array}$ & $\begin{array}{l}-0.359 * * * \\
(0.027)\end{array}$ & $\begin{array}{l}-0.303^{* * *} \\
(0.103)\end{array}$ & $\begin{array}{l}0.091^{* * *} \\
(0.023)\end{array}$ & $\begin{array}{c}0.025 \\
(0.112)\end{array}$ & $\begin{array}{c}0.017 \\
(0.025)\end{array}$ \\
\hline Remove outliers & & & & & & \\
\hline Using sampling weights & & & & & & \\
\hline Controls for demographics & & & & & & \\
\hline Observations & & & & & & \\
\hline $\mathrm{R}^{2}$ & & & & & & \\
\hline
\end{tabular}

Notes: The table reports the slope and intercept in the following regression: $E_{i}^{\text {post }} \pi=a+b * \operatorname{Treat}_{i}+\gamma * \operatorname{Treat}_{i} *$ $E_{i}^{\text {pre }} \pi+\psi * E_{i}^{\text {pre }} \pi+$ Controls + error. Columns (1) and (2) consider the immediate change in expectations after the treatment, columns (3) and (4) are for beliefs after three months, columns (5) and (6) are for beliefs after six months. Results are from Huber robust regressions to control for outliers and influential observations. Robust standard errors are reported in parentheses. 
Appendix Table 11: Extensive margin for purchases of durable goods by type of good.

Dep. var. is indicated in the title of the panel
Actual spending, horizon, month

$1^{\text {st }}$ follow-up wave $2^{\text {nd }}$ follow-up wave

\begin{tabular}{llc} 
Panel A. Spending on housing, $\times \mathbf{1 0 0}$ & & \\
Posterior inflation expectations & -0.040 & -0.030 \\
& $(0.033)$ & $(0.046)$ \\
\hline Observations & 10,471 & 10,428 \\
R-squared & 0.089 & 0.097 \\
$1^{\text {st }}$ stage F-stat & 105.6 & 107.5 \\
\hline & & \\
Panel B. Spending on cars, & & \\
$\times \mathbf{1 0 0}$ & & $-0.399^{* * *}$ \\
Posterior inflation expectations & $-0.261^{* *}$ & $(0.154)$ \\
& $(0.101)$ & 10,381 \\
\hline Observations & 10,405 & 0.083 \\
R-squared & 0.071 & 102.7 \\
$1^{\text {st }}$ stage F-stat & 104.1 & \\
\hline
\end{tabular}

Panel C. Spending on appliances, electronics and similar items, $\times 100$

Posterior inflation expectations

$-1.056^{* * *}$

$-1.716^{* * *}$

$(0.209)$

$(0.304)$

Observations

R-squared

10,418

0.039

$1^{\text {st }}$ stage F-stat

101.8

0.046

95.73

Notes: the table reports estimates of the causal effect of inflation expectation on the extensive margin for purchases of durable goods. See notes to Table 9 for more details. 
Appendix Table 12: Average Household Responses of Unemployment Expectations to Treatments.

\begin{tabular}{lll}
\hline \multirow{2}{*}{ Treatments } & \multicolumn{2}{c}{$\begin{array}{c}\text { Outcome: immediate forecast revision of } \\
\text { unemployment forecast }\end{array}$} \\
\cline { 2 - 3 } & \multicolumn{1}{c}{$(1)$} & $(2)$ \\
\hline T5 (pop growth) & -0.026 & -0.027 \\
T6 (UE) & $(0.046)$ & $(0.046)$ \\
T4 (gas prices) & $-1.041^{* * *}$ & $-1.052^{* * *}$ \\
T2 (past inflation) & $(0.050)$ & $(0.049)$ \\
& $0.173^{* * *}$ & $0.166^{* * *}$ \\
T3 (inflation target) & $(0.046)$ & $(0.047)$ \\
& $-0.185^{* * *}$ & $-0.195^{* * *}$ \\
T7 (Fed inflation forecast) & $(0.046)$ & $(0.047)$ \\
& $-0.128^{* * *}$ & $-0.129^{* * *}$ \\
T8 (FOMC statement) & $(0.046)$ & $(0.046)$ \\
& $-0.125^{* * *}$ & $-0.127^{* * *}$ \\
T9 (USA Today coverage) & $(0.045)$ & $(0.046)$ \\
& $-0.375^{* * *}$ & $-0.384^{* * *}$ \\
& $(0.046)$ & $(0.046)$ \\
\hline Remove outliers & $-0.109^{* *}$ & $-0.109^{* *}$ \\
Using sampling weights & $(0.046)$ & $(0.046)$ \\
Controls for demographics & & \\
\hline Observations & Yes & Yes \\
$\mathrm{R}^{2}$ & Yes & Yes \\
\hline \hline
\end{tabular}

Notes: The table reports the average change in unemployment expectations of individuals in each treatment group relative to those in the control group. Columns (1) and (2) consider the immediate change in expectations after the treatment. In each case, differences in beliefs are measured relative to initial beliefs from the first wave measured before all treatments. Treatments are described in detail in the text. Results are from Huber robust regressions to control for outliers and influential observations. Robust standard errors are reported in parentheses. 
Appendix Table 13: Treatment effects by gender.

\begin{tabular}{|c|c|c|c|c|}
\hline \multirow[b]{2}{*}{ Breakdown of Sample: } & \multicolumn{2}{|c|}{$\begin{array}{l}\text { Revision of inflation } \\
\text { expectations (baseline) }\end{array}$} & \multicolumn{2}{|c|}{$\begin{array}{l}\text { Normalized revision of } \\
\text { inflation expectations }\end{array}$} \\
\hline & Female & Male & Female & Male \\
\hline Treatment Group: & $(1)$ & $(2)$ & (3) & $(4)$ \\
\hline T5 (pop growth) & $\begin{array}{l}-0.157 \\
(0.223)\end{array}$ & $\begin{array}{l}-0.179 \\
(0.255)\end{array}$ & $\begin{array}{l}-0.055 \\
(0.121)\end{array}$ & $\begin{array}{l}-0.050 \\
(0.121)\end{array}$ \\
\hline T6 (UE) & $\begin{array}{l}-0.576^{* * *} \\
(0.217)\end{array}$ & $\begin{array}{l}-0.166 \\
(0.252)\end{array}$ & $\begin{array}{l}-0.134 \\
(0.118)\end{array}$ & $\begin{array}{l}-0.052 \\
(0.126)\end{array}$ \\
\hline T4 (gas prices) & $\begin{array}{l}1.702^{* * *} \\
(0.238)\end{array}$ & $\begin{array}{l}1.481^{* * *} \\
(0.280)\end{array}$ & $\begin{array}{l}0.904 * * * \\
(0.127)\end{array}$ & $\begin{array}{l}0.876^{* * *} \\
(0.139)\end{array}$ \\
\hline T2 (past inflation) & $\begin{array}{l}-1.500^{* * *} \\
(0.208)\end{array}$ & $\begin{array}{l}-0.623^{* *} \\
(0.255)\end{array}$ & $\begin{array}{l}-0.372^{* * *} \\
(0.114)\end{array}$ & $\begin{array}{l}-0.126 \\
(0.131)\end{array}$ \\
\hline T3 (inflation target) & $\begin{array}{l}-1.487 * * * \\
(0.205)\end{array}$ & $\begin{array}{l}-0.551^{* *} \\
(0.241)\end{array}$ & $\begin{array}{l}-0.371^{* * *} \\
(0.112)\end{array}$ & $\begin{array}{l}-0.060 \\
(0.119)\end{array}$ \\
\hline T7 (Fed inflation forecast) & $\begin{array}{l}-1.429 * * * \\
(0.213)\end{array}$ & $\begin{array}{l}-0.695^{* * *} \\
(0.239)\end{array}$ & $\begin{array}{l}-0.413^{* * *} \\
(0.118)\end{array}$ & $\begin{array}{l}-0.209 * \\
(0.122)\end{array}$ \\
\hline T8 (FOMC statement) & $\begin{array}{l}-1.602 * * * \\
(0.212)\end{array}$ & $\begin{array}{l}-0.851^{* * *} \\
(0.250)\end{array}$ & $\begin{array}{l}-0.366^{* * *} \\
(0.118)\end{array}$ & $\begin{array}{l}-0.286^{* *} \\
(0.127)\end{array}$ \\
\hline T9 (USA Today coverage) & $\begin{array}{l}-0.790^{* * *} \\
(0.214)\end{array}$ & $\begin{array}{l}-0.236 \\
(0.274)\end{array}$ & $\begin{array}{l}-0.260^{* *} \\
(0.116)\end{array}$ & $\begin{array}{l}-0.045 \\
(0.131)\end{array}$ \\
\hline Observations & 4,978 & 2,080 & 3,872 & 1,769 \\
\hline R-squared & 0.069 & 0.053 & 0.058 & 0.059 \\
\hline
\end{tabular}

Notes: The table reports treatment effects on inflation expectations by gender. Columns (1) and (2) reproduce results reported in Table 8 but the sample is restricted to respondents who report positive probabilities for at least two bins of inflation outcomes in the pre-treatment inflation expectation question. Columns (3) and (4) report treatment effects for revisions normalized by pre-treatment uncertainty about future inflation, that is, $\left(E_{i}^{\text {Post }} \pi-E_{i}^{\text {Prior }} \pi\right) / E s t d_{i}^{\text {Prior }} \pi$, where $E s t d_{i}^{\text {Prior }} \pi$ is the standard deviation of the distribution for inflation expectations reported by a respondent. All estimates are based on Huber robust regressions. Heteroscedasticity robust standard errors are reported in parentheses. ${ }^{* * *}, * *, *$ denote statistical significance at 1,5 , and 10 percent levels. 
Appendix Table 14: Average Household Responses to Treatments using Generalized Beta Distribution.

\begin{tabular}{|c|c|c|c|c|c|c|}
\hline \multirow{3}{*}{ Treatments } & \multicolumn{6}{|c|}{ Outcome: forecast revision } \\
\hline & \multicolumn{2}{|c|}{ Immediate revision } & \multicolumn{2}{|c|}{ Revision after 3 months } & \multicolumn{2}{|c|}{ Revision after 6 months } \\
\hline & (1) & $(2)$ & (3) & $(4)$ & $(5)$ & $(6)$ \\
\hline \multirow[t]{2}{*}{ T5 (pop growth) } & $-0.218 * *$ & $-0.229 * *$ & -0.095 & -0.106 & 0.067 & 0.076 \\
\hline & $(0.105)$ & $(0.104)$ & $(0.093)$ & $(0.094)$ & $(0.100)$ & $(0.101)$ \\
\hline \multirow[t]{2}{*}{ T6 (UE) } & $-0.339 * * *$ & $-0.332 * * *$ & $-0.393 * * *$ & $-0.412 * * *$ & -0.134 & -0.130 \\
\hline & $(0.104)$ & $(0.104)$ & $(0.095)$ & $(0.096)$ & $(0.099)$ & $(0.099)$ \\
\hline \multirow[t]{2}{*}{ T4 (gas prices) } & $1.447 * * *$ & $1.447^{* * *}$ & $-0.167 *$ & $-0.163^{*}$ & -0.123 & -0.155 \\
\hline & $(0.114)$ & $(0.113)$ & $(0.095)$ & $(0.097)$ & $(0.100)$ & $(0.100)$ \\
\hline \multirow[t]{2}{*}{ T2 (past inflation) } & $-1.031^{* * *}$ & $-1.062 * * *$ & -0.066 & -0.085 & $0.301^{* * *}$ & $0.304^{* * *}$ \\
\hline & $(0.104)$ & $(0.103)$ & $(0.093)$ & $(0.094)$ & $(0.100)$ & $(0.100)$ \\
\hline \multirow[t]{2}{*}{ T3 (inflation target) } & $-0.991 * * *$ & $-0.985 * * *$ & $-0.389 * * *$ & $-0.444 * * *$ & 0.003 & 0.008 \\
\hline & $(0.102)$ & $(0.102)$ & $(0.095)$ & $(0.095)$ & $(0.098)$ & $(0.099)$ \\
\hline \multirow[t]{2}{*}{ T7 (Fed inflation forecast) } & $-1.040 * * *$ & $-1.061 * * *$ & $-0.329 * * *$ & $-0.318 * * *$ & 0.148 & $0.183^{*}$ \\
\hline & $(0.102)$ & $(0.102)$ & $(0.095)$ & $(0.096)$ & $(0.099)$ & $(0.099)$ \\
\hline \multirow[t]{2}{*}{ T8 (FOMC statement) } & $-1.193 * * *$ & $-1.212 * * *$ & -0.155 & $-0.167 *$ & 0.102 & 0.139 \\
\hline & $(0.102)$ & $(0.102)$ & $(0.095)$ & $(0.096)$ & $(0.102)$ & $(0.103)$ \\
\hline \multirow[t]{2}{*}{ T9 (USA Today coverage) } & $-0.451 * * *$ & $-0.477 * * *$ & $-0.174^{*}$ & $-0.222 * *$ & 0.126 & 0.104 \\
\hline & $(0.105)$ & $(0.104)$ & $(0.094)$ & $(0.095)$ & $(0.099)$ & $(0.099)$ \\
\hline Remove outliers & Yes & Yes & Yes & Yes & Yes & Yes \\
\hline Using sampling weights & Yes & Yes & Yes & Yes & Yes & Yes \\
\hline Controls for demographics & No & Yes & No & Yes & No & Yes \\
\hline Observations & 18,982 & 18,972 & 11,645 & 11,651 & 11,534 & 11,416 \\
\hline $\mathrm{R}^{2}$ & 0.047 & 0.061 & 0.003 & 0.020 & 0.002 & 0.017 \\
\hline
\end{tabular}

Notes: The table reports the average change in inflation expectations of individuals in each treatment group relative to those in the control group. Inflation expectations are measured as means of the generalized beta distribution estimated for each respondent separately, as in the Survey of Consumer Expectations. Columns (1) and (2) consider the immediate change in expectations after the treatment, columns (3) and (4) consider the changes in beliefs after three months, columns (5) and (6) report changes in beliefs over a six month horizon. In each case, differences in beliefs are measured relative to initial beliefs from the first wave measured before all treatments. Treatments are described in detail in the text. For each time horizon, the second column uses the same specification as in the first column but augmented with respondent-specific controls. Results are from Huber robust regressions to control for outliers and influential observations. Robust standard errors are reported in parentheses. 
Appendix Figure 1. The joint distribution of posterior (immediately after the treatment) and prior beliefs about future inflation.
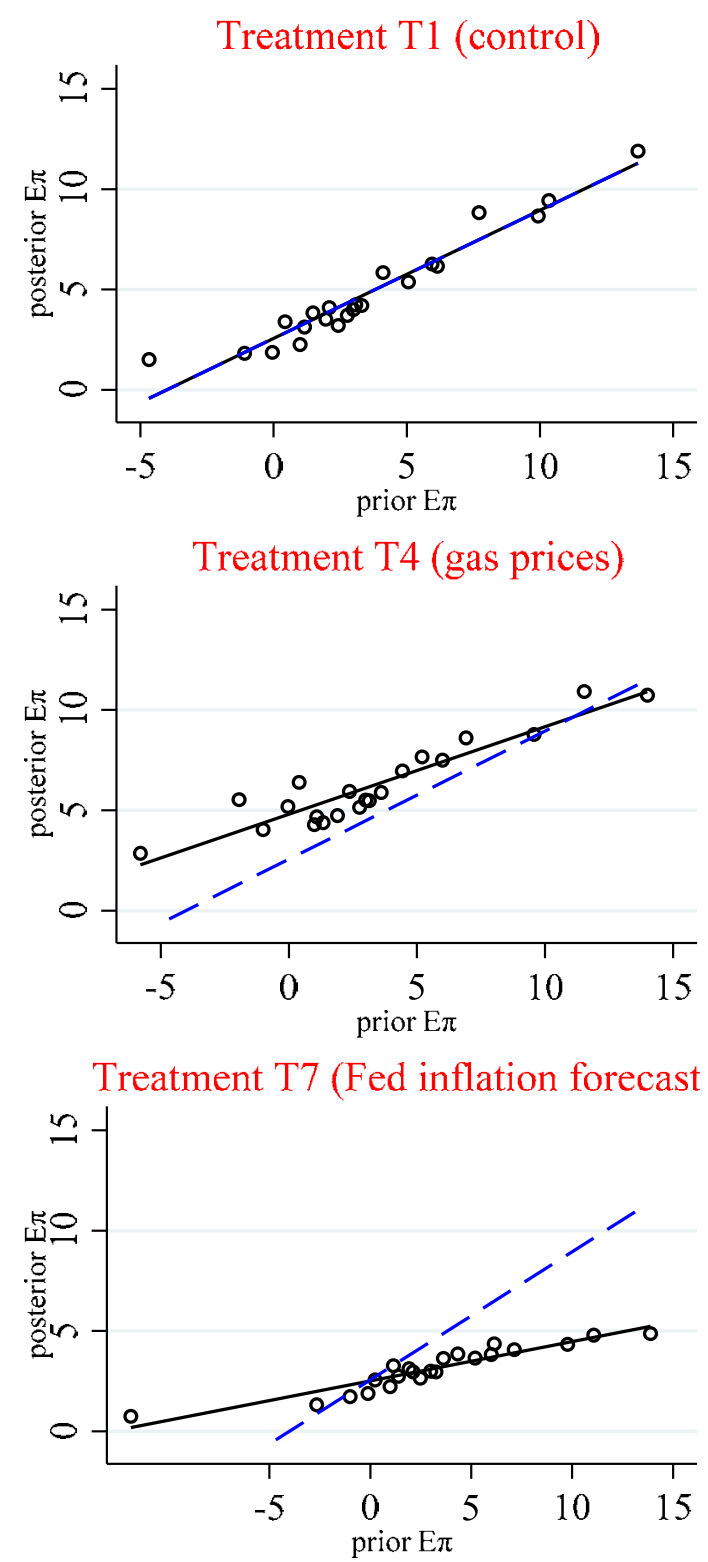

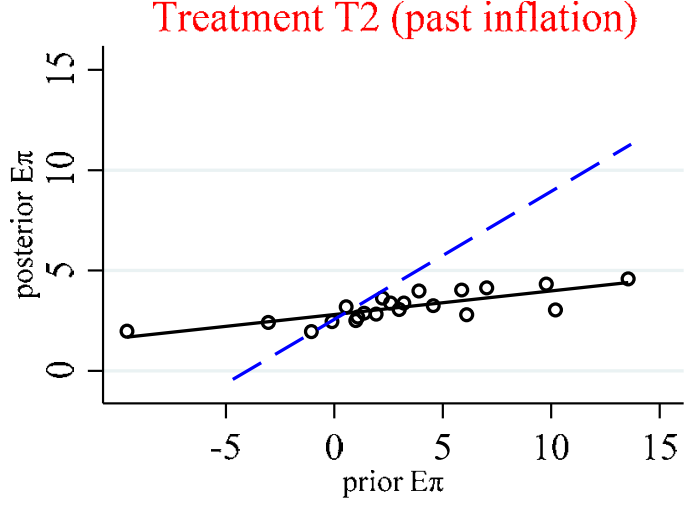

Treatment T5 (pop growth)
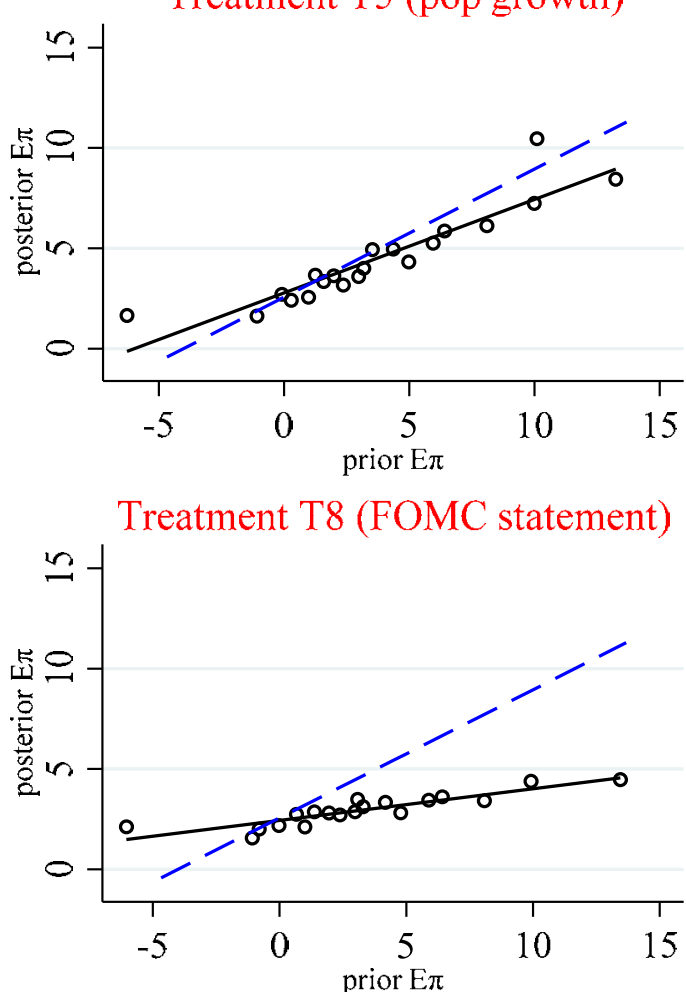

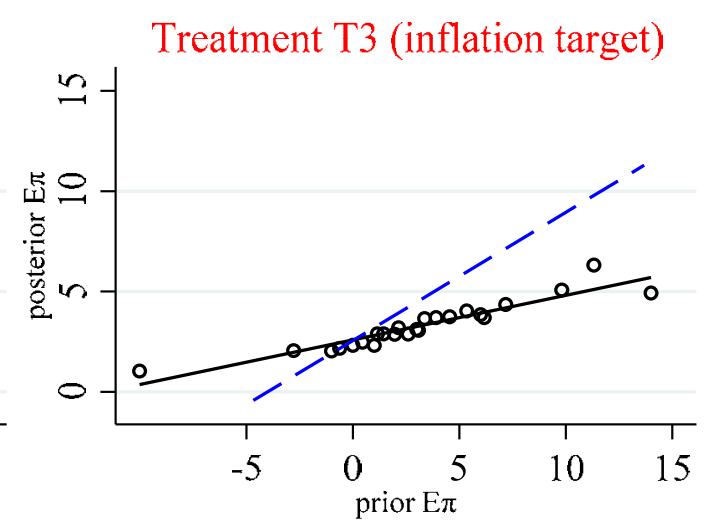

Treatment T6 (UE)
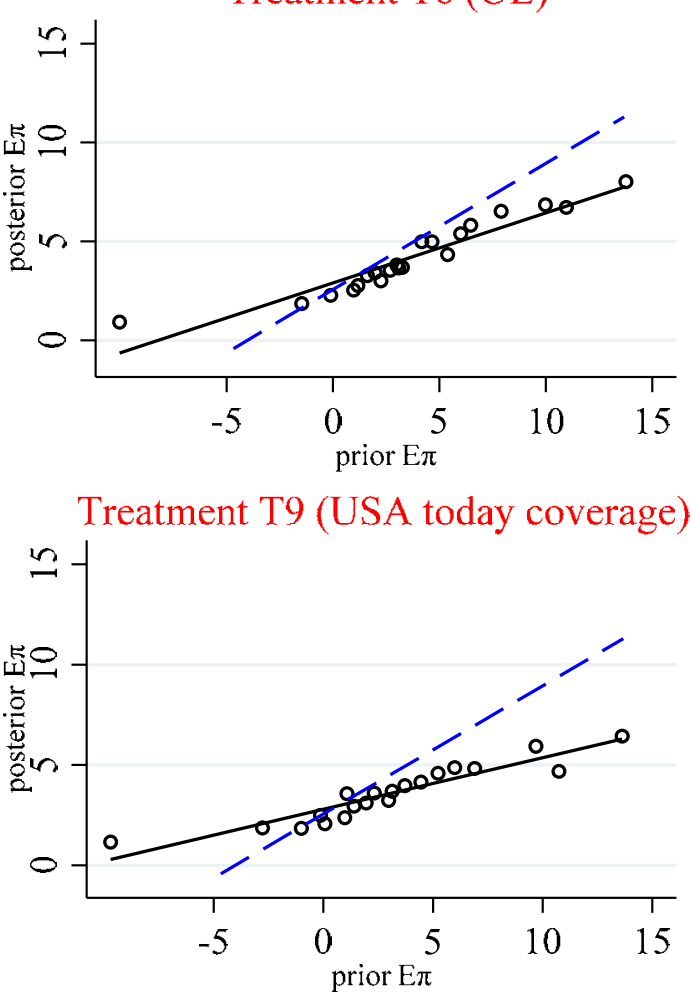

Notes: the figure reports a binscatter plot of 12-month-ahead inflation expectations before treatment and immediately after treatment. Each circle represents 2.5 percent of the sample. The black line shows fitted regression. The blue line shows fitted regression for the control group. 
Appendix Figure 2. Distribution of revisions of inflation forecasts (immediately after treatment) by treatment arm.

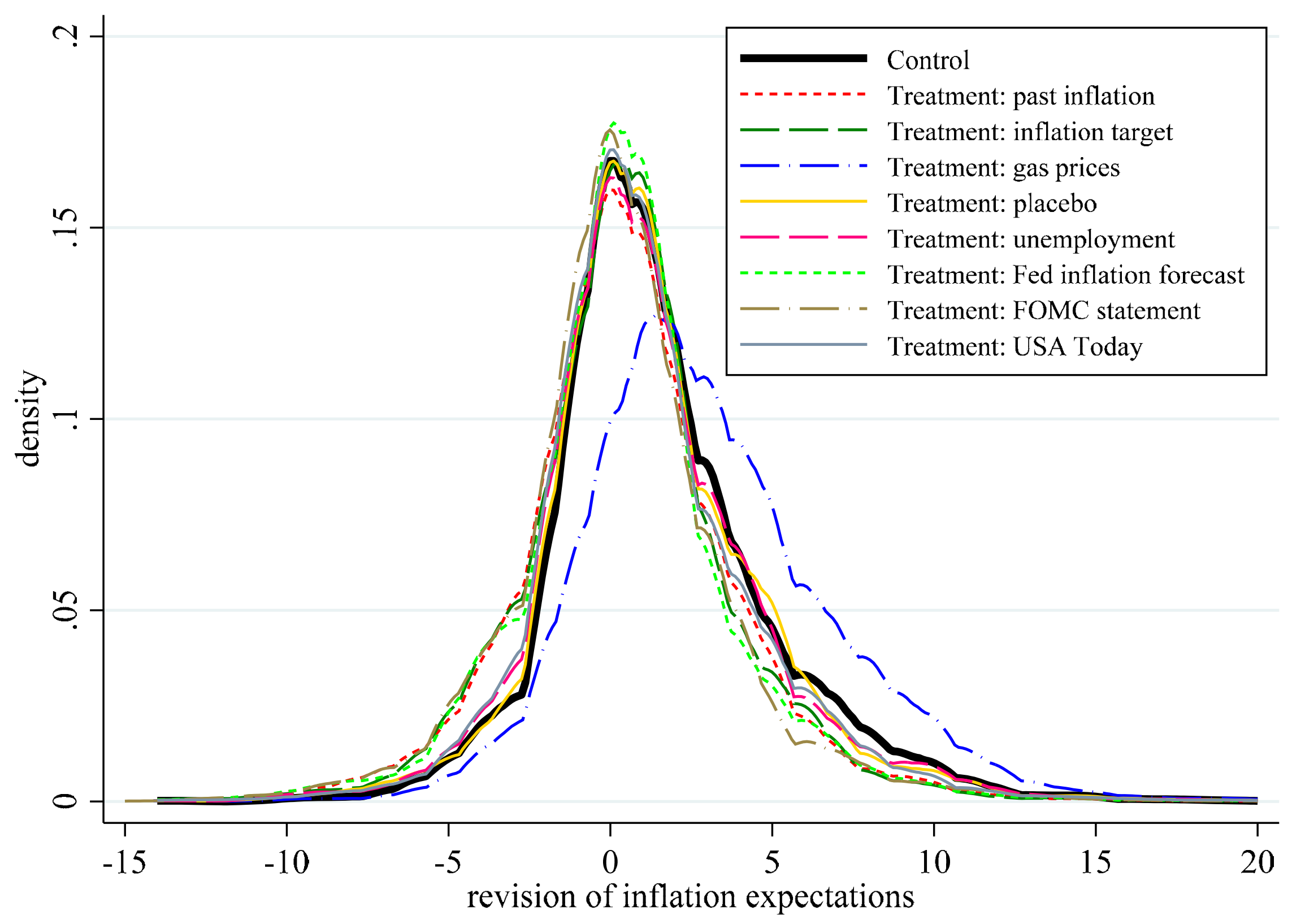

